\title{
DETERMINING POTENTIAL END OF SERVICE LIFE DEMOLITION WASTE OF RESIDENTIAL HOUSES IN CANADA
}

\author{
by \\ Tofayel Hussain, Bachelor of Applied Tech. \\ A MRP presented to Ryerson University \\ in partial fulfillment of the requirements for the degree \\ of Master of Building Science (MBSc) \\ in the Building Science Program
}

Toronto, Ontario, Canada, 2014

(C) Tofayel Hussain 2014 


\section{AUTHOR'S DECLARATION FOR ELECTRONIC SUBMISSION OF A MRP}

I hereby declare that I am the sole author of this MRP. This is a true copy of the MRP, including any required final revisions.

I authorize Ryerson University to lend this MRP to other institutions or individuals for the purpose of scholarly research

I further authorize Ryerson University to reproduce this MRP by photocopying or by other means, in total or in part, at the request of other institutions or individuals for the purpose of scholarly research.

I understand that my MRP may be made electronically available to the public 


\begin{abstract}
Construction and demolition (C \& D) waste generation is identified as an environmental topic of concern globally. Canadian Construction Association (CCA), Natural Resources Canada (NRCan) and other researchers have identified wood waste as the key material to focus on in residential housing construction. With this point in mind, it seems prudent to identify waste generation at the demolition stage of houses.
\end{abstract}

Two low-rise single-family detached houses were evaluated to determine their potential demolition waste generation. Wood, concrete, masonry (brick), gypsum and asphalt waste generation was measured, quantified and ranked accordingly.

The results determined concrete had the highest waste generation potential representing around $60 \%(\mathrm{~kg})$ at the demolition stage. The findings are contrary to the wood waste focus in residential construction. Therefore, the findings suggest more focus needs to be placed on concrete use in residential construction moving forward, as much as wood has been in most recent decades. 


\section{Acknowledgements}

No piece of work is ever the product of one individual. With that in mind, I would like to take this opportunity to acknowledge all those who helped me, taught me and guided me in my graduate studies.

(i) Professor Hitesh Doshi for being my supervisor throughout this entire process from enrollment to finish.

(ii) Professor Vera Straka for reviewing and giving feedback for my work as a secondary advisor.

(iii) Professor George Hanna, of engineering at George Brown College, who helped me gather and verify material estimation for the study houses, specifically wood estimates.

(iv) All the teachers who taught me and whom I benefited from in the past two years including Dr. Zaiyi Liao, Dr. Russell Richman, Dr. Mark Gorgolewski, Dr. Miljana Horvat, Dr. Hua Ge, and Dr. Jane Hao.

(v) All my peers who I studied with and benefited from tremendously. 


\section{Table of Contents}

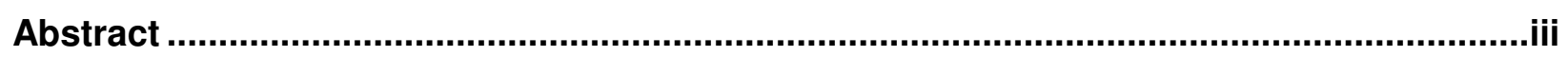

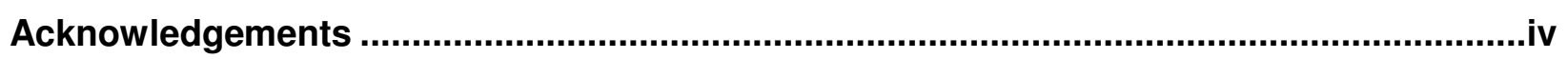

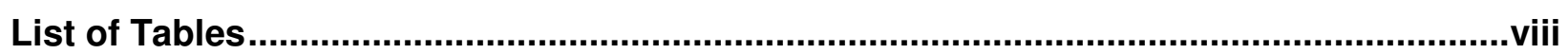

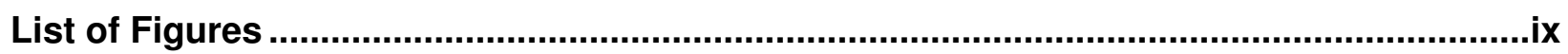

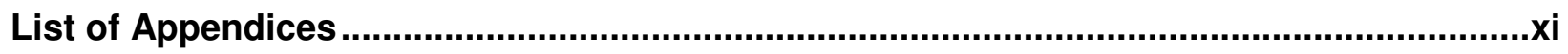

1.0 Introduction

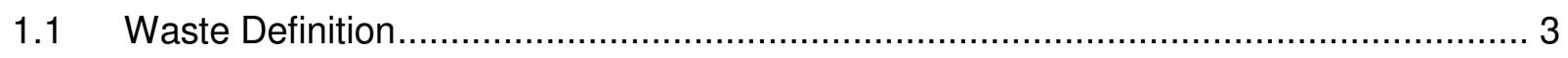

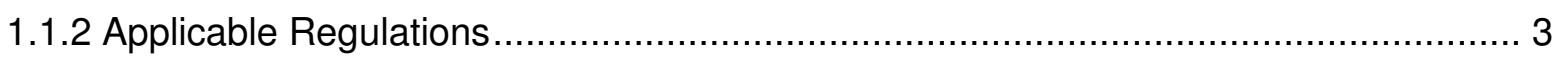

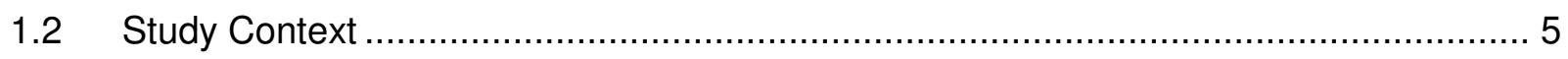

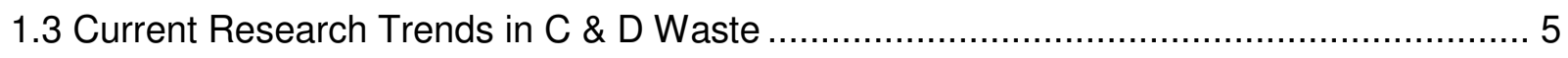

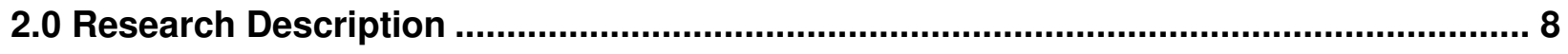

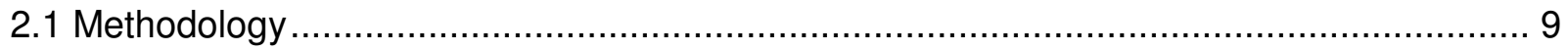

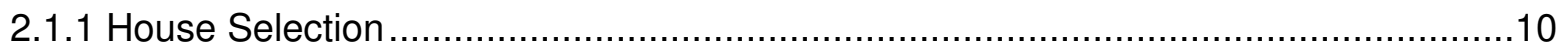

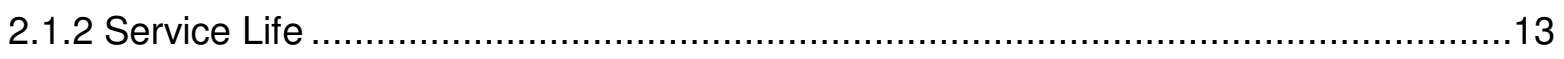

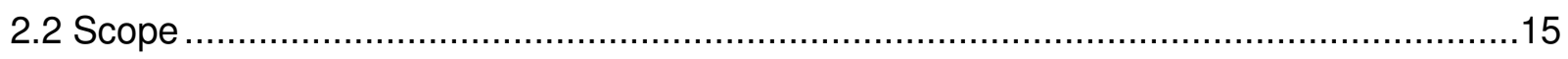

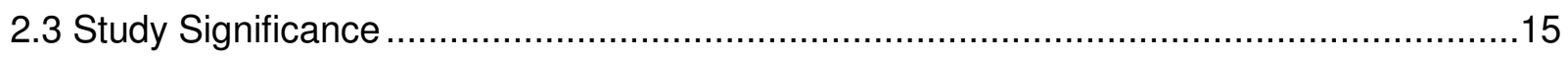

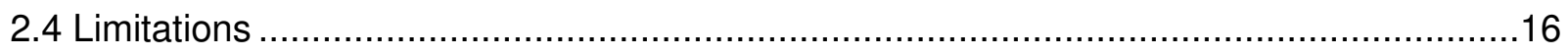

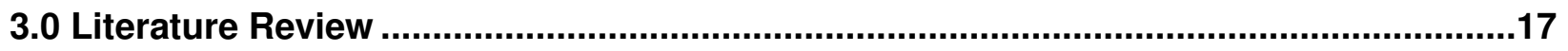

3.1 Case Studies: Waste Composition.......................................................................19

3.1.1 Canadian Construction Association Case Study ............................................19 


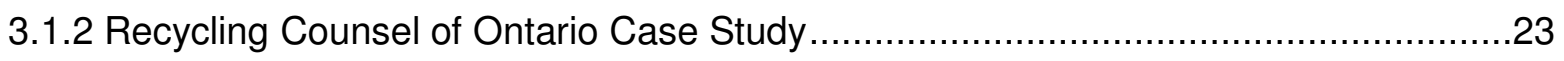

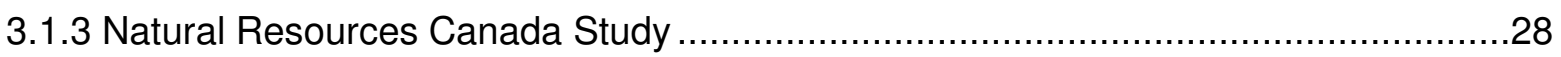

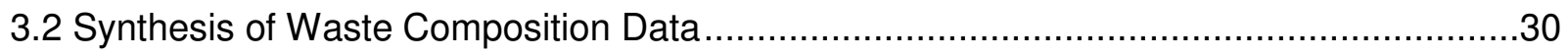

3.2.1 Canadian C \& D Waste Composition....................................................................

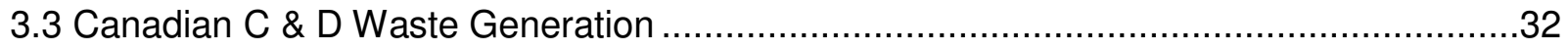

3.4 Waste Minimization Methods and Guides ……….........................................................

3.4.1 Design/Pre-Construction Phase (D-Phase) ……..................................................34

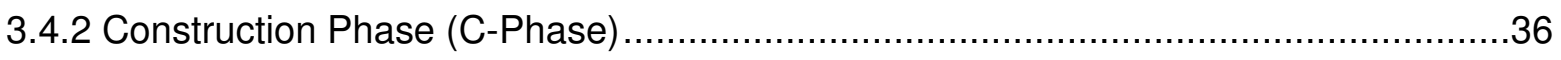

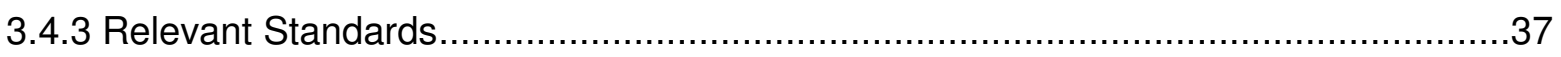

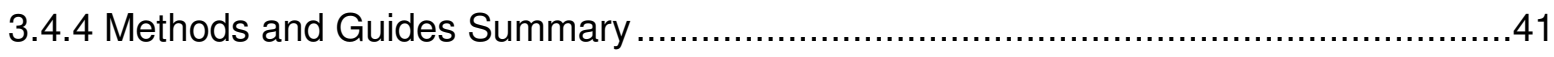

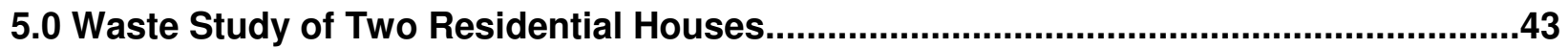

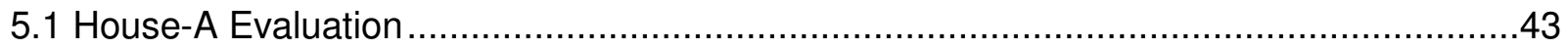

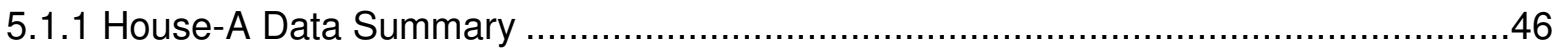

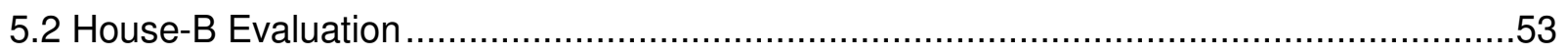

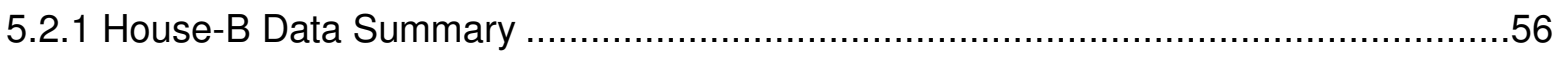

5.3 Service Life Waste Accumulation ......................................................................62

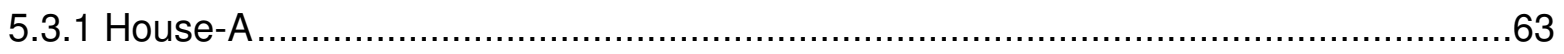

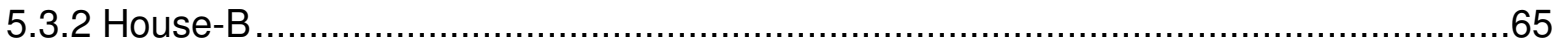

5.3.3 Alternative Materials Life Expectancy .................................................................68

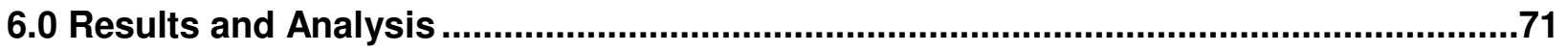

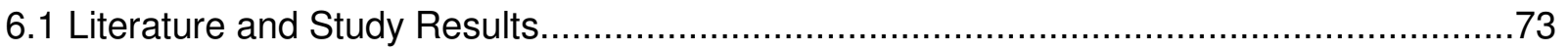




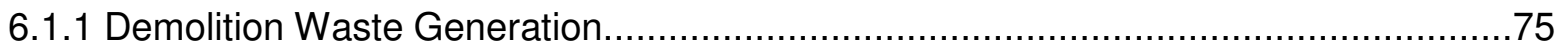

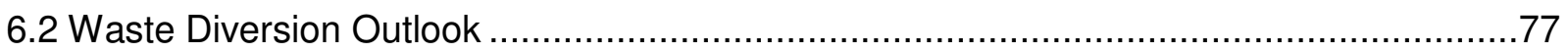

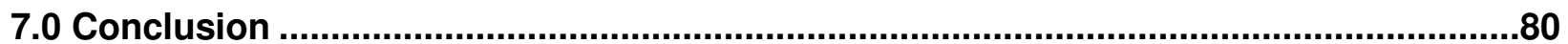

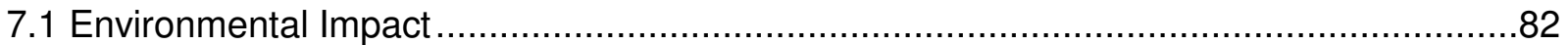

7.2 Recommendations and Future Study................................................................. 84

Appendices

References 


\section{List of Tables}

Table 1: Topical stream of C \& D research in past decades (Source: Yuan \& Shen, 2010) ....... 6

Table 2: C \& D Waste Proportion by Country (Source: Tam \& Tam, 2008) ...........................18

Table 3: Weight by tonnes for constructing custom home .............................................24

Table 4: Weight by Tonnes for Constructing Whole Village Communal Living........................26

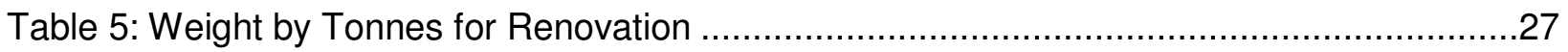

Table 6: Weight by Tonnes for Demolition.............................................................27

Table 7: US C \& D Waste Composition (Source: US EPA, 1998) .....................................29

Table 8: C \& D Projects Waste Composition .......................................................

Table 9: House-A Material Elements Quantity Summary Chart .......................................47

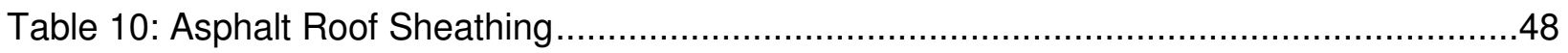

Table 11: House-B Material Elements Quantity Summary Chart ........................................56

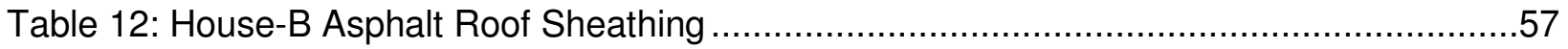

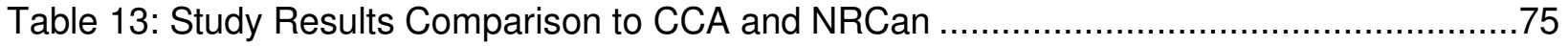

Table 14: Energy and Emissions of Waste Materials (Source: GreenSpec, 2012) .................83 


\section{List of Figures}

Figure 1: Residential Housing Construction by Type (Source: CMHC, 2012) ........................10

Figure 2: Downtown Housing Type Survey (Image Source: Google Map, 2012) ....................11

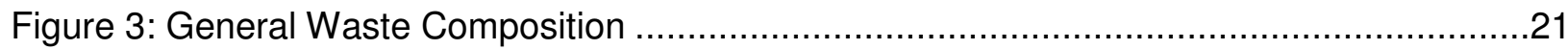

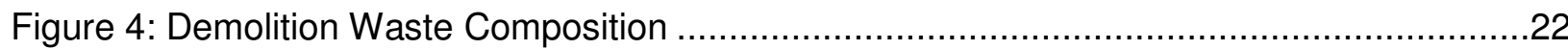

Figure 5: Canadian Residential Waste Composition (Source: NRCan, 2006) .........................29

Figure 6: House-A Two-storey Brick Veneer .............................................................44

Figure 7: House-A Building Configuration Layout ....................................................45

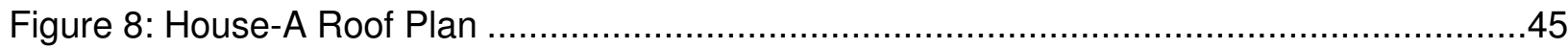

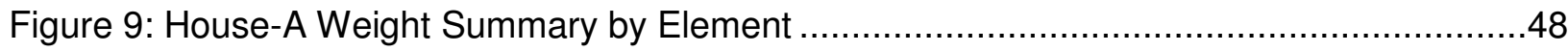

Figure 10: House-A Material Composition Percentage .................................................49

Figure 11: House-A Combined Wood Quantity......................................................... 51

Figure 12: House-A Waste Material Composition ..........................................................51

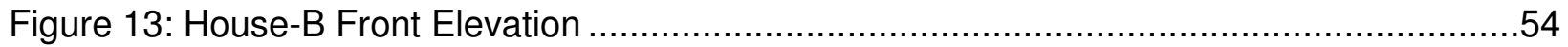

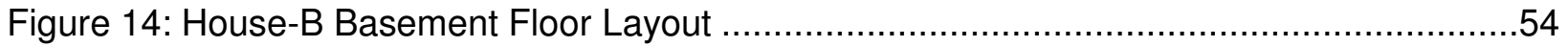

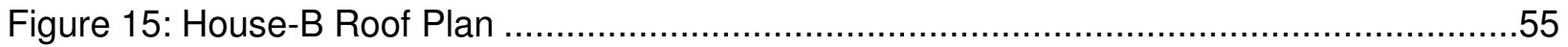

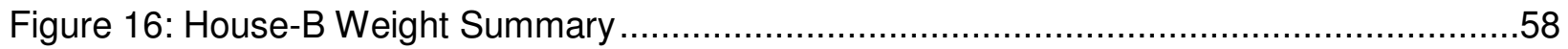

Figure 17: House-B Material Composition Percentages ..................................................59

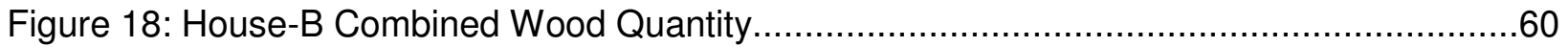

Figure 19: House-B Waste Material Composition .........................................................60

Figure 20: House-A Total End of Service Life Waste Generation ....................................64

Figure 21: House-A Total Service Life Waste Generation Composition...................................65

Figure 22: House-B Total End of Service Life Waste Generation ......................................66

Figure 23: House-B Total Accumulation Composition .....................................................67

Figure 24: Effect of Vinyl Siding Substitution for Brick Cladding ........................................ 70 
Figure 25: House-A Waste Material Normalization ..................................................72

Figure 26: House-B Waste Material Normalization ...................................................72

Figure 27: House-A and House-B Potential Total Service Life Waste Generation ....................74

Figure 28: Residential Housing Demolition Waste Composition Percentage by Weight ...........77

Figure 29: End of Service Life Waste Generation Composition Range (kg) for Houses............82 


\section{List of Appendices}

Appendix A - House A Information

Appendix B - House B Information

Appendix C 


\subsection{Introduction}

The impact of the construction industry in its totality, between the phases of construction, operation and end of service life for buildings, has major effects on climate change. It is predicted that 50 percent of total greenhouse gas emissions into the atmosphere comes from the built environment (Khasreen et al, 2009). In addition, researchers predict roughly 40 percent of total global energy use is attributed to buildings (Dixit et al, 2010). The construction and operational energy use of buildings contribute to almost one-quarter of global $\mathrm{CO}_{2}$ emissions (Monahan and Powell, 2011). Although operational energy use far outweighs the construction and demolition (C \& D) energy use, it is still a noteworthy energy consumption consideration as mentioned by Monahan and Powell (2011). Some researchers such as Khasreen et al (2009) predict roughly 80 percent of a building's energy consumption lies in the operational energy use, while 20 percent in the construction phase. The impact of construction waste and its methods for recycling and reuse of building materials are being considered far more critically now than in past decades (Yuan and Shen, 2010), mainly to reduce waste production, alleviate energy use and lessen the impact on climate change.

Researchers including Lu and Yuan (2011) have recognized the emerging concern of waste generation and its effect as a global issue in the discussion of sustainable practise moving forward. There is little doubt that waste generation is reaching a climax as a global issue, as some studies have indicated that C \& D waste represents approximately $40 \%$ of total solid waste going into landfills around the globe (Nitivattananon and Borongan, 2007). Considering the many streams of waste generation from private and public sectors, C \& D waste is one of the largest producers of waste on earth as mentioned by Nitivattananon and Borongan (2007). The current global population is approximately 7 billion and is expected to reach over 9 billion, and perhaps even 10 billion considering high growth projections according to United Nations 
(2004), by year 2050. Population growth tends to be a key factor in resource consumption rate and an increase in population can lead to an increase in consumption, and consequently, increase in waste generation.

Within the local populous of the Greater Toronto Area (GTA), a 48 percent rise in population is projected by year 2036, equating to an increase of 3 million people from the current population of over 5 million in the GTA (Ontario Ministry of Finance, 2011). Given the magnitude of this population increase, a major topic of concern will be construction and housing, and subsequently, the waste that will be generated.

The residential housing industry has undergone strategic changes in design and energy use in recent decades. Funded programs and certified standards such as the Canadian Mortgage and Housing Corporation (CMHC) Equilibrium Housing Program and Passive House (Passivehaus) Standards have come into existence to address some of the energy related issues. Without question, energy efficiency is among the main object of many new programs and standards by which energy resources are better managed and conserved, and as a result, greenhouse gas emissions are reduced. However, growing interest for waste minimization is receiving increased awareness in research as well. Waste management is climbing into a recognizable global issue as Lu and Yuan (2011) and Nitivattananon and Borongan (2007) have mentioned, and its link to climate change may not be as apparent as the impact of energy use and consumption.

Currently, residential housing construction pays minimal attention to strategies for minimizing $\mathrm{C}$ \& D waste generation during the design phase (discussed in forthcoming sections), whereas as much attention is placed during the construction phase. Although service life considerations are implemented for specific materials and components of a building, it is considered from a cost estimations perspective, such as with LEED New Homes 2009, and rarely from a waste 
generation perspective. Such a method needs change if better waste management practices are to be implemented over a house's service life. A reduction of waste generation in the construction industry will definitely help improve and limit waste generation locally, and on the global scale. Waste generation can be of many types; thus it is necessary to define waste in its scope and material for the purposes of this particular study.

\subsection{Waste Definition}

Waste generated from a particular project may vary in material composition and quantity based on project specifics, and can be either solid or liquid. Such variations can come from many things including the type of project (e.g. residential, commercial, industrial or institutional), and the scale and material specification of the building. Material specification is an important one because some materials are more wasteful than others considering product installation on the construction site, and the related labour that is required. For this study, solid waste stream from residential construction will be the focus.

The technical definition of $C \& D$ waste can vary in literature depending on factors mentioned above most notably construction type, however, the most suitable definition which encompasses a large range of factors would be: "building debris, rubble, earth, concrete, steel, timber, and mixed site clearance materials, arising from various construction activities including land excavation or formation, civil and building construction, site clearance, demolition activities, roadwork, and building renovation" (Shen et al, 2004).

\subsubsection{Applicable Regulations}

In the province of Ontario, many provincial regulations and standards play a role in $C \& D$ waste management. One of the largest and most significant waste management legislation in Ontario 
is O. Regulation 347, which came into existence in 1992, under the Environmental Protection Act (e-Laws, 2012). The regulation sets out wide range of technical definitions, including waste generators, commercial waste and sets minimum standards for disposal and treatment facilities for waste management in Ontario. The regulation includes up to 100 definitions relating to waste management practise in all types of sectors.

Furthermore, under the Environmental Protection Act, there are two other key Regulations that specifically govern construction and demolition projects in Ontario. Regulations 102 and 103 govern waste generation for large scale construction projects in Ontario (e-Laws, 2012). Regulation 102 requires owners of new construction or demolition projects larger than $2000 \mathrm{~m}^{2}$ in total floor area to conduct a waste audit and implement waste reduction plan. In addition, Regulation 103 requires projects larger than $2000 \mathrm{~m}^{2}$ to have source separation of waste and to recycle accordingly to material generation (e-Laws, 2012). Single houses in Canada are generally between 150 to $220 \mathrm{~m}^{2}$ in floor area (CMHC , 2004), and a development of about 10 such homes need to be built for Regulations 102 and 103 to take effect. Thus, only large scale residential projects (or developments) can fall under these two regulations.

According to Regulation 347, designated waste from new construction projects includes cardboard, brick, concrete, drywall (unpainted), steel and wood (untreated), while waste from demolition projects is similar and includes brick, drywall (unpainted), steel, concrete and wood (untreated) (e-Laws, 2012). The type of materials mentioned here are parallel to the definition quoted from Shen et al (2004). Also, the designated waste for both construction and demolition projects are very much identical, meaning the material that contributes mostly to $C \& D$ waste are very much the same, though they take place at different times of a building's lifespan. 
In addition to these major regulations, municipalities may also implement other by-laws to prohibit certain types of waste dumping into landfills to encourage recycling (Canadian Construction Association, 1992). However, dumping these types of C \& D waste material into landfills can be more feasible as tipping fees for disposal are relatively cheap (Recycling Counsel of Ontario, 2006).

\subsection{Study Context}

Canada produces relatively small amount of waste compared to its land mass and in contrast to other wealthy nations such as the United States (Carlos et al, 2002). That statistic is skewed due to Canada's relatively lower population in comparison to the United States and other nations in the globe. However, Canada's population is projected to rise in the near future and one of the most effected provinces will be Ontario and specifically the Greater Toronto Area, as mentioned earlier. As such, the focus of this paper will be on residential housing construction specifically in the GTA, which in fact is very similar to the North American housing industry.

\subsection{Current Research Trends in C \& D Waste}

A recent study by Yuan and Shen (2010) outlined the current trends in C \& D waste research in academic journals. Between the years of 2000 to 2009, over 7000 waste related academic journals were published, of which 87 were directly related to the topic of C \& D waste management. The 87 journals included 6 streams of research including (1) waste generation, (2) reduction, (3) reuse, (4) recycling, (5) management and (6) human factors in waste management, as shown in Figure 1 below. Furthermore, the study found that researchers in Hong Kong, Australia and the United States contributed most to this field of research within that time span, with overwhelming majority of authors situated in Hong Kong. Yuan and Shen (2010) 
suggest that more research into the generation of $C \& D$ waste should be the focus for future research, particularly for developing countries around the globe, which makes up 10.34 percent of the research in the past decade (Table 1).

Table 1: Topical stream of C \& D research in past decades (Source: Yuan \& Shen, 2010)

\begin{tabular}{|l|c|c|c|c|c|c|c|c|c|c|c|}
\hline \multicolumn{1}{|c|}{ TOPIC } & 2000 & 2001 & 2002 & 2003 & 2004 & 2005 & 2006 & 2007 & 2008 & 2009 & Total (\%) \\
\hline $\begin{array}{l}\text { C\&D waste } \\
\text { generation }\end{array}$ & 0 & 0 & 1 & 0 & 1 & 0 & 1 & 2 & 0 & 4 & $9(10.34)$ \\
\hline $\begin{array}{l}\text { C\&D waste } \\
\text { reduction }\end{array}$ & 0 & 2 & 1 & 0 & 2 & 1 & 2 & 3 & 1 & 1 & $13(14.94)$ \\
\hline $\begin{array}{l}\text { C\&D waste } \\
\text { reuse }\end{array}$ & 2 & 0 & 0 & 1 & 0 & 0 & 0 & 1 & 1 & 1 & $6(6.90)$ \\
\hline $\begin{array}{l}\text { C\&D waste } \\
\text { recycling }\end{array}$ & 0 & 2 & 2 & 0 & 3 & 1 & 4 & 3 & 3 & 5 & $23(26.44)$ \\
\hline $\begin{array}{l}\text { C\&D waste } \\
\text { management } \\
\text { in general }\end{array}$ & 2 & 1 & 0 & 6 & 4 & 3 & 1 & 6 & 5 & 5 & $33(3.93)$ \\
\hline $\begin{array}{l}\text { Human factors } \\
\text { in C\&D waste } \\
\text { management }\end{array}$ & 0 & 1 & 0 & 0 & 0 & 0 & 0 & 0 & 1 & 1 & $3(3.45)$ \\
\hline
\end{tabular}

Given the relatively lower focus of $C \& D$ research on waste generation within the past decade as opposed to waste management and waste recycling, the aim of this study is then to address the concept of waste generation. The strategy for waste generation minimization is most effective in the decision process or design phase of a project, as many researchers have identified that the best method to reduce waste generation of construction is by implementing strategies in the design process, rather than the construction phase (Faniran and Caban, 1998). But the waste generation effect is most experienced at the end of a building's lifespan or end of service life, where solid waste from demolition has to be dealt with and is far greater than the material waste generated during construction. Moreover, topic 2 (reduction), 3 (reuse) and 4 (recycling) in Table 1 make up the waste hierarchy in sequential order, thus making waste reduction the most effective way to manage waste.

The quantitative impact of waste is most experienced at the end of a building's service life, as such; the aim of this research is geared towards determining the potential waste generated (and 
its composition) at the end of service life for current design of houses. This can reveal key types of material that cause the most waste generation in the residential housing industry and only after this type of study can strategizes be directed towards most wasteful solid waste materials. 


\subsection{Research Description}

In order to effectively reduce waste generation, the first step would be to recognize the composition of waste generation in the residential housing industry. This must be clearly understood if there is to be a realistic and representative attempt to reduce waste generation. Thus the objective of this study is to quantify and compare end of service life demolition waste of two residential houses, particularly in the province of Ontario, Canada. The content will focus on the material aspect of waste and attempt to quantify waste composition by weight $(\mathrm{kg})$. The framework for the waste quantification is intended to cover materials used in key elements such as walls, foundation, roof and interior finish, prior to any furnishing.

With this objective in mind, it seems plausible to consider a research question as follows:

What is the waste generation of residential houses currently designed and constructed at the end of their service life in 50 years?

To fulfill this research question, other relevant inquires can be derived from this and include:

(a) What is the current status of C \& D waste generation in Canada and the globe?

(b) What methods or guidelines are currently used to help reduce C \& D waste generation in residential housing?

(c) Are there any gaps or other methods, techniques or considerations that have not been looked at in literature or case studies?

(d) Does the concept of waste minimization exist that takes into consideration a house's end of service life demolition waste generation?

(e) If so, what does it address? If not, what is missing within the research?

(f) How can this approach of demolition waste quantification help towards sustainable practice moving forward? 


\subsection{Methodology}

To fulfill this research objective, the overall methodology of this study is the following.

(i) Literature review of current C \& D waste generation in Canada and the globe, and relevant case studies with waste composition

(ii) Identify and evaluate current methods, techniques or concepts used to minimize $C$ \& D waste generation

(iii) Recognize if end of service life waste generation is accounted for in research

(iv) Quantify demolition waste generation at the end of a house's service life and assess the waste impact by weight $(\mathrm{kg})$

(v) Compare the quantitative data of demolition waste generation results with case studies and literature

(vi) Identify key materials in residential houses that need to apply waste reduction strategies moving forward

(vii) Evaluate overall research process (steps (i) to (vii)) and identify areas of further research

In reference to step (iv), two sequential steps will be followed to gather information in regards to the end of service life waste generation. First (step one), the chosen house (discussed in forthcoming sub-sections) will be assessed to determine the amount of material (in weight quantity) that currently makes up the house. This is the potential end of service life waste generation. Secondly (step two), any material that will need replacement during the house's service life will be added to the quantity of material determined in the first step. This is the total potential end of service life waste generation. 


\subsubsection{House Selection}

In reference to step (iv) in the methodology sub-section, potential waste generation at the end of service life for two single-family residential homes will be quantified by weight $(\mathrm{kg})$ following the literature review.

The 2003 GTA Land Inventory Survey revealed that 35\% of all residential housing approved for development that year was single-family detached homes, and $46 \%$ were apartment units, while semi-detached homes accounted for $7 \%$, and row houses at $12 \%$ (CMHC, 2003). This proportion has remained similar up to 2012 as shown in Figure 1 below, however, row houses have climbed in recent years and single-detached homes have fallen (CMHC, 2012).

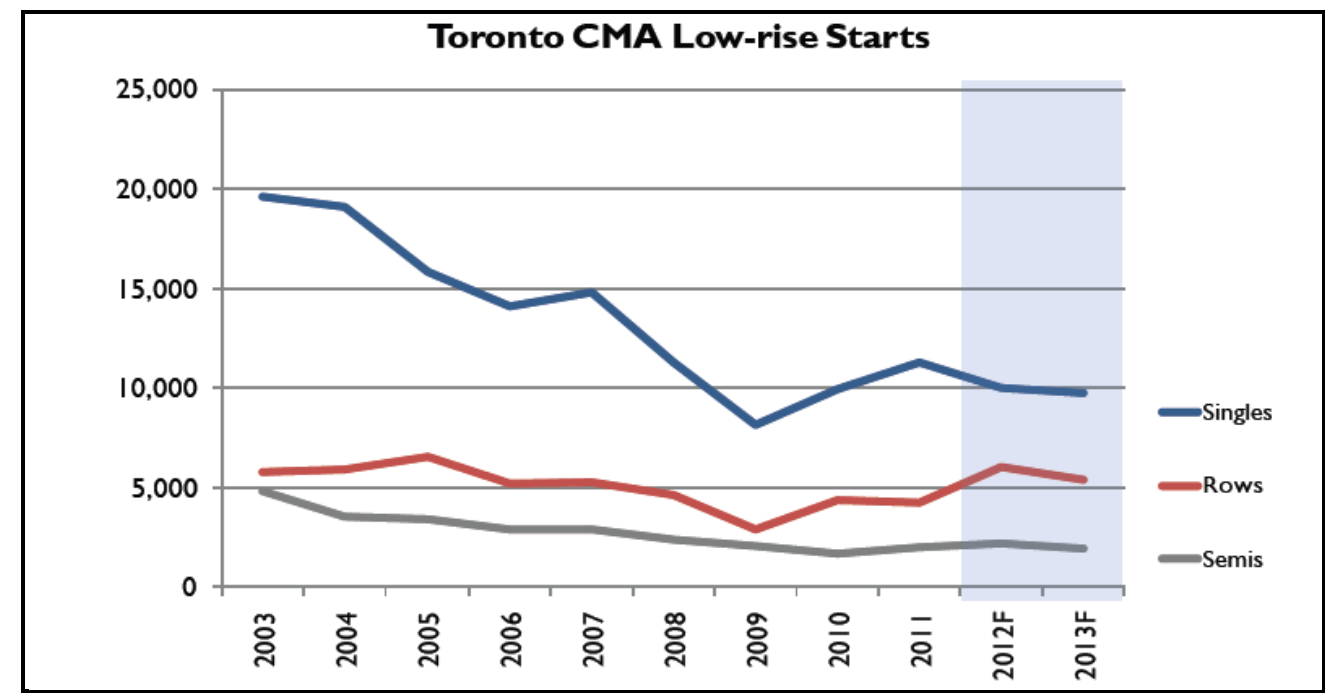

Figure 1: Residential Housing Construction by Type (Source: CMHC, 2012)

What is clear from this is that single-detached homes (shown as the blue in Figure 2) are more common than any other type of low-rise residential housing being built (or existing) in the GTA area. Therefore, it is relevant and plausible to consider these types of houses specifically for the waste generation study due to it being most representative of residential housing in the GTA. If the majority of existing housing stock in the GTA area are single-family detached, it is also likely 
that this type of housing will potentially contribute to most demolition waste at the end of its service life.

Furthermore, it seems most applicable to select brick veneer houses for this step (iv) as a large number of residential homes today (either existing or being built) are comprised of brick cladding (Hebron, 2012). To further strengthen this observation, a small survey was conducted in a downtown Toronto neighbourhood near Spadina Avenue and Dundas Street (Figure 2 below).

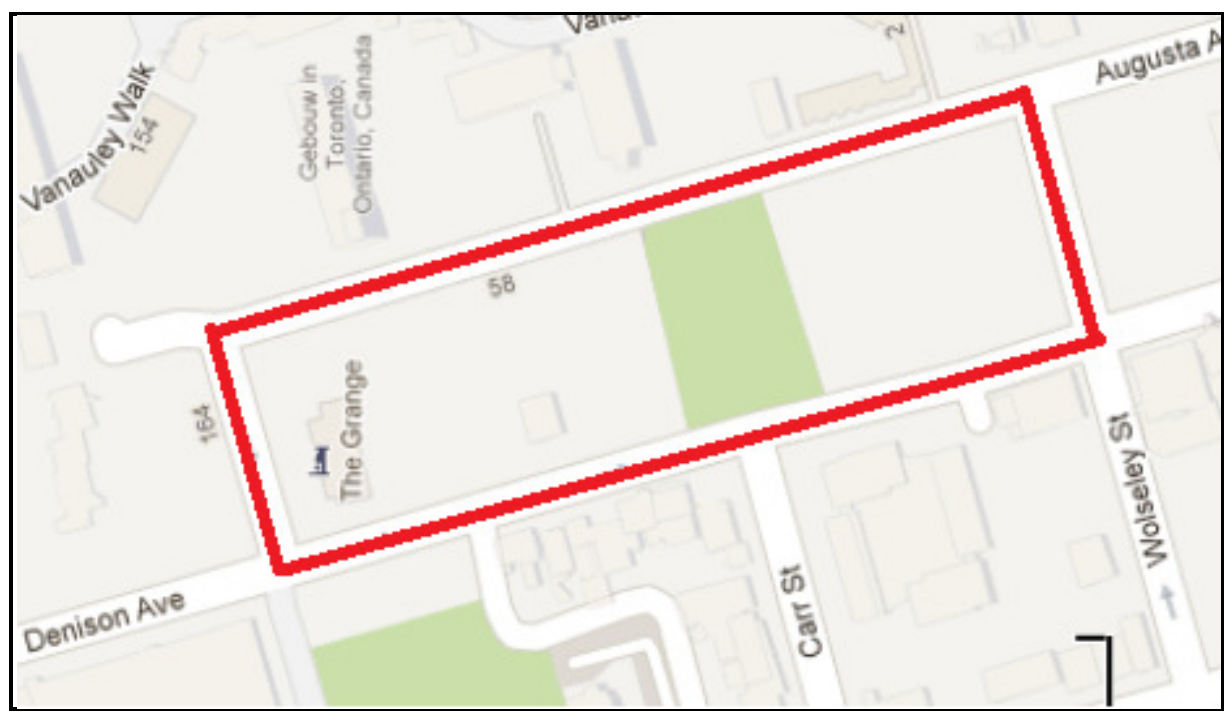

Figure 2: Downtown Housing Type Survey (Image Source: Google Map, 2012)

The intent of the survey was to identify the number of brick veneer cladding types versus other claddings types used in this neighbourhood, and the red outline identifies the particular block that was surveyed.

The survey revealed that 58 of the 62 homes/addresses used brick veneer as the exterior cladding system. The other 4 were vinyl siding and stone facades. The houses types included single-detached, semi-detached and bungalows. Although the neighbourhood is old and many of the buildings were built sometime during the past century, this survey enforces the 
observation made by Hebron (2012). Thus the selection of single-detached brick veneer houses for this study is representative of the current housing market stock, and the resulting waste that will be accumulated in the near future when houses reach their end of service life and are demolished.

One two-storey home and a single-storey home will be used for the evaluation to compare and contrast the potential end of service life waste. Furthermore, the level of waste intensity can be determined from this which can help evaluate whether a single or multiple storey residential building is potentially more wasteful.

The intent behind this approach is to evaluate the difference between the two houses and determine which type may be more efficient from a waste perspective in relation to its configuration. The other intent is to evaluate the potential waste material quantity and composition, and to observe if they are similar or different. If two different houses reveal comparable information, the results of this is study will be much stronger in terms of the indentified waste material type expected at the end of service life, which is most wasteful, and whether that matches with the sited literature and case studies for residential housing.

\subsubsection{Study Houses}

As mentioned in section 2.1.1 in the methodology sub-section, single-detached homes are most common in Toronto for low-rise residential houses, and have been for the past decade (CMHC, 2012). Consequently, the existing housing stock and new houses being built are mostly singledetached homes. Given that is the case, it's more logical to consider single-detached houses for this part of the study to gather representative data. As such, two houses were selected with two 
parameters in mind. First, they should be low-rise residential houses. Second, they should be representative of houses built in Ontario. With this in mind, two low-rise single-family detached residential houses were chosen as listed below.

(1) Two-storey Standard Brick Veneer House

(2) Standard Brick Veneer Bungalow

One interesting point to note is that the average Canadian family size is shrinking nationally, however, the size of single-family homes have increased (RCO, 2006). Moreover, the estimated average Canadian house in 2000 was $210 \mathrm{~m}^{2}\left(2,299 \mathrm{ft}^{2}\right)$, and this average shrunk to $185 \mathrm{~m}^{2}$ $\left(2000 \mathrm{ft}^{2}\right)$ in recent years, according to CMHC sources (Hopper, 2012)

\subsubsection{Service Life}

Athena Institute defines service life as, "the actual period of time during which the building or any of its components performs without unforeseen costs or disruption for maintenance and repair" (Athena Institute, 2006). Service life comes to an end when the building is of no use, or a change of use is needed, and is demolished.

The applicability of service life in this study will relate mostly to steps (iv) and (v) in the methodology. A review of several papers with similar nature of study (residential housing and lifecycle estimations) revealed the appointed service life used in the studies were quite arbitrary (predominately 50 years or higher) as was the case in Bajpai et al, Bowyer et al (2001), Lippke et el (2004). Furthermore, some Athena Institute studies, including one particularly in the United States found that overwhelming majority of residential houses have a service life of 50 years or more (with many extending beyond 75 years), and the contributing factors for the end of service 
life are many asides from physical condition including redevelopment plans and change of use (Athena Institute, 2004). A paper written by O'Connor (2004) confirms this observation from the same survey results.

Accordingly, a service life of 75 years will be used in this study for step (iv) in the methodology, as it represents a medium-to-high service life of residential houses. A best case scenario for service life is assumed due to unpredictable factors that determine housing service life such as redevelopment plans, change of use and physical condition.

The types of material that will be evaluated in terms of its potential end of service life waste generation are key elements that have been looked into in literature and case studies discussed in forthcoming sections. In section 3.0, CCA (1992), RCO (2006) and NRCan (2006) identified wood, concrete, masonry (brick), and gypsum as most noteworthy when it comes to residential waste. Therefore, the key housing material subject to material quantification for potential end of service life waste generation are as follows:

(a) Concrete (e.g. walls, footing and slab)

(b) Masonry (e.g. masonry walls)

(c) Wood (e.g. studs, plates, joists, sheathing, bridging)

(d) Gypsum (e.g. interior finish)

(e) Asphalt (e.g. roofing)

Foundation elements will represent concrete material use in the building, masonry will include brick generally, and floor/wall framing will represent wood material. The demolition waste generation at the end of service life will be deemed waste in accordance to Regulation 347, 103, and 102, and that which can be dumped into landfills (as discussed in sub-section 1.1.2). 


\subsection{Scope}

The subject matter of this study deals with the realm of construction and demolition waste, specifically end of service life waste generation from low-rise residential homes in the GTA. The waste quantification (steps (iv) and (v)) of this study will solely focus on the waste generated from low-rise residential construction of 2 common single-family detached houses with different configuration but similar construction type. The current housing stock in mostly made up of single-detached homes in the GTA, as shown in Figure 1 (above).

\subsection{Study Significance}

Research by Faniran and Caban (1998) and Yuan and Shen (2011) and many others, affirm that the best strategy to manage $C \& D$ waste is to use the 3R's (reduce, reuse, recycle) principle in descending order. Thus the best strategy to minimize $C$ \& $D$ waste generation is reduction. However, reduction for what type of construction material needs to be identified in order to strategize effective waste minimization practice in the preliminary (design) stages where major decisions are made.

The end of service life waste quantification will reveal the waste material type that contributes to demolition waste in residential housing. By having this type of information prior to the beginning of a housing project, informed decisions can be made in the selection process of a house to reduce $C \& D$ waste generation. This study is intended to encourage construction of housing with focus on end of service life waste minimization, and ultimately, helping to alleviate the environmental impact. The research will focus on the Canadian market, but the implications of 
this study will not be exclusive to Canada but North America as well, due to the similarity in construction methods in the residential housing industry.

\subsection{Limitations}

Two similar low-rise single-detached residential houses will be evaluated from an end of service life waste generation perspective; hence, row houses, semi-detached houses, and residential apartments are not subject to this study. As a result, the findings of this study will be within the scope of single-detached homes. However, row houses and semi-detached homes are similar in construction methods to single-detached houses; therefore the findings will still be relatable and relevant. 


\subsection{Literature Review}

Researchers recognize the emerging concern of solid waste generation and its effect on a global scale as an alarming issue moving forward (Lu and Yuan, 2011). The same can be said about Canada as studies have been produced within the past decades on quantifying $C \& D$ waste generation nationally. Some studies have looked into the aspect of C \& D waste and have conceptualized a general make-up of $C \& D$ waste generation in Canada. As mentioned in the introduction, Nitivattananon and Borongan (2007) predict global C \& D waste production to be around $40 \%$ in landfills. Poon (1997) also recognizes that is the case around the globe. The Canadian C \& D waste proportion production however, is not as high according to the Recycling Counsel of Ontario (RCO) and Environment Canada.

Environment Canada in 1992 predicted the total amount of C \& D waste from all construction, renovation and demolition activities accounted for over 11 million tonnes (RCO, 2006). RCO extrapolated this data according to the population at the time of the study (1992), and predicted that 12.5 million tonnes of C \& D waste was produced in Canadian in 2006, based on population of 32 million in 2005 (RCO, 2006). Although the dynamics of such a forecast is complex and dependent upon many factors aside from just population, it certainly gives a perspective of what can be anticipated in Canada. Also, the generated waste per capita amounted to 390 $\mathrm{kg} /$ person/year $(1.07 \mathrm{~kg} /$ day) according to the population of 32 million ( $\mathrm{RCO}, 2006)$.

Furthermore, RCO predicts that Canada's C \& D waste accounts for $25 \%$ of total waste proportion in landfills by volume (RCO, 2006). This is far below the stated $40 \%$ Nitivattananon and Borongan (2007) have predicted. To gain a deeper perspective into this matter, C \& D waste generation of other countries around the globe is listed in Table 2 below. 
Table 2: C \& D Waste Proportion by Country (Source: Tam \& Tam, 2008)

\begin{tabular}{|l|c|}
\hline Country & $\begin{array}{l}\text { C \& D waste to total } \\
\text { waste proportion (\%) }\end{array}$ \\
\hline Australia & 44 \\
\hline Brazil & 15 \\
\hline Denmark & $25-50$ \\
\hline Finland & 14 \\
\hline France & 25 \\
\hline Germany & 19 \\
\hline Hong Kong & 38 \\
\hline Japan & 36 \\
\hline Italy & 30 \\
\hline Netherlands & 26 \\
\hline Norway & 30 \\
\hline Spain & 70 \\
\hline United Kingdom & $>50$ \\
\hline United Sates & 29 \\
\hline
\end{tabular}

It is evident from this table that some of the countries listed are close to and exceed the $40 \%$ benchmark predicted by Nitivattananon and Borongan (2007). What is also clear is that Canada's C \& D waste proportion in landfills is $25 \%$ (other studies have shown the number as high as $30 \%$ ), and is on the lower end of the scale relative to countries such as UK, Spain, Australia, Hong Kong and Japan. Furthermore, the $40 \%$ benchmark is reached or close to 6 of the 14 countries listed.

What is uncertain from this data is the attributed weight of the waste for each respective country. This can be significant considering the nature and size of construction activity in the country, as well as the population, which make up the economy. For example, Australia's C \& D waste generation represents $44 \%$ of total waste in the country, while United States (US) generation is $29 \%$. Although Australia's percentage is higher, US C \& D waste in landfills may be far more in total quantity and weight due to the size of its economy compared to Australia's economy. The US supports over 300 million people, while Austria serves just over 21 million (World Bank, 2011), and the sheer size and frequency of construction activity for the two 
countries will differ. Therefore, it is not clear if these percentages (Table 1 above) represent a volume or weight ratio in the total amount of $C \& D$ waste produced in the country in landfills. Thus this data is better suited to serve as more of a general guideline.

\subsection{Case Studies: Waste Composition}

Similar to the estimate discussed above in regards to the C \& D waste amount in landfills, waste composition of construction materials can also serve as a key principle for the betterment of waste reduction management. The reason being, it gives insight and identifies what type of materials are most wasteful, and therefore, the material needing most attention when it comes to waste reduction can be identified. Again, case studies have delved into this matter specifically and have formulated data on the composition of C \& D waste in Canada.

\subsubsection{Canadian Construction Association Case Study}

In 1992, the Canadian Construction Association (CCA) conducted a study in the Toronto area through partnership with the National Research Council, under Natural Resources Canada (NRCan), to produce a report on pressing waste management issues in the construction industry and the pending problems of waste generation that is filing landfills (CCA, 1992). The intent of the study, and report was to provide industry personnel with a framework of all interconnected factors that influenced waste generation including regulations, current practise, and recyclability of materials, hazardous waste and government agencies at play across the nation. The report also identified C \& D waste composition in Canada, particularly in Toronto in southern Ontario.

Consequently, it was also during this time period (early 1990's) that the consolidation of many waste management regulations were conceived and later implemented in Ontario such as 
Regulation 347, Regulation 102 and 103 under the Environmental Protect Act, which was discussed in sub-section 1.1.2 in the introduction. The methods, materials and techniques of modern day construction in the residential industry are not that different from past decades in Canada. The waste composition information was gathered by CCA in 1992.

The C \& D waste generation data was collected by CCA (1992) from 5 specific project types including:

(1) residential low-rise (6 samples),

(2) commercial low-rise (2 samples),

(3) residential and commercial high-rise (5 samples),

(4) demolition (5 samples),

(5) and renovation (6 samples)

What is unknown about these sample projects are the details of the sample buildings, such as size ( $\mathrm{m}^{2}$ area), category of construction (e.g. woodframe, curtain wall, concrete, etc.), and whether they are representative of typical homes/buildings in the Canadian market. However, given the fact that they are samples within the Toronto area, with 6 low-rise residential houses, it is fair to assume there were representative houses for the study.

Also, it not clear whether the composition of waste (expressed as a percentage) gathered in this study represents a volume or weight ratio, but the nature of the study seems to indicate a volume ratio. Nevertheless, 24 total samples were taken as part of the study and therefore, it should provide a general statistic/guideline on waste composition in the region, and by extension, within the nation. The result of the CCA survey is represented in the following charts (Figure 3 \& 4) below accordingly. 
In reference to the project types mentioned above (e.g. residential low-rise, commercial low-rise, residential and commercial high-rise, demolition, and renovation), CCA's evaluation of waste composition falls into 2 categorical streams, (a) general construction waste composition, which includes renovation as well, and (b) demolition waste composition. General construction waste composition is depicted below.

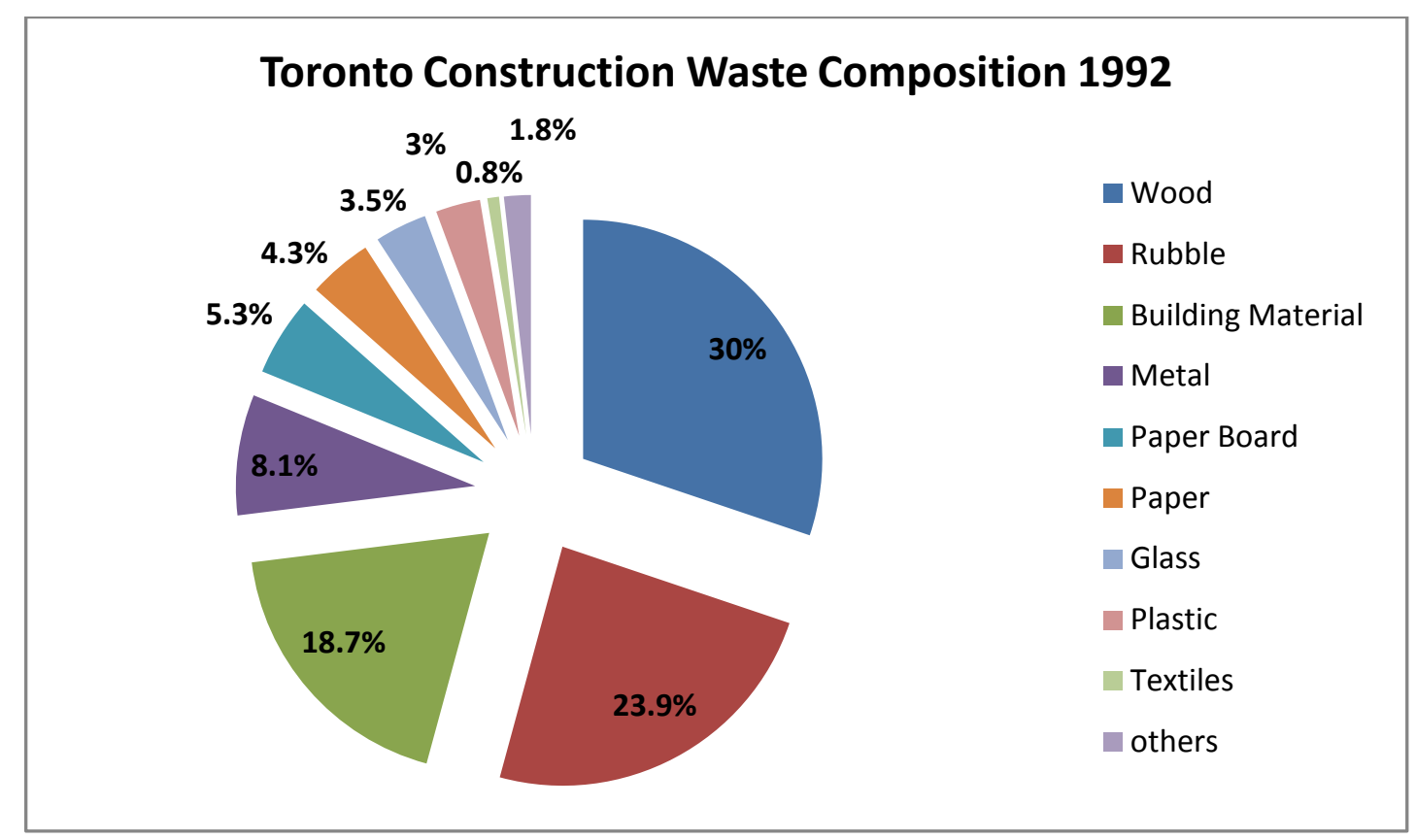

Figure 3: General Waste Composition

Source: CCA, 1992 (adapted from the original chart for better visual display)

Important to note that rubble, which is the second highest type of waste, is characterised in this study as brick/concrete type material, while building material ( $3^{\text {rd }}$ highest) is asphalt/tar-based (e.g. roads, parking lots, shingles, tar paper, etc) products. Without surprise, wood turned out to be the highest producer of waste in construction according to the market in 1992, given the project types mentioned earlier. Wood in Canada is readily available and is moderately renewable, and therefore, the application of this material is optimal for the residential housing industry. Low-rise residential woodframe construction is very similar in the US as well, and new construction waste for wood is estimated to be around $42 \%$ (RCO, 2006). Therefore, North 
American (Canada and US) surveys confirm that wood is the most wasteful material when it comes to new construction. However, given the scope of this research, the demolition waste generation is more noteworthy and relevant. The composition of demolition waste is shown in Figure 4 below.

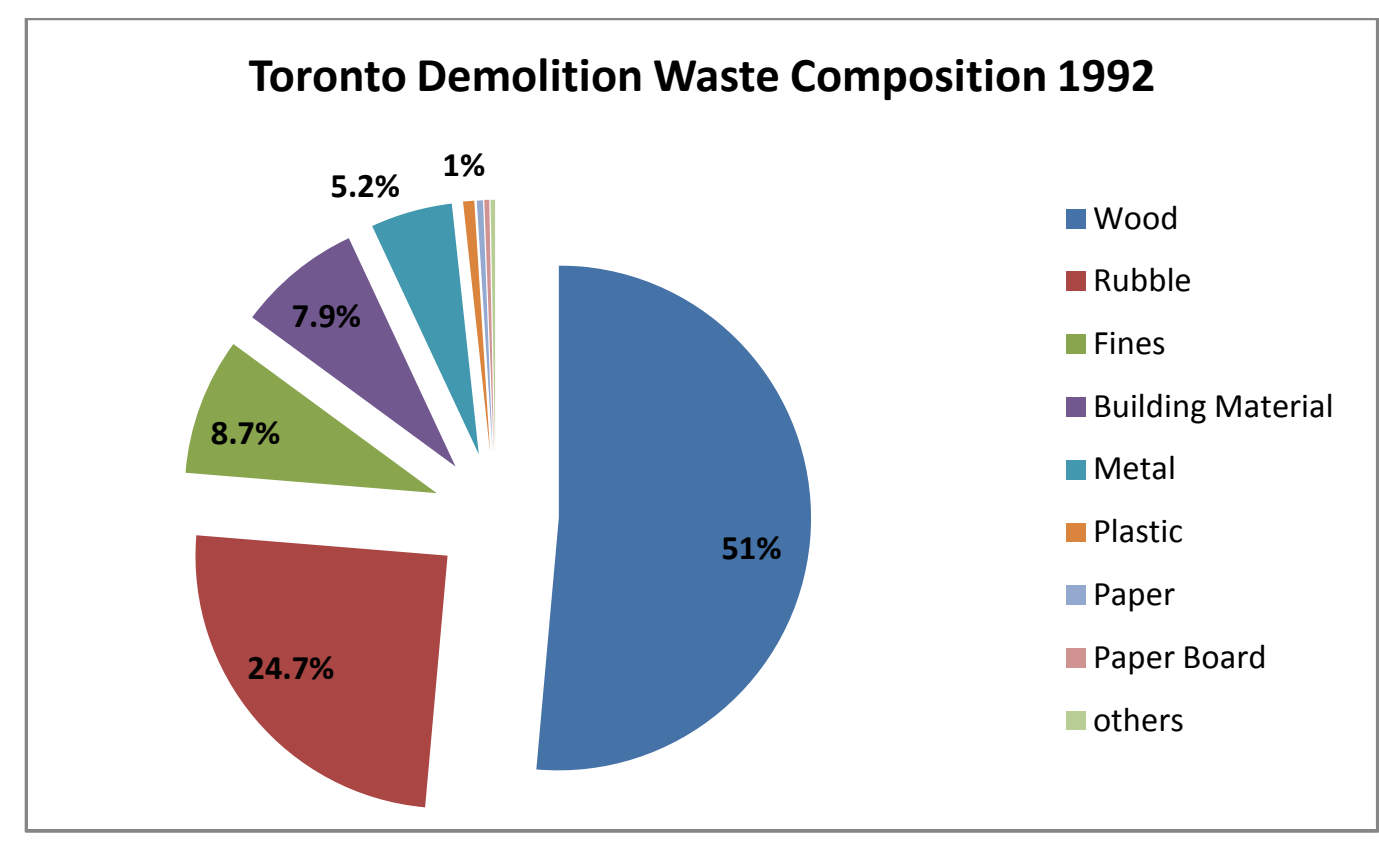

Figure 4: Demolition Waste Composition

Source: CCA, 1992 (adapted from the original chart for better visual display)

Here we see that material composition is fairly identical to general construction composition (Figure 3 above), however, the proportion of waste is very different. Wood waste is accounted for $51 \%$ of the waste coming from demolition activities, and rubble waste is second representing $25 \%$ of total waste. The last three slices are paper $(0.4 \%)$, paper board $(0.3 \%)$, and others $(0.3 \%)$. The data from construction and demolition activities is clearly conveying that wood in general is the largest producer of waste in C \& D activities in Canada, at least for the time being in 1992, for both construction (including renovation) and demolition activities. However, demolition waste composition in the US report wood comprises only $16 \%$ of the total demolition 
waste generation (RCO, 2006). Clearly the reports conflict between Canada and the US when it comes to demolition waste composition, while construction composition was more similar.

These results however, are conditional to the type of samples taken and because the exact characteristic of project parameters are not know, the results can be skewed and taken out of context, which may be contrary to the original intent of CCA. As such, to better clarify and verify the validity of this data, a comparative analysis of other recent projects within this decade will be contrasted to gain insight into the nature and accuracy of the study done by CCA in 1992 . This will also shed light into whether industry practice has remained alike in terms of $C \& D$ activity and the resulting waste that is produced.

\subsubsection{Recycling Counsel of Ontario Case Study}

Recycling Counsel of Ontario $(\mathrm{ROC})$ conducted a recent study comparable in nature to the one CCA conducted in 1992. The study was supported by the federal and provincial levels of government, as well industry partners. To better formulate the accuracy and relevance of the 1992 study done by CCA to present date, RCO's study in 2006 will be contrasted to CCA in terms of waste composition to find which commonalities are still present to date.

Much like the study done by CCA (1992), RCO (2006) sample projects also concentrated around Toronto, representative of a large metropolitan in Canada. RCO was involved with about 15 case studies with case specific benchmarks for each study. For example, some case studies focused on wood reduction, while others focused on gypsum reduction and recycling. Only select cases that resemble projects used in the CCA (1992) study will be looked at and compared, and therefore a total of 4 case studies are selected for these purposes. 
The stream of the 4 case studies is divided into construction, renovation, and demolition projects, and will be specifically compared to the results from CCA 1992 study. Each RCO case study and its comparison to the CCA report are divided into subsections below.

\subsubsection{New Construction Comparison}

A subdivision (custom homes) located in St. David's, Ontario was constructed with the specific goal of managing drywall off-cuts to reduce waste and assess net cost-benefit between recycling and landfilling (RCO, 2006). Eight homes with an average $186 \mathrm{~m}^{2}\left(2000 \mathrm{ft}^{2}\right)$ in floor area were being constructed with a total of $1486 \mathrm{~m}^{2}\left(16,000 \mathrm{ft}^{2}\right)$. After completing approximately $863 \mathrm{~m}^{2}\left(9,300 \mathrm{ft}^{2}\right)$ of area (roughly the equivalent of 4.65 houses), the weight average of gypsum waste recycled per $\mathrm{ft}^{2}$ was determined as $0.49 \mathrm{lbs}$, which amounted to a total of 2.11 tonnes (roughly 1 metric tonne) of gypsum waste. The RCO (2006) study suggests that custom homes generally produce more gypsum off-cut waste (in new construction) due to the irregularity of shapes and corners in the design, as opposed to a typical track house. Nevertheless, the key information needed from this is case study is the waste composition in new construction which is shown in Table 3 below.

Table 3: Weight by tonnes for constructing custom home

\begin{tabular}{|l|c|c|}
\hline Material & Weight (tonnes) & Percentage (\%) \\
\hline Wood (Dimensional \& Manufactured) & 1.02 & 58.3 \\
\hline Metals & 0.10 & 5.7 \\
\hline Plastics & 0.03 & 1.7 \\
\hline OCC (corrugated cardboard) & 0.60 & 34.3 \\
\hline \multicolumn{2}{|c|}{} & $\mathbf{1 0 0}$ \\
\hline Total & \multicolumn{2}{|c|}{ Source: RCO, 2006 (adapted from original table with percentage column) }
\end{tabular}

By comparing this subdivision construction waste composition to the CCA (1992) surveyed data, it can be seen that the waste proportions do not match. In the CCA data (Figure 3 in sub-section $3.1 .1)$; wood $(30 \%)$, rubble (24\%) and building material (19\%) were the top three producers of 
waste, while wood (58\%) and OCC (34\%) are the major waste streams in this custom homes project. Though the results are not identical, the validity of the CAA study can still remain intact because this subdivision was a custom homes project, in addition to the fact that gypsum was specifically recycled in this project and was not accounted for in the waste composition percentages given in Table 3 above. If it was the case, the ratio of wood waste would fall below $58 \%$ with the added gypsum waste. The CCA study results indicated far less wood waste in new construction compared to this custom homes project; therefore, a deeper look into another new construction case study should depict a clearer picture.

Another new construction case study RCO undertook was the Whole Village Project (communal living) in Caledon, Ontario. It was being constructed with a specific goal to reduce waste in material and cost. The projects underline principle stemmed from a housing study that concluded as follows:

"Recent housing studies have indicated that as the average Canadian family size shrinks, the average size of a new single family home has actually grown. This has meant that the overall environmental footprint of housing has increased. The Whole Village co-housing project offers a thought-provoking alternative to this dynamic." (RCO, 2006).

The concept of community living is an unconventional type of family dwelling where the space is shared amongst the community through dynamic design of spaces to accommodate interaction between personal and public space (RCO, 2006). The project estimates over 2 tonnes of waste accumulation (Table 4 below), mainly involving kitchen furnishing material (e.g. cabinets, stoves, counter tops, dishwasher, etc.). 
Table 4: Weight by Tonnes for Constructing Whole Village Communal Living

\begin{tabular}{|l|c|c|}
\hline Material & Weight (tonnes) & Percentage (\%) \\
\hline Mixed (wood, metal, particle board) & 2.126 & 50 \\
\hline Melamine over particle board & 1.04 & 24.5 \\
\hline Solid maple wood & 0.14 & 3.2 \\
\hline Steel cabinet door hinges & 0.03 & 0.7 \\
\hline Steel door pulls & 0.01 & 0.2 \\
\hline Plastic laminate countertops & 0.18 & 4.2 \\
\hline Dishwasher (mixed metals and plastic) & 0.26 & 6 \\
\hline Electric Stoves & 0.37 & 8.7 \\
\hline Range hoods & 0.09 & 2.1 \\
\hline \multicolumn{2}{|c|}{} \\
\hline Total & $\mathbf{4 . 2 5}$ & $\mathbf{1 0 0}$ \\
\hline
\end{tabular}

Source: RCO, 2006 (adapted from original table with percentage column)

This project represents 10 family units (private) incorporated into a community sharing spaces for dining rooms, living rooms (semi-private spaces), etc. This case study also indicates wood and related material (metal and particle board) accounts for half of the accumulated waste. Much like the custom home project in St. David's discussed prior, this study also places wood as most wasteful. Moreover, the wood waste for this Whole Village project falls much closer to the CCA reference of $30 \%$ than the St. David's project because the mix of metal and particle board are also accounted for in the $50 \%$ wood waste. Although both of the RCO case studies, St. David's and Whole Village, have not matched with the CCA (1992) waste composition data, it shows that wood waste may be greater in more recent times, such as these case specific studies done in 2006. Nonetheless, it its clearly established that wood is accounted for being most wasteful in new construction for residential low-rise housing.

\subsubsection{Renovation Comparison}

The Memorial college is located in Toronto and has been is service for over 30 years (RCO, 2006). The specific goal of this project was to reuse material salvaged from this old college into a new building location, employing adaptive design principles. The new building was an existing 
3-storey school to be adapted for new occupancy type. A total of 5 materials were salvaged from the old college building as shown in Table 5 below.

Table 5: Weight by Tonnes for Renovation

\begin{tabular}{|l|c|c|}
\hline Material & Weight (tonnes) & Percentage (\%) \\
\hline Metal Stalls -steel & 1.36 & 0.04 \\
\hline Asphalt & 16.36 & 0.5 \\
\hline Clay Brick & 51.14 & 1.6 \\
\hline Concrete & 3,005 & 97.7 \\
\hline Florescent Light Fixtures & 1.42 & 0.04 \\
\hline \multicolumn{2}{|c|}{} & $\mathbf{1 0 0}$ \\
\hline Total Source: RCO, 2006 (adapted from original table with percentage column)
\end{tabular}

This building falls under commercial type occupancy, and therefore, the material composition results have reflected that. As such, concrete (98\%) was the number one utilized material along with brick being in a distant second place. Again, comparing this to the CAA study, the results do not match mainly due to it being an adaptive renovation project with commercial type occupancy.

\subsubsection{Demolition Comparison}

The Canadian Department of National Defence operates 4 buildings in north Toronto and the specific goal of this project was to divert waste by employing a deconstruction plan for the buildings and observe the related cost benefit (RCO, 2006). According to the results, the diverted waste composition from the building is listed in Table 6 below.

Table 6: Weight by Tonnes for Demolition

\begin{tabular}{|l|l|l|}
\hline Material & Weight (tonnes) & Percentage (\%) \\
\hline Concrete & 8,965 & 95.5 \\
\hline Structural steel & 54.82 & 0.05 \\
\hline Rebar & 97 & 1 \\
\hline Copper & 6.1 & 0.006 \\
\hline Wood & 257.52 & 2.7 \\
\hline Ceramic toilets & 1.66 & 0.001 \\
\hline & & \\
\hline
\end{tabular}


The 4 buildings fall under a commercial type building, and therefore, the waste data retrieved will reflect as such. It can be seen again; much like the previous renovation project, that concrete $(96 \%)$ has the highest rate of diversion and wood falls into a distant second place with 3 percent.

In these last two case studies waste composition is significantly different from the previous two (Table 3: St. David's and Table 4: Whole Village), and almost opposite to the CCA waste composition data. Important to note that these two studies involved commercial buildings, and therefore, would not resemble waste composition of residential housing. However, the CCA study comprises of projects in 5 different streams (section 3.1.1) including commercial projects which represents half (12) the total of 24 samples used in the study. The statistic that stands out most is that over $95 \%$ of waste generation is concrete for both the college and national defence buildings. A study by Natural Resources Canada (NRCan) also reveals a more holistic view of $\mathrm{C}$ \& $D$ generation in the residential industry is Canada.

\subsubsection{Natural Resources Canada Study}

A study in 2006 was conducted by Natural Resources Canada (NRCan, 2006) which revealed that 4.2 tonnes of residential C \& D waste was disposed annually into landfills in Canada (Figure 5 below). However, the study is not clear on classifying what types of residential projects (demolition, construction or renovation) were surveyed to gather the information. Nonetheless, it can be seen that wood ranks in at number one, again, with $26 \%$ waste ratio. Although this study exclusively dealt with the residential sector, it is still relatively close to the data CCA (1992) predicted at $30 \%$ construction wood waste. 


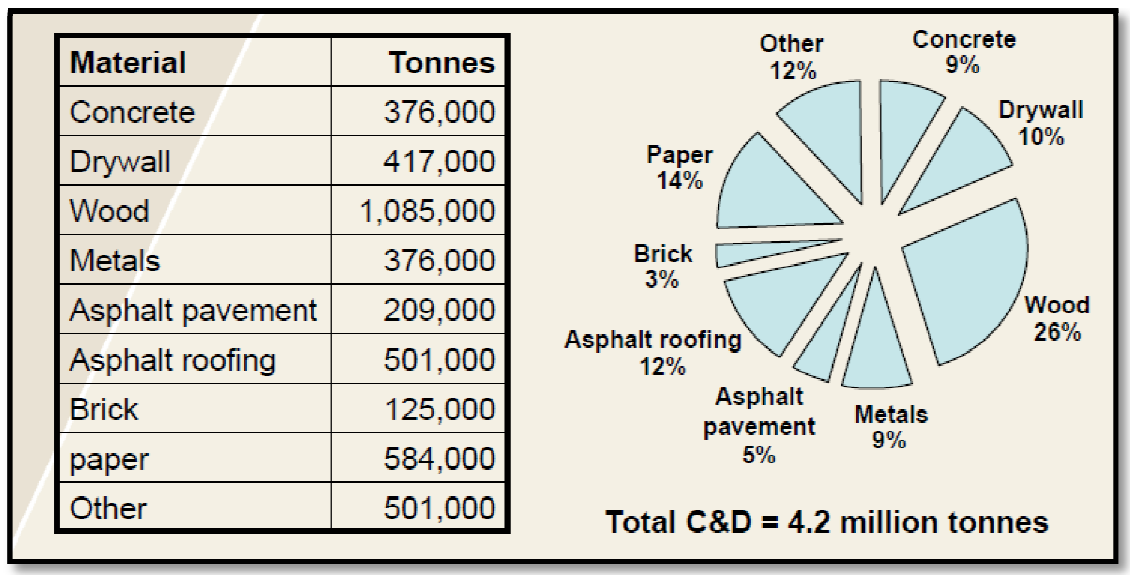

Figure 5: Canadian Residential Waste Composition (Source: NRCan, 2006)

Furthermore, studies in the US to identify C \& D waste have also been conducted by many researchers and one such study was done by Environmental Protection Agency (EPA) in 1998 to identify the general C \& D waste composition much like the CCA study in 1992. Part of the result of the study is shown in Table 7 below (US EPA, 1998).

Table 7: US C \& D Waste Composition (Source: US EPA, 1998)

\begin{tabular}{|l|c|c|}
\hline \multicolumn{1}{|c|}{$\begin{array}{c}\text { Building-Related C\&D } \\
\text { Material }\end{array}$} & $\begin{array}{c}\text { Quantity Generated } \\
\text { (million tons) }\end{array}$ & $\begin{array}{c}\text { Percent of C\&D Debris } \\
\text { Stream }\end{array}$ \\
\hline Concrete Rubble & 66 to 83 & $40-50 \%$ \\
\hline Wood & 33 to 49 & $20-30 \%$ \\
\hline Gypsum Drywall & 8 to 25 & $5-15 \%$ \\
\hline Asphalt Roofing & 2 to 16 & $1-10 \%$ \\
\hline Metals & 2 to 8 & $1-5 \%$ \\
\hline Bricks & 2 to 8 & $1-5 \%$ \\
\hline Plastics & 2 to 8 & $1-5 \%$ \\
\hline Total & $\mathbf{1 6 4}$ & $\mathbf{1 0 0 \%}$ \\
\hline
\end{tabular}

By comparison to the CCA (1992) study, wood waste proportion is relatively closer to this study done in the US, as does the $26 \%$ wood waste predicted by NRCan (2006). However, one clear difference is that rubble is estimated to be around $40-50 \%$, whereas in the CCA study it was estimated around $24 \%$, which is a significant difference. This difference can be attributed to the type and frequency of samples that were taken to generate this data. 


\subsection{Synthesis of Waste Composition Data}

Having looked into a variety of case studies including CCA (1992), RCO (2006) and NRCan (2006), and gained a general picture of waste composition. However, it is apparent that specific case studies as done by RCO (2006), do not match the generic waste composition data produced by CCA in 1992. It was clear however, that 2 of the residential case studies (St. David's and Whole Village) were very similar in material composition, but not in terms of proportion. The nature of the case studies conducted by the RCO was geared towards specific goals for case specific projects rather than a holistic evaluation.

On the other hand, the latter two case studies (Memorial College and Defence Buildings) were contrary to the results of CCA (1992). One explanation is that these two case studies were of the commercial type, and therefore do not represent a combined residential and commercial average waste composition, as done by CCA, along with the size and nature of the projects which were different. If the first two case studies (St. David's and Whole Village) were to be combined to determine the average wood waste ratio, wood turns out to be $54 \%$ as opposed to the $30 \%$ predicted by CCA (1992) for the construction stream. Therefore, what can be understood from this is that the census on predicting the exact composition of $C \& D$ waste proves to be difficult, and perhaps even harder to verify because it is governed by many factors that may not be a constant variable throughout project to project and location to location. Nevertheless, all of the studies (CCA, RCO, and NRCan) are unanimous that wood is the most wasteful material when it comes to $C \& D$ waste generation.

\subsubsection{Canadian C \& D Waste Composition}

Having looked into past case studies (CCA, 1992) and deeper into case studies in recent times (RCO, 2006), it is clear that a census on estimating C \& D waste composition is very difficult. 
The nature of predicting such composition is conditional based on parameters such as the type of projects, their size, location and the pattern on how sampling is employed during specific stages of a project which is precisely confirmed by Begum et al (2006). As such, it seems more practical to predict waste composition by giving a general range much like how it is given in Figure 7 above. This method will be utilized to synthesize both construction and demolition waste composition in Canada from the three case studies of CCA (1992), RCO (2006) and NRCan (2006), and a summary table is presented below to show C \& D projects waste composition. An average of the three studies is also given in the last column.

Table 8: C \& D Projects Waste Composition

\begin{tabular}{|l|c|c|c|c|}
\hline Material & CCA 1992 (\%) & RCO 2006 (\%) & NRCan 2006 (\%) & AVERAGE (\%) \\
\hline Wood & $30-51$ & $50-58^{*}$ & 26 & 40 \\
\hline Concrete/Rubble & $24-25$ & $96-98^{* *}$ & 9 & 44 \\
\hline Gypsum & $9-19$ & $\mathrm{n} / \mathrm{a}$ & 10 & 12 \\
\hline Metal related & $8-5$ & $1-5$ & 9 & 6 \\
\hline Paper related & $1-10$ & $25-34$ & 14 & 16 \\
\hline Plastic & $1-3$ & $2-4$ & $\mathrm{n} / \mathrm{a}$ & 3 \\
\hline Others & $1-5$ & $2-5$ & $12-29$ & 9 \\
\hline
\end{tabular}

${ }^{*}$ Represents range from residential case studies by RCO

${ }^{* *}$ Represents range from commercial case studies by RCO

The RCO percentages are gathered from the case studies analyzed in section 3.1.2 of this paper. As shown above, CCA (1992), RCO (2006) and NRCan (2006) C \& D waste composition studies were all applied to get a generic range which was then converted into an average percentage. Important to note that the final averages do not equal to $100 \%$ for reasons of being an average derived from ranges. Coincidently, the averages correspond well with the data US EPA retrieved (Figure 5 above) in regards to the US C \& D waste composition. This shows a resemblance of $C \& D$ activity and waste generation between and Canada and the US, representing larger part of North America. Of course if it were just new construction was, as it was evident from some of the case studies discussed, wood waste usually turned out to be the highest waste material in residential construction. However, when factoring in demolition waste, concrete often has the highest quantity of waste material in that stream because it is a common 
material for commercial/industrial type buildings. Despite RCO (2006) proving this fact, as discussed in the National Defence buildings case study, CCA (1992) still observed wood waste as the highest in demolition waste attributed for $51 \%$ of the waste, even more so than the $30 \%$ in new construction. Therefore, this discrepancy needs to be further looked at and will be evaluated with the quantification of end of service life waste generation from the two houses chosen for this study in later sections of this paper, as listed in the methodology steps (iv) and (v).

\subsection{Canadian C \& D Waste Generation}

The total C \& D waste accumulation in Canada is expected to be around 12.5 million tonnes annually, according to population index in 2006 (RCO, 2006). By comparison, the United States generates roughly 136 million tonnes of C \& D waste annually (Guy \& Gibeau, 2003). Although that may seem high at first glance, it is still comparable to the Canadian industry considering the population difference of about 300 million (approximately $1 / 10$ in ratio). This equates to approximately $1.24 \mathrm{~kg}$ per capita/day of C \& D waste generation for the US, which is slightly higher than Canada's generation at $1.07 \mathrm{~kg}$ per capita/day (RCO, 2006). Moreover, as mentioned in the introduction section, construction waste accounts to about 25 percent of total solid waste generation in Canada, and for the United Sates it is estimated to be around 30 percent. Furthermore, Table 8 also shows the potential similarity in C \& D waste composition as well. Therefore, the C \& D industry in Canada and the United States are comparable and similar in activity, except at a much smaller scale in Canada given the significant population difference. Thus it can be said that $C \& D$ waste generation is dependent on many factors, and population is among the most important. Such was also the case with Table 2 shown earlier in the literature review. 
In specific to determining and harmonizing $C \& D$ waste composition, it proved difficult in this study. Estimation of C \& D waste generation/composition was problematic and its nature is well understood with the following statement, "The composition of C \& D debris is highly variable and depends critically on the type of activity where sampling is done, as well as the many different type of buildings and construction practices in existence" (Begum et al, 2006). As a result, an average was determined using ranges from a few sources, which included CCA (1992), RCO (2006) and NRCan (2006), rather than rely on one study. However, the results obtained from using this method were comparable to the US EPA (1998) study, which perhaps solidifies some basis of the method used. As such, according to the results, concrete/rubble is the highest waste producer in general construction (including renovation and demolition) activity not exclusive to residential industry, at $44 \%$, wood waste places at a close second with $40 \%$, paper related waste is at $16 \%$, and gypsum waste placing forth with $12 \%$ waste factor. Metals, plastic and other building materials fall in after these four (Table 8 above).

In conclusion, the insight into C \& D waste composition in Canada is conceptualized by this attempt, and many case studies have verified wood and concrete waste is two of the major concerns in the industry when it comes to waste management, and wood is the main waste material when it comes to the residential industry in particular. Although concrete placed first on the waste composition factor when commercial projects were added, much of that is accumulated from demolition activities, whereas, new construction activities in the residential sector unanimously recognize wood as highest waste material.

Furthermore, the difference is C \& D waste generation between Canada and the United States was found to be significant, but it is attributed to a major difference in population and size of industries. Nonetheless, when compared with a unit rate Canada generates approximately 1.07 kg per capita/day, while the United States generates slightly higher at $1.24 \mathrm{~kg}$ per capita/day. 
Overall, wood seems to be main concern researchers put forward for waste generation in the residential industry, either in construction or demolition. Whether this is the right approach or not will further be explored with the end of service life evaluation of two low-rise residential houses done in later sections.

\subsection{Waste Minimization Methods and Guides}

The current status of $C \& D$ waste composition and generation in the Canadian context, along with some reference to US data has been discussed and conceptualized in the previous subsection. The significance of waste management is well justified by Poon's (1997) statement that C \& D waste represents the largest portion of total waste into landfills in the globe. Having recognized its magnitude and impact, as well as some perspective into C \& D waste status in other countries around the globe, it is appropriate to discuss some current methods used in the industry geared towards waste minimization.

Numerous strategies for minimizing $C$ \& $D$ waste have been published and presented in academic journals to date. These strategies found in literature will be put into two categorical streams of either design/pre-construction phase (D-phase) or construction phase (C-phase), to gauge the emphasis placed by current and past researchers on current $C \& D$ research in respects to project phase or timeline.

\subsubsection{Design/Pre-Construction Phase (D-Phase)}

Strategies found in literature for reducing C \& D waste during the design/pre-construction phase are many. One design concept that is gaining popularity in industry is design for deconstruction, which enables building material and components to be reused. Also, one unique article was 
found in a magazine tilted BioCycle (2007) with an article titled, "Designing Buildings on the Front End to Reduce Waste". This article stressed the selection of building material in the Dphase for recycling and reuse at the end of a building's service life, and advocates the concept of waste management from a whole-building perspective. Although it is not directly speaking about deconstruction design, it alludes to the concept of a closed-loop system where materials selected can be recycled and reused after the service life of a building. This concept certainly needs to be the key moving forward if better waste management practise are to be implemented.

Rounce (1998) suggested that waste sources are primarily at the design phase, involving design changes with the unpredictability in the number of drawings and details. In essence, waste consideration, labour, time or solid waste, at preliminary stages will facilitate informed decision making which will have a better impact on reducing waste generation. It is true the decisions that have the most impact financially are decisions made in the D-phase of a project, and it is reasonable to say such a condition is the same for waste minimization strategies.

Smart framing is also a design method, relatively simple but effective, used in the industry and advocated by many researchers including Lstiburek (2010). According to Building Science Corporation (2010), smart framing can be cheaper because lumber use is reduced by 5 to 10 percent, and it uses 30 percent less wood pieces. Modular design has also been proven to be an effective design strategy as Gu et al (1997) demonstrated.

Furthermore, one interesting study done by Sassi (2008) looks into and defines closed-loop material cycle (CLMC) for building materials which identifies materials that can be infinitely recycled, without major loss of mass or quantity (an example given is steel as opposed to concrete). The author formulates a concept termed closed-loop cycle (CLC) for materials, and 
suggests its benefit to waste minimization from a lifecycle perspective of materials used in construction. Though design for disassembly is an excellent approach, the author expresses its short-term benefit as opposed to the alternative long-term and more comprehensive benefit of CLMC approach.

\subsubsection{Construction Phase (C-Phase)}

Much of literature in $C \& D$ waste minimization focuses on the possible methods or strategies to control waste during the construction phase of a project. A survey conducted by Faniran and Caban (1998) formulated 5 waste sources namely, design changes, material scraps, packaging waste, design errors and poor weather. All these waste factors are encountered at the construction phase with the possibility of design changes occurring prior to construction, but most often during the construction phase. Nevertheless, design changes can be a direct result of decisions made in the C-phase.

Shen et al (2004) suggested a practical mapping model of material waste flows on construction sites for better waste management through project management function. Moreover, Shen and Tam (2002) suggest that C \& D waste management must stream into project management functions to better manage waste on construction projects.

Zhang (2005) developed waste-based management approaches for residential housing construction to reduce waste at all levels including labour and site management. Cha (2009) developed a waste management assessment tool based on influence factors that play a key role for reducing waste commonly encountered on construction projects. This approach is intended to help companies better assesses their performance in regards to waste management, thus enabling them to identify problems and improve upon them. 
These are some examples that demonstrate the focus of waste management research in literature that are integrated during the construction phase of a project. Subsequently, these strategies also bridge into the realm of project management, which is encouraged by Shen and Tam (2002). It is therefore evident C \& D waste minimization strategies in literature place focus in both the D-phase and C-phase of a project.

\subsubsection{Relevant Standards}

Two guides or standards will be briefly touched upon that integrate waste minimization practise. LEED (2009) and Toronto Green Standard (2010) are examples of a national and local standard. Some key C \& D waste related credits in LEED New Construction (NC) \& New Homes $(\mathrm{NH})$ will be summarized to give an indication of the type of $\mathrm{C} \& \mathrm{D}$ waste minimization strategies LEED currently employs. In addition, some of the requirements of Toronto Green Standard (TGS) will be compared. The credits will be divided into D-phase or C-phase strategy to help identify how these credits fare in comparison to the literature sited in the previous section.

Majority of the C \& D waste related credits for LEED NC are found in the Material Resources (MR) category. MR Credit 1.1 Building Reuse (maintain walls, floors, and roofs) and credit 1.2 Building Reuse (maintain interior non-structural elements) can be categorized into the D-phase strategy for $C \& D$ waste reduction. The application of these two credits must be done during the C-phase.

MR Credit 2, Construction Waste Management requirement is to recycle or salvage (reuse) C \&

D waste material from disposal into landfills. To achieve this task designated material such as "cardboard, metal, brick, mineral fibre panel, concrete, plastic, clean wood, glass, gypsum 
wallboard, carpet and insulation" (LEED, 2009), must either be recycled, reused or donated to charitable organizations (i.e. Habitat for Humanity), and the materials suggested as recyclable are designated as waste under the Ontario Regulation 347 (discussed in sub-section 1.1.2), where it states for new construction; "cardboard, brick, concrete, drywall (unpainted), steel and wood (untreated)" (e-Laws, 2012). This credit falls under C-phase strategy for C \& D waste minimization. Also, MR credit 3 is Material Reuse, which is similar to the other 3 credits already mentioned and falls under D-phase strategy.

One other relevant credit related to C \& D waste is in the Regional Priority category, Credit 1 , Durable Building. The requirement is to conform to CSA S478-95 (R2007); Guideline on Durability of Buildings. The key point is to ensure that a building meets design criteria for excepted service life, or exceeds those requirements. The aim is to avoid premature deterioration/failure of building components and harmonize differential service life (components that differ in service life expectancy) (Athena Institute, 2004). This credit touches upon C \& D waste minimization over a building's service life and done in the D-phase.

The major concern this credit presents is the requirement of "guarantee a durable building" in accordance to the CSA guideline, and the industry seems to be reluctant to take on this credit (Athena Institute, 2004). However, the comprehensive approach of this credit suggests it may be the most effective approach to $C$ \& $D$ waste minimization in all of LEED NC guideline.

LEED NH (2009) is specifically geared for low-rise residential homes. Much like LEED NC, emphasis is placed on energy targets, thus energy related credits represent approximately $28 \%$ of the total credits while C \& D waste related credits account for less than $10 \%$, which are mainly in the categories of Innovation \& Design Process (ID) and Material and Resources (MR). 
ID prerequisites credits 2.1 (Durability Planning) and 2.2 (Durability Management), and credit 2, Durability Management, require durability planning in the design process, and implementation of that plan in the construction process. The strategies fall under D-phase (credit 2.1) and C-phase (credit 2.2).

Credit 1, Material Efficient Framing, in MR category is intended to "optimize the use of framing materials" (LEED NH, 2009). Prerequisite 1.1, Framing Order Waste Factor, requires construction to meet a limit of $10 \%$ waste factor according to cost inventory. According to the credit, waste factor is; "defined as the percentage of framing material ordered in excess of the estimated material needed for construction" (LEED NH, 2009). Furthermore, Credits 1.2 (Detailed Framing Documents), 1.3 (Detailed Cut List and Lumber Order), 1.4 (Framing Efficiencies) and 1.5 (Off-site Fabrication) are all geared towards strategies to minimize framing waste in construction. Credits (1.4 and 1.5) would be a C-phase strategy, while the former two credits (1.2 and 1.3) are D-phase strategy.

Perhaps the most comprehensive credit relating to $C \& D$ waste minimization is in credit 3 of MR category. Credit 3.1, Construction Waste Management Planning, and credit 3.2, Construction Waste Reduction, are geared towards waste reduction and recycling. Prerequisite 3.1 requires documentation of waste diversion options, either through reduction, reuse, or recycling. This credit directly addresses C \& D waste minimization for new homes, and its strategy is divided between D-phase (anticipation of all waste to be encountered) and C-phase (quantifying diversion rate achieved).

Moreover, MR credit 3.2, Construction Waste Reduction, takes the initiative even further than credit 3.1. Two strategies are given as options to reduce waste, first of which is option A; "calculate the weight OR volume of waste generated and divide that by the building floor area of 
the project" (LEED NH, 2009), or divert more waste according to option B; "divert $25 \%$ or more of the total materials taken off the construction site from landfills and incinerators" (LEED NH, 2009). This credit would also fall into a C-phase strategy.

Given the framework of LEED and its application on a national scale, another more local standard, Toronto Green Building (TGS) was recently incorporated to facilitate performance measure in buildings (TGS, 2012). It is a two-tier system, where compliance to the first tier is required for new buildings in Toronto. Similar to LEED, TGS low-rise residential requirements also places much emphasis on energy performance. Compliance is expected in 5 categories including Air Quality, Greenhouse Gas Emission, Water Efficiency, Ecology and Solid Waste (TGS, 2010).

The strategy to reduce solid waste includes construction waste management, reuse and recycling of buildings materials. All three strategies must be planned in the D-phase, but applied mostly in the C-phase of a project. What is most noteworthy is the required $75 \%$ recycling of non-hazardous C \& D waste. Although $75 \%$ is a very high number, the application is during construction and demolition. It was established from literature that much attention is given to $C$ \& D waste during the construction of projects. However, the demolition waste should be the key to minimizing waste, as most of the waste from building a house will come from demolition waste generation at the end of a building's service life, which will be demonstrated in forthcoming sections. Therefore, demolition waste should be the focus in residential housing, more so than the construction phase waste. 


\subsubsection{Methods and Guides Summary}

The three documents, LEED NC, NH and TGS, have much similarity in its guidelines. What is fairly clear and evident is the concentration on C \& D waste minimization credits in relation to energy related credits, which seems to be the emphasis at present time, which was also mentioned in the introduction section. Energy related requirements makes up a major portion of overall credit breakdown for LEED NC, and $\mathrm{NH}$ where it was calculated to be $28 \%$ for energy, and well below $10 \%$ for C \& $\mathrm{D}$ waste reduction.

It can be said both LEED NC and NH cover C \& D waste minimization strategies with quite a balanced approach within the scope of D-phase and C-phase strategies. The results of the literature sited in previous sections 3.4.1 and 3.4.2 also determined a balance of C-phase and D-phase strategies, while some of the researchers such as Shen and Tam (2002) promote Cphase approach that streams into construction management.

The process by which construction waste generation is most affected by is not agreed upon by researchers, either it be due to design issues, on-site management, or quality of work hindered by external conditions. However, it is evident within literature that most acknowledge design related issues as being the most influential (Lu and Yuan (2011), Faniran and Caban (1998), and others). Literature review, along with the relevant standards and guides, also proved that $\mathrm{C}$ \& D waste research specifically in residential application is concentrated on reducing construction waste generation, with less emphasis on demolition waste generation.

According to many researchers (Lu and Yuan (2011), Faniran and Caban (1998), Rounce (1998), the best strategy to minimize C \& D waste is in the D-phase. The findings of LEED framework points to a well balanced approach between D-phase and C-phase strategies in C \& D waste, but what is more important and which can have the most impact is demolition waste. 
Accordingly, the next section of this research paper will evaluate $C \& D$ waste accumulation, specially the end of service life waste generation, for two low-rise houses to demonstrate the importance of concentrating $C$ \& $D$ waste minimization efforts to the demolition phase of a project, rather than the construction phase. This evaluation will also identify most wasteful materials and can guide designers on material specific strategies during the D-phase of a project for waste minimization that will have the most impact. 


\subsection{Waste Study of Two Residential Houses}

Literature proved that $C \& D$ waste issues are a major concern in waste generation around the globe. Such was also the case in Canada and the US. Furthermore, studies done by CCA (1992), RCO (2006) and NRCan (2006) showed that wood was the most wasteful material in construction, and particularly in the residential industry. Literature and case studies identified key waste materials in C \& D waste composition to be wood, concrete, gypsum, and masonry. Most of these studies identified waste that was attributed to construction and demolition combined, but it seems more prudent to strategize waste reduction from an end of service life waste perspective due to the greater amount that can be generated. Moreover, researchers point and give much attention to waste that is generated during construction, while giving minimal attention to waste that is generated at the end of a building's service life. Conceptually, it seems there is more potential for waste generation at end of a building's service life, rather than during construction. Given that it may be the case, this research section, methodology steps (iv) and (v), will evaluate potential waste contribution of low-rise residential houses in Ontario built to current practices and demolished in 75 years. The evaluation of the two houses follows.

\subsection{House-A Evaluation}

The house is a two-storey home with an unfinished heated basement. The basement floor includes a washroom. The ground floor includes a kitchen with a dining area, and a living/family room. The second floor includes three bedrooms and two bathrooms (one attached to the master bedroom). The bathroom holds a single sink, toilet and a bathtub. The overall summary of the building is listed below.

Dwelling Type: two-storey Detached Residential 
Total Storey's: 2 Floors with Unfinished Heated Basement

Building Coverage (with porch): $123 \mathrm{~m}^{2}\left(1321 \mathrm{ft}^{2}\right)$

Total Gross Floor Area: $189 \mathrm{~m}^{2}\left(2029 \mathrm{ft}^{2}\right)$

Total Rooms: Kitchen/Dinning, Living, 3 bedrooms, 3 washrooms

Maximum Occupants: 6 Occupants

A total of 6 occupants will be assumed, meaning 2 occupants per bedroom for 3 bedrooms in the house, for data normalization purposes between the two houses in later part of this study. Figures 6 below depicts front elevation of House-A with its two door garage. The applicable elevations are included in Appendix A. This house is single-detached family home common in southern Ontario.

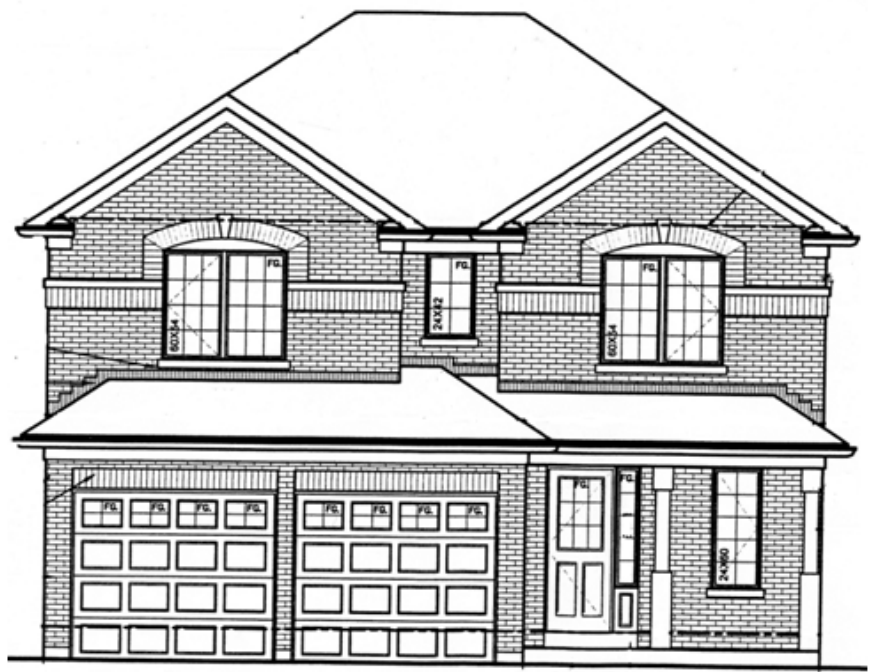

Figure 6: House-A Two-storey Brick Veneer

The total building height is approximately $10.6 \mathrm{~m}$ (35 feet) from footing to top of the roof. Majority of the windows are located on the front and back elevations of the house. The house layout is rectangular in shape (Figure 7 below); while its width is roughly $9.6 \mathrm{~m}$ (32 feet) and length is $13.4 \mathrm{~m}$ (44 feet). 


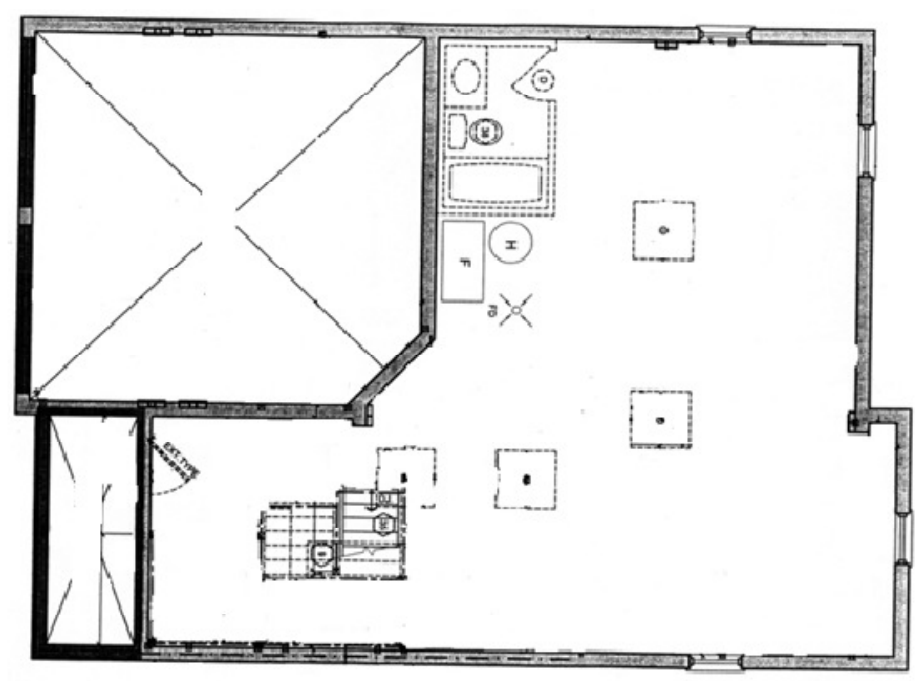

Figure 7: House-A Building Configuration Layout

The relevant details of the basement, first floor and second floor plans are included in Appendix A. The building envelope is also made up of typical brick veneer wall construction, concrete foundation with asphalt roofing. The plan view of the roof is depicted below.

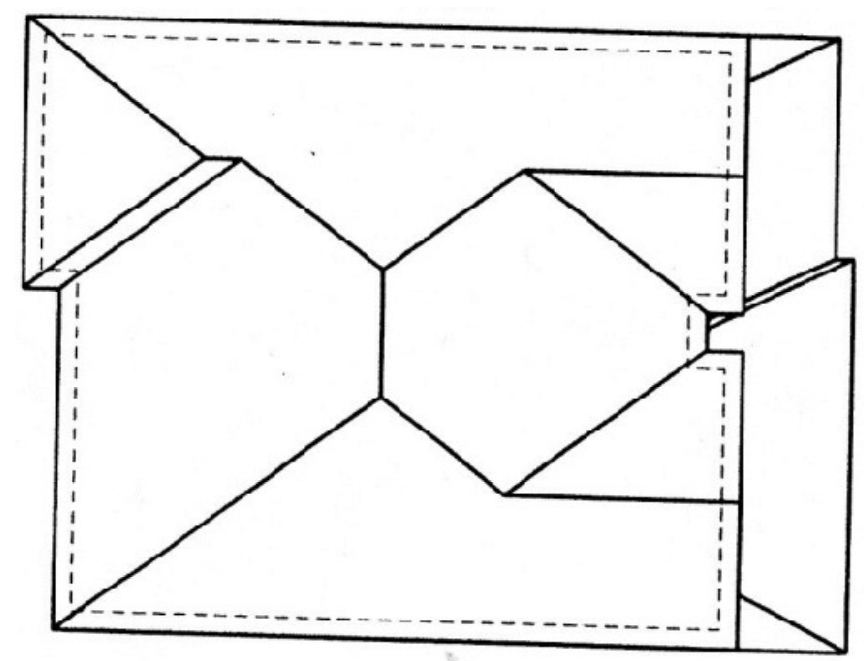

Figure 8: House-A Roof Plan 
The envelope assembly (from exterior to interior) common on the four facades of the house is as follows:

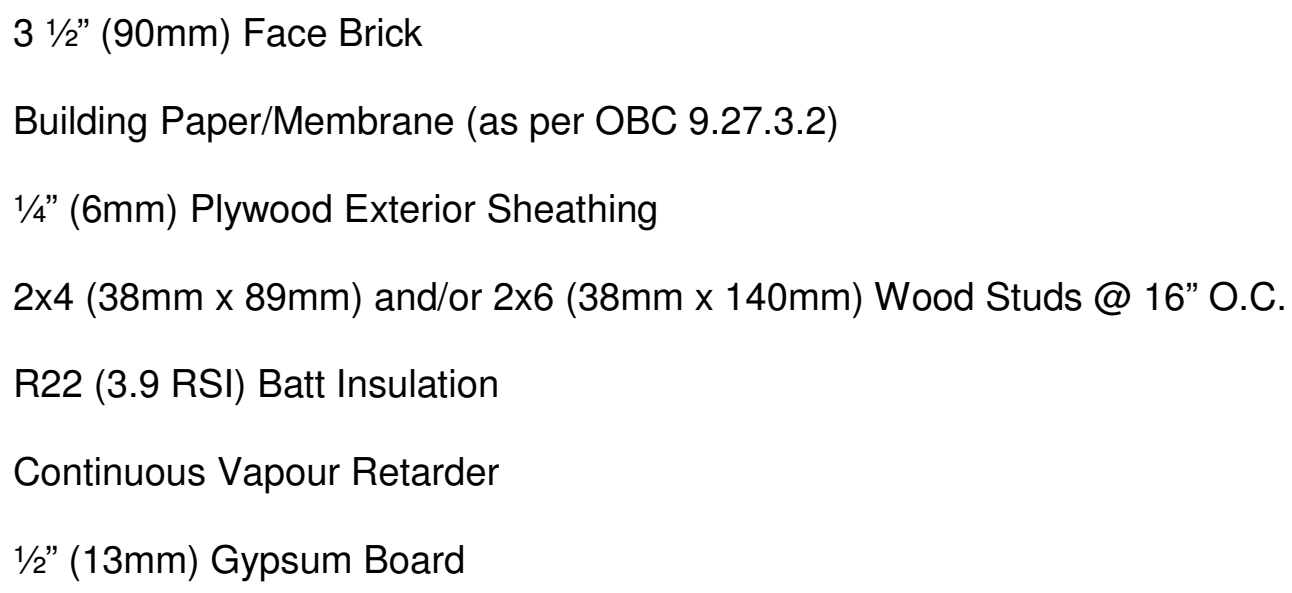

Also, in certain details 4" $(100 \mathrm{~mm})$ concrete stones are used, and will also be included in the material. The materials will be quantified in weight $(\mathrm{kg})$ ratio according to the 6 material elements as listed in section 2.1.2. Also, 4 feet by 8 feet $\left(2.98 \mathrm{~m}^{2}\right)$ floor sheathing will also be accounted for.

The waste factor for each material during construction will not be accounted for, as this is an evaluation of the potential waste at the end of its service life. For example, $10 \%$ wood waste factor is commonly used in the industry, and LEED NH (2009) uses it as a benchmark for wood waste reduction, however, it will not be applied in this study since the focus is just potential end of service life waste generation. Similar waste factors also relate to brick, gypsum, asphalt roofing and other common building materials.

\subsubsection{House-A Data Summary}

As mentioned in the methodology section (2.1), this is step one of the end of service life waste generation. Given the key elements mentioned in section 2.1.2, House-A detailed evaluation list 
of potential waste generation by weight is in Appendix A, and the summary of the detailed list is shown in Table 9 below. The potential end of service life waste material of the house is ranked from highest weighted total to lowest weighted total.

Table 9: House-A Material Elements Quantity Summary Chart

\begin{tabular}{|l|c|c|}
\hline \multicolumn{3}{|c|}{ HOUSE-A SUMMARY CHART } \\
\hline Elements & Quantity (kg) & Rank \\
\hline Concrete Elements Quantity & 106,484 & $\mathbf{1}$ \\
\hline Cladding (Masonry) Quantity & 45,381 & $\mathbf{2}$ \\
\hline Wood (Ground) Floor Framing Quantity & 3946 & $\mathbf{6}$ \\
\hline Wood (Second) Floor Framing Quantity & 3273 & $\mathbf{7}$ \\
\hline Wood (Basement) Wall Quantity & 484 & $\mathbf{9}$ \\
\hline Wood (Ground Floor) Wall Quantity & 5636 & $\mathbf{5}$ \\
\hline Wood (Second Floor) Wall Quantity & 6959 & $\mathbf{3}$ \\
\hline Gypsum (Interior Board) & 5959 & $\mathbf{4}$ \\
\hline Asphalt (Roofing) & 2959 & $\mathbf{8}$ \\
\hline \multicolumn{2}{|c|}{} & \\
\hline Total & $\mathbf{1 8 0 , 6 6 9}$ & $\mathbf{( 9 )}$ \\
\hline
\end{tabular}

House-A material quantity indicates concrete has the most mass of material in the house, and masonry cladding is a distant second. It is evident from this that wood does not represent the most amount of material quantity by weight in this house. These numbers represent potential waste at the end of the house's service life. This is contrary to what researchers in literature and case studies by CCA (1992), RCO (2006) and NRCan (2006) have said when it comes to C \& D waste accumulation in residential housing. This discrepancy will be further explored later on.

A factor of 3.4 (to estimate the total interior gypsum board required per $\mathrm{ft}^{2}$ of flooring area) was used for the gypsum calculation which was retrieved from a local Toronto drywall tapping company (Drywall Installation and Taping Service Toronto, 2011). Also, the estimation for asphalt roofing is also calculated in a similar factored method using a slope rake factor as shown in Table 10 below (Sentrigard, 2012). 
Table 10: Asphalt Roof Sheathing

\begin{tabular}{|l|c|c|c|}
\hline \multicolumn{4}{|c|}{ ROOF AREA (ft ${ }^{2}$ ) } \\
\hline Slope & Area & Rake Factor & Total Area \\
\hline $8: 12$ & 471 & 1.202 & 566 \\
\hline $6: 12$ & 340 & 1.118 & 380 \\
\hline $4: 12$ & 102 & 1.054 & 108 \\
\hline & & & $\mathbf{1 , 0 4 8}$ \\
\hline
\end{tabular}

The detail of gypsum and asphalt is also included in Appendix A. The overall information determined in this evaluation, as shown in Table 9, is generated into chart form in the following sub-section.

\subsubsection{House-A Summary Graphs}

A visual representation of Table 9 (from above) is the potential waste generation at the end of service life material quantity of House-A, and is shown in bar chart form in Figure 9 below. It is clear that the concrete material of the home, which comprises mostly of concrete footings, walls and slabs, carries most quantity in weight ratio over all other building material. The detail of the summary is given in Appendix A.

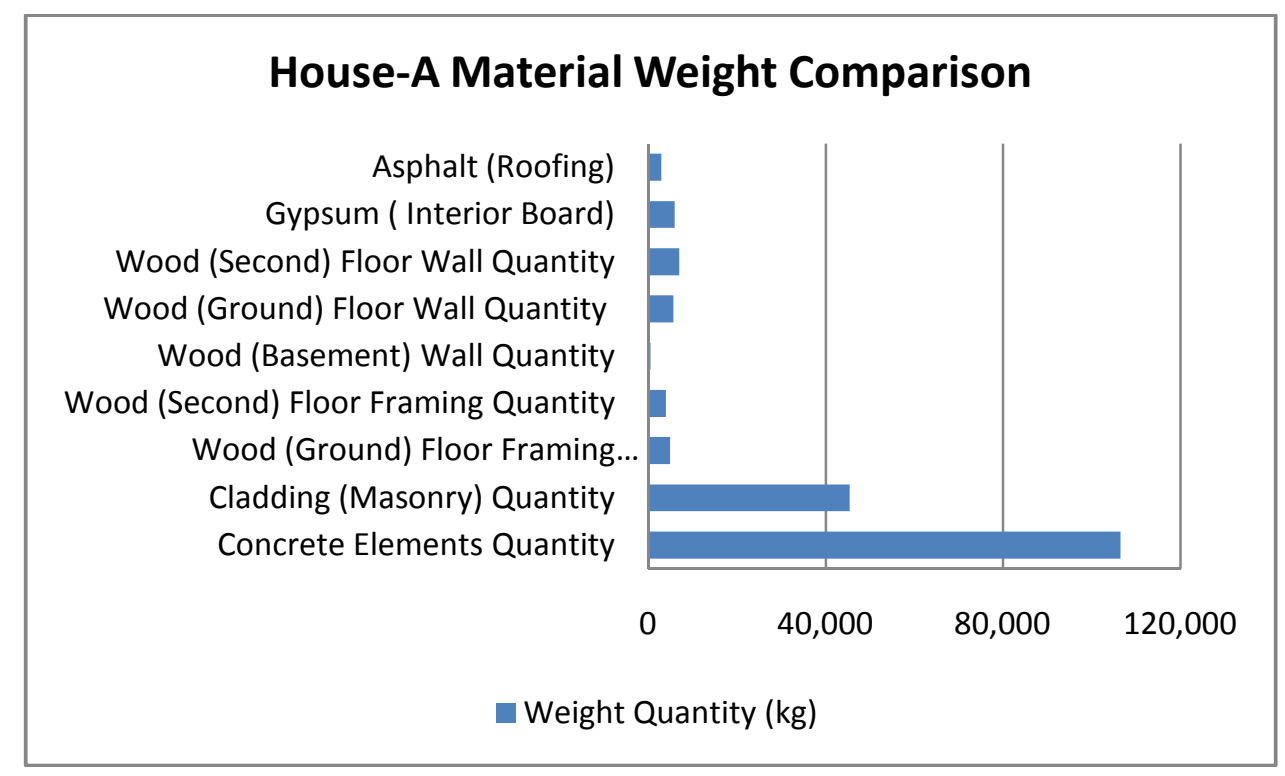

Figure 9: House-A Weight Summary by Element 
This composition of potential end of service life waste materials by weight (Figure 9) for HouseA is shown in graph form in Figure 10 below.

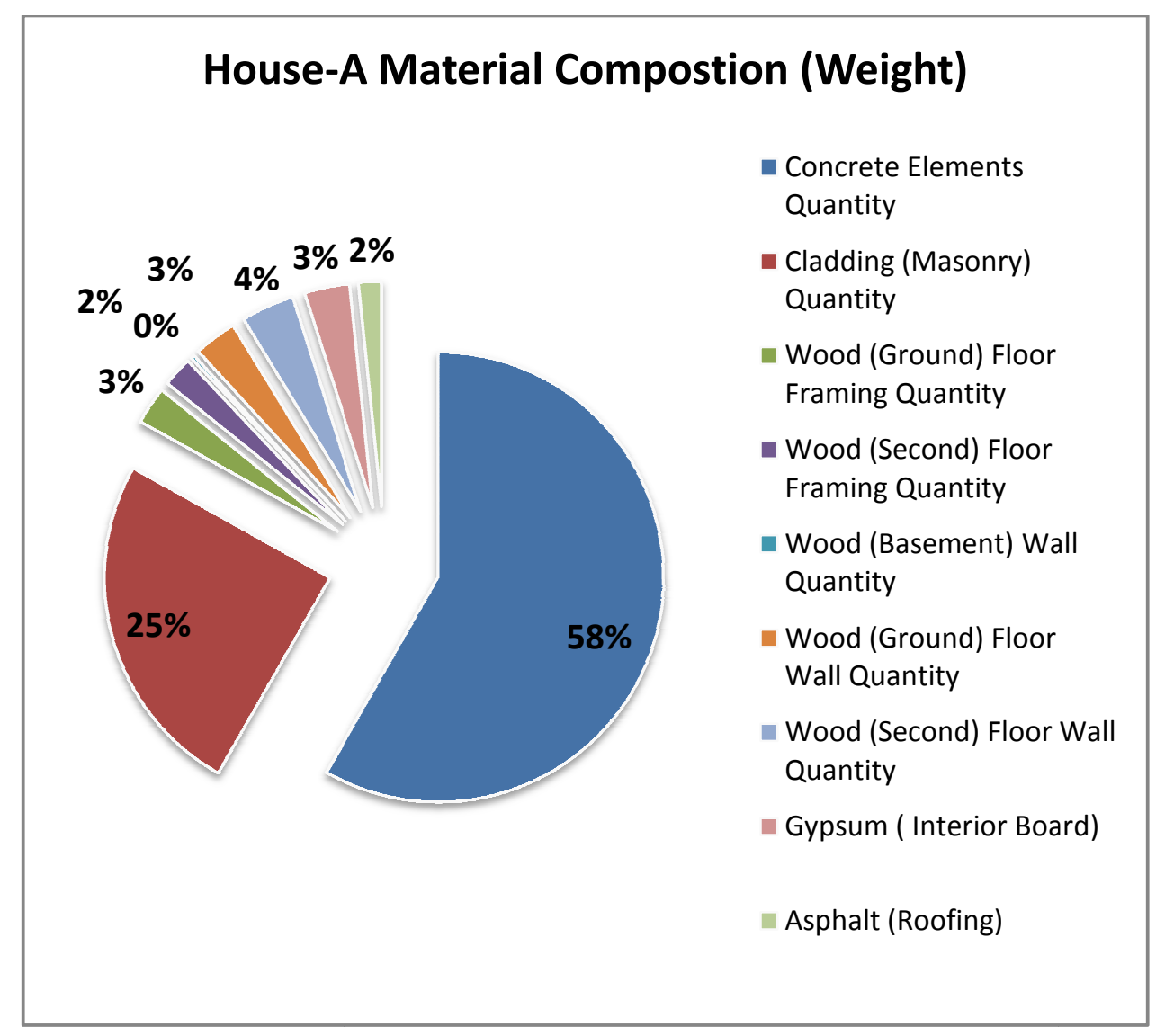

Figure 10: House-A Material Composition Percentage

As mentioned, concrete material used in the foundation of the house ranks as the highest in weight ratio at $58 \%$, and in a distant second, above grade masonry material weight ratio is $25 \%$. The rest of the categories of materials falls very close together (Figure 10), however, note that gypsum board for the interior of the building ranks fourth making up almost $3.3 \%$ of total weight quantity. 
What is interesting and worth a deeper look into the data is the composition of wood products. Recall in the literature review section (3.1.1) were wood was considered the most wasteful material in residential construction in both new construction (30\%) and demolition (51\%) according to the study done by CCA (1992) in Toronto. Similarly NRC (2006) reported wood waste as the highest wasteful material in residential construction at $26 \%$. Although the apparent data looks contradicting, a deeper look reveals no such thing.

This evaluation of House-A is the potential end of service life waste material present in the existing (completed) house, and not the waste that is generated during construction, but it is precisely what would be generated during the end of service life demolition stage of the house. Therefore, construction waste and demolition waste are completely different sets of data, and need to be considered proportionately, contrary to what some studies in literature and case studies have done including NRCan (2006). Nevertheless, to gauge a truer picture of wood material quantity for House-A, the walls and flooring portions are combined into one material stream, as they in fact the same material. This representation of combined wood portion by weight for House-A is shown in Figure 11 below, to reveal a more categorical data stream of materials.

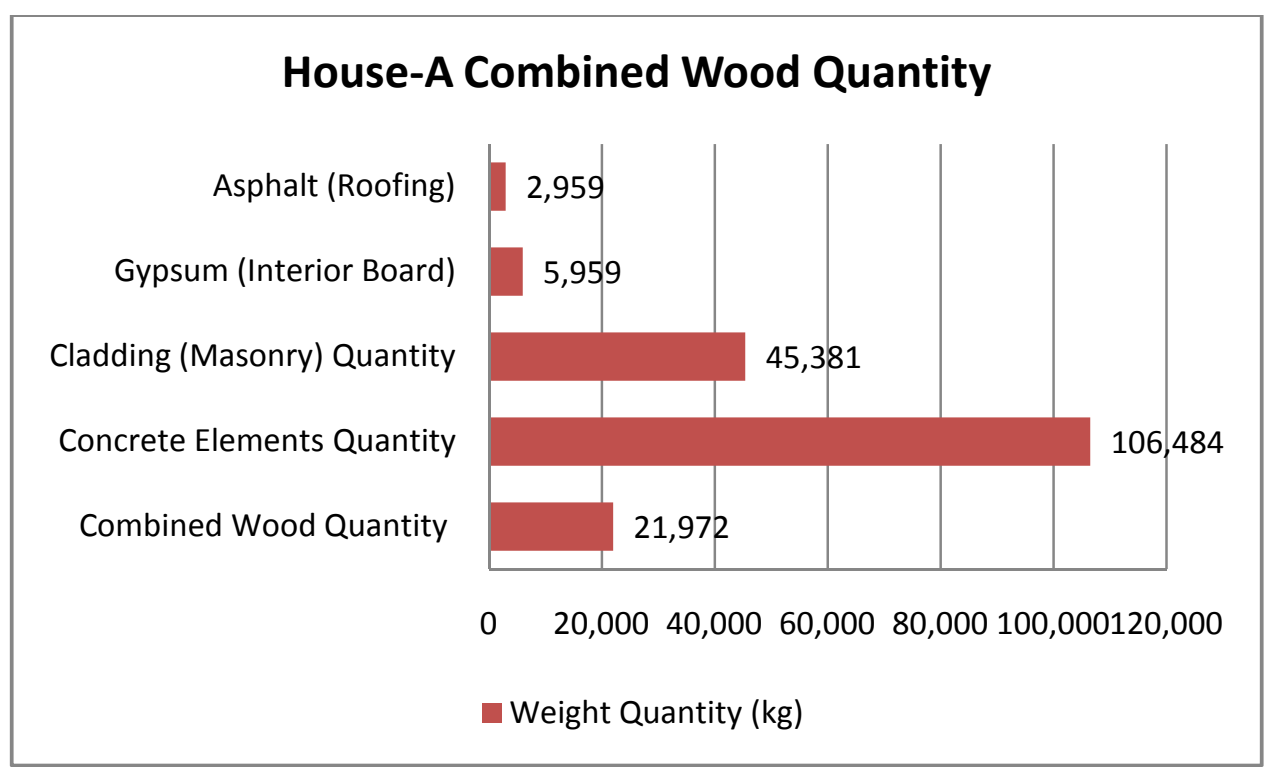


The combined wood portions added together include the following elements (refer to Table 9, Figure 10): (1) Ground Floor Framing, (2) Second Floor Framing, (3) Basement Wall Framing, (4) Ground Floor Wall Framing and (5) Second Floor Wall Framing. All 5 of these elements are combined into one categorical stream and represented as "combined wood". The chart below shows the adjustments when wood material by weight is combined rather than separate as shown in Figure 11 above.

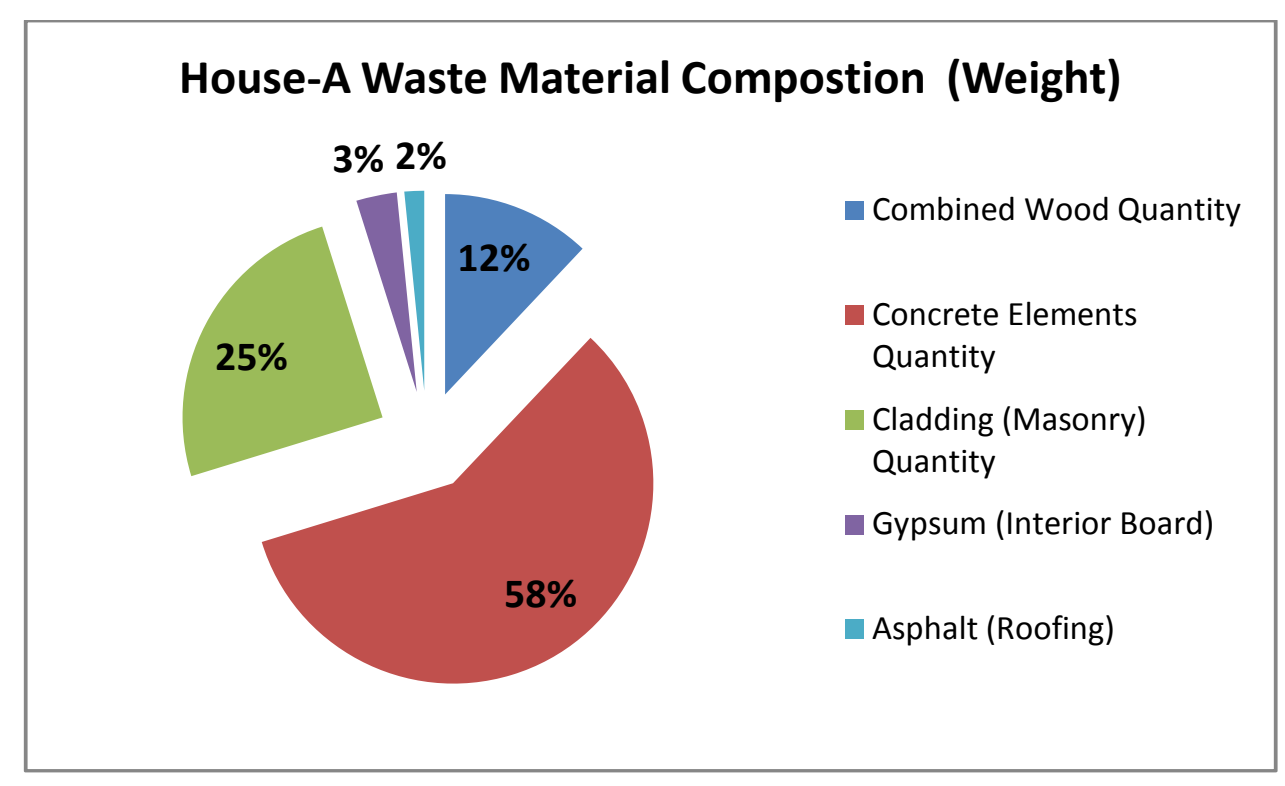

Figure 12: House-A Waste Material Composition

Based on this adjustment, the ranking of potential wood waste comes into $3^{\text {rd }}$ place after concrete $\left(1^{\text {st }}\right)$ and brick masonry $\left(2^{\text {nd }}\right)$. As result of this method, we see wood represented as $12 \%$ of the total weighted material in House-A, surpassing gypsum board and asphalt roofing significantly where in Figure 10 wood was separated.

Furthermore, given the significantly lower proportion of total weight of wood does not negate the possible large volumetric portion of wood for House-A. The density of typical softwood is 510 
$\mathrm{kg} / \mathrm{m}^{3}$, which essentially makes up all the wood products used for constructing the house (Hutcheon and Handegord, 1996). By comparison, lightweight concrete and dense concrete fall between 1920 and $2250 \mathrm{~kg} / \mathrm{m}^{3}$, while masonry is also around $2000 \mathrm{~kg} / \mathrm{m}^{3}$, and gypsum board being $800 \mathrm{~kg} / \mathrm{m}^{3}$ (Hutcheon and Handegord, 1996). Clearly concrete and brick masonry materials are much heavier in weight per unit area. On the contrary, if the measurements of the quantities were determined by volume, wood may represent a higher percentage than the estimated $12 \%$ determined for House-A. This may have been the case with some of the case studies in the literature review section where wood was deemed the most wasteful material in residential C \& D waste.

If a volumetric measurement is applied to the concrete, cladding and wood materials for HouseA with the given densities mentioned above, a different set of data appears. Concrete waste would remain above all at $47.3 \mathrm{~m}^{3}$, however, wood waste will amount to $43 \mathrm{~m}^{3}$, while masonry cladding would account for $22.7 \mathrm{~m}^{3}$. Clearly wood rises significantly when the unit of measurement varies between weight and volume. This reveals a key point of measurement difference, and an insight into the potential method of wood estimates used in the case studies from CCA (1992), RCO (2006) and NRCan (2006) which differ significantly with the results and method of House-A potential end of service life waste generation.

The data generated in this section (5.3) represents step 1 of the 2-step process of the potential end of service life waste generation mentioned in the methodology (section 2.1). This data for House-A represents potential end of service life waste generation, however, the added waste accumulated over the 75-year service life period (which is step 2) will also be evaluated for both houses following House-B evaluation in the next section. 


\subsection{House-B Evaluation}

This house is a bungalow and consists of a ground floor and an unfinished heated basement. The basement floor includes a washroom. The ground floor includes a kitchen, dining room, living room, family room, office room, 3 bedrooms and 2 washrooms (one attached to the master bedroom).

Similar to House-A, a total of 6 occupants is assumed to occupy this house (see section 5.1), and the overall summary of the house is listed below.

Dwelling Type: Detached Residential Bungalow

Total Storey's: 1 Floor with Unfinished Heated Basement

Building Coverage (with porch): $353 \mathrm{~m}^{2}\left(3801 \mathrm{ft}^{2}\right)$

Total Gross Floor Area: $296 \mathrm{~m}^{2}\left(3189 \mathrm{ft}^{2}\right)$

Total Rooms: Kitchen, Dinning, Living, Family, Office, 3 bedrooms, 2 washrooms Maximum Occupants: 6 Occupants

This house was chosen due to its apparent difference in configuration and housing type, which is a bungalow in comparison to the previous two-storey House-A. Figures 13 and 14 below depict the front elevation and configuration of House-B with a 3-car garage. The four elevations, plans and other relevant information are included in Appendix B. 


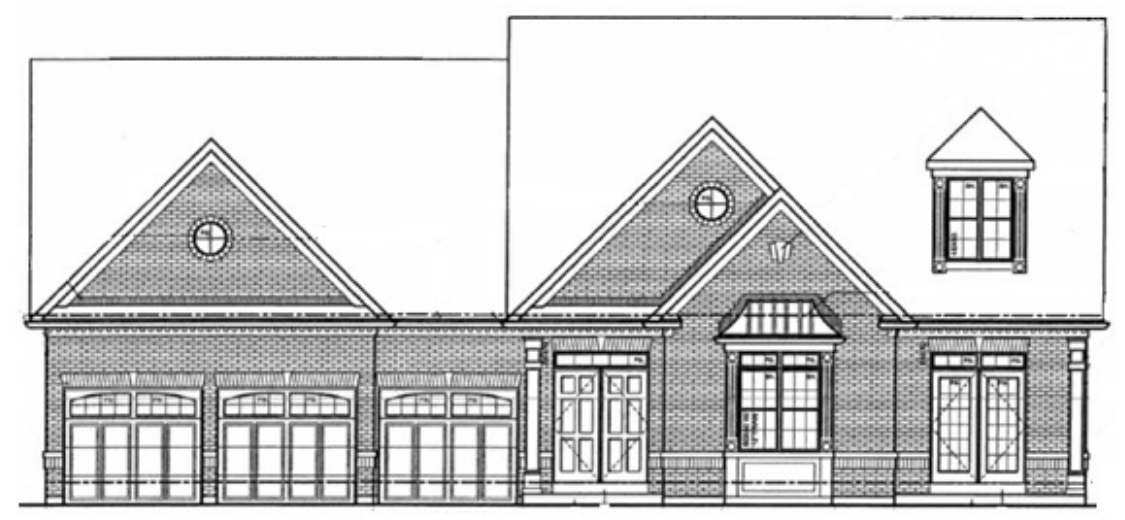

Figure 13: House-B Front Elevation

The total building height is roughly $10.8 \mathrm{~m}$ (35.5 feet) from footing to top of the roof. Majority of the windows are located on the rear elevation of the house.

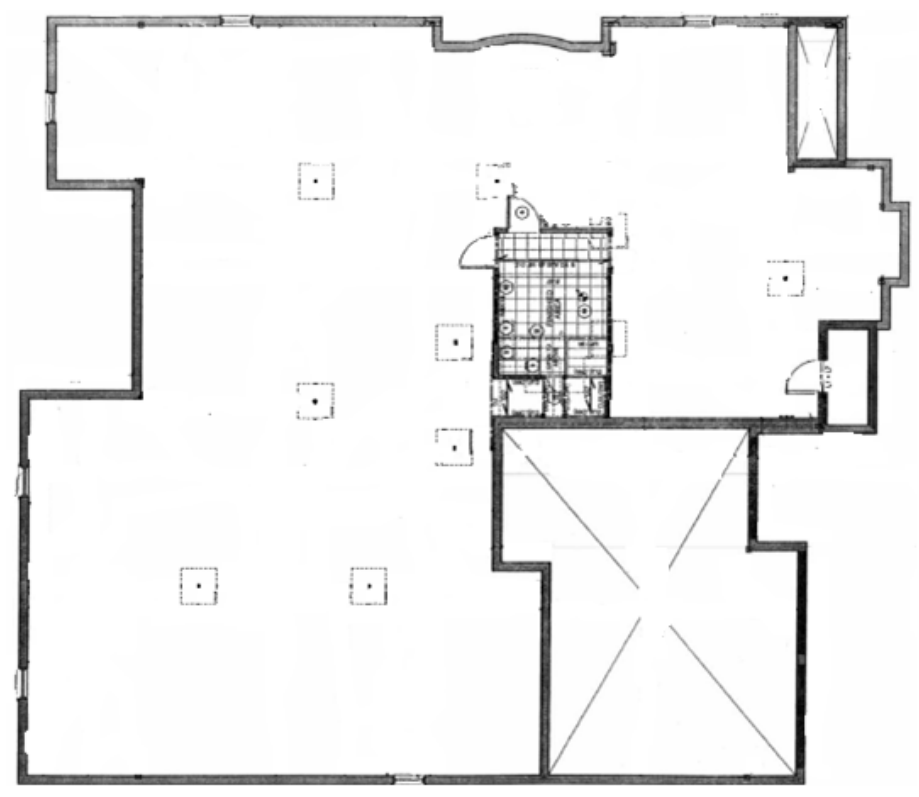

Figure 14: House-B Basement Floor Layout

The house layout is more cubical than rectangular in shape (as in Figure 14 above), contrary to House-A where it is much more rectangular than cubical. The length is roughly $19.2 \mathrm{~m}$ (63 feet) and the width $18.6 \mathrm{~m}$ (61 feet). 
The building envelope is also made up of brick veneer wall construction, concrete foundation with asphalt roofing, much like House-A. The building envelope assembly (from exterior to interior) common on the four facades of the house are as follows:

\section{$31 \frac{1}{2 \prime}(90 \mathrm{~mm})$ Face Brick}

Building Paper/Membrane (as per OBC 9.27.3.2)

1/4" (6mm) Plywood Exterior Sheathing (as per OBC 9.23.16)

2x6 (38mm x 140mm) Wood Studs @ 16” (400mm) O.C.

Min. R17 (3.0 RSI) Batt Insulation

Continuous Vapour Retarder

$1 / 2 "$ (13mm) Gypsum Board

In comparison to House-A, the wall assembly is very similar in construction with the exception of occasional details of $4 "(100 \mathrm{~mm})$ concrete stones. Also, 4 feet by 8 feet $\left(2.98 \mathrm{~m}^{2}\right)$ floor sheathing will also be accounted for. The plan view of the roof is depicted below, with the top-right being the entrance porch into the house.

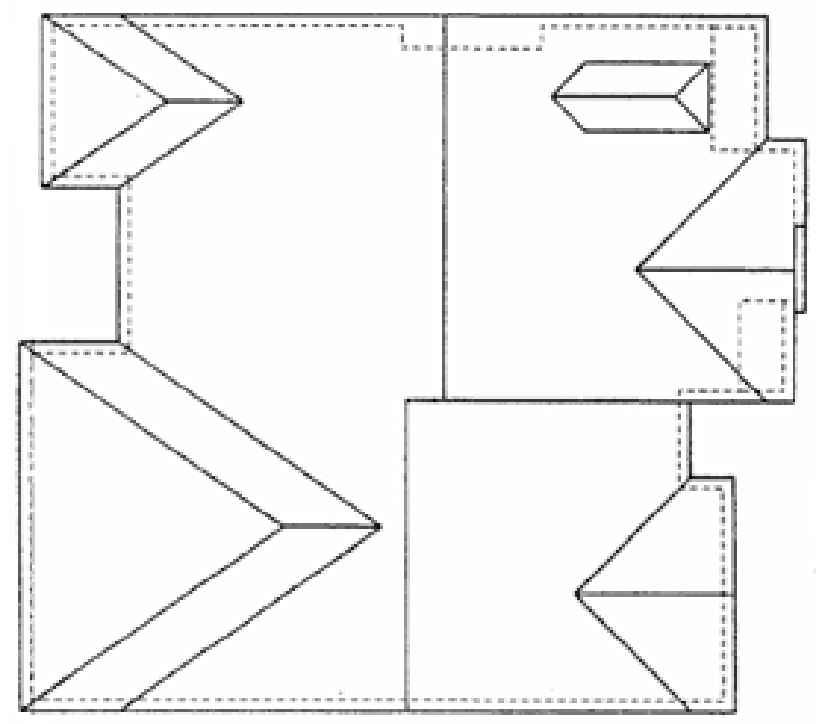

Figure 15: House-B Roof Plan 
Given the key materials mentioned in section 2.1.2, the nature and information given for this house will follow the sequence used for House-A, as done in sub-section 5.1.1. This quantification will represent potential end of service life (demolition) waste generation.

\subsubsection{House-B Data Summary}

As mentioned in the methodology section (2.1), this quantification is step 1 of the potential end of service life waste generation. House-B evaluation detailed list of material quantity and weight is included in Appendix B, and the summary of the detailed list is given below in Table 11. The total material quantity of the house is divided by material, including the ranking of material quantity from the highest weighted total to lowest weighted total.

Table 11: House-B Material Elements Quantity Summary Chart

\begin{tabular}{|c|c|c|}
\hline \multicolumn{3}{|c|}{ HOUSE-B SUMMARY CHART } \\
\hline Elements & Quantity (kg) & Rank \\
\hline Concrete Elements Quantity & 206,640 & 1 \\
\hline Cladding (Masonry) Quantity & 64,945 & 2 \\
\hline Wood (Floor) Framing Quantity & 10,478 & 4 \\
\hline Wood (Wall) Framing Quantity & 15,177 & 3 \\
\hline Gypsum (Interior Board) & 9349 & 5 \\
\hline Asphalt (Roofing) & 7503 & 6 \\
\hline Total & 314,092 & (6) \\
\hline
\end{tabular}

House-B material quantity indicates concrete has the most weight of material in the house, which comprises mostly of concrete footings, walls and slabs. Masonry is in a distant second. It is also evident that wood does not represent the most amount of material quantity by weight for this house. What is apparent is that House-B resembles House-A in exactly the same way in its material elements raking. House-A ranking was (1) concrete, (2) masonry, (3) second floor wall quantity (this house is a bungalow so it is first floor framing), (4) gypsum board and (5) asphalt. 
Despite the difference in configuration, spacing, size, design and type of low-rise residential house, the result show comparable data. In addition, the results of this house also strengthens the contrary data found initially with House-A, as opposed to literature and specific case studies by CCA (1992), RCO (2006) and NRCan (2006) that indicate wood as the highest waste material in residential construction. These numbers in Table 11 represent potential waste generation at the end of the house's service life. This discrepancy will be further explored in later sections of this paper. Also discussed below are the quantities of gypsum sheathing and asphalt roofing, and the quantification of these two materials as given in Table 11 above.

A factor of 3.4 (to estimate the total interior gypsum board required per $\mathrm{ft}^{2}$ of flooring area) was used for the gypsum calculation which was retrieved from a local Toronto drywall tapping company (Drywall Installation and Taping Service Toronto, 2011). Also, the estimation for asphalt roofing is also calculated in a similar factored method using a slope rake factor as shown in Table 12 below (Sentrigard, 2012).

The estimation for the asphalt sheathing used for the roof of House-B is calculated in an identical manner to House-A. The specifications of House-B lists weight ratio for the asphalt shingles as $30.5 \mathrm{~kg} / \mathrm{m}^{2}$. Given the different slopes of the roof for House-B, the total area per slope was calculated and the total roofing area was determined using a slope rake factor as shown in the Table 12 below (Sentrigard, 2012).

Table 12: House-B Asphalt Roof Sheathing

\begin{tabular}{|c|c|c|c|}
\hline \multicolumn{4}{|c|}{ ROOF AREA (ft ${ }^{2}$ ) } \\
\hline Slope & Area & Rake Factor & Total Area \\
\hline $7: 12$ & 1,660 & 1.157 & 1,920 \\
\hline $10: 12$ & 171 & 1.302 & 222 \\
\hline $12: 12$ & 362 & 1.414 & 512 \\
\hline & & & \\
\hline
\end{tabular}




\begin{tabular}{|l|l|l|l|}
\hline & Total & 2,654 \\
\hline
\end{tabular}

The detail of gypsum and asphalt for House-B is included in Appendix B. All the information calculated in this section is generated into chart form and presented in the following sub-section.

\subsubsection{House-B Summary Graphs}

A visual representation of Table 11 (from above) representing the existing waste material quantity of House-B is shown in the bar chart in Figure 16 below.

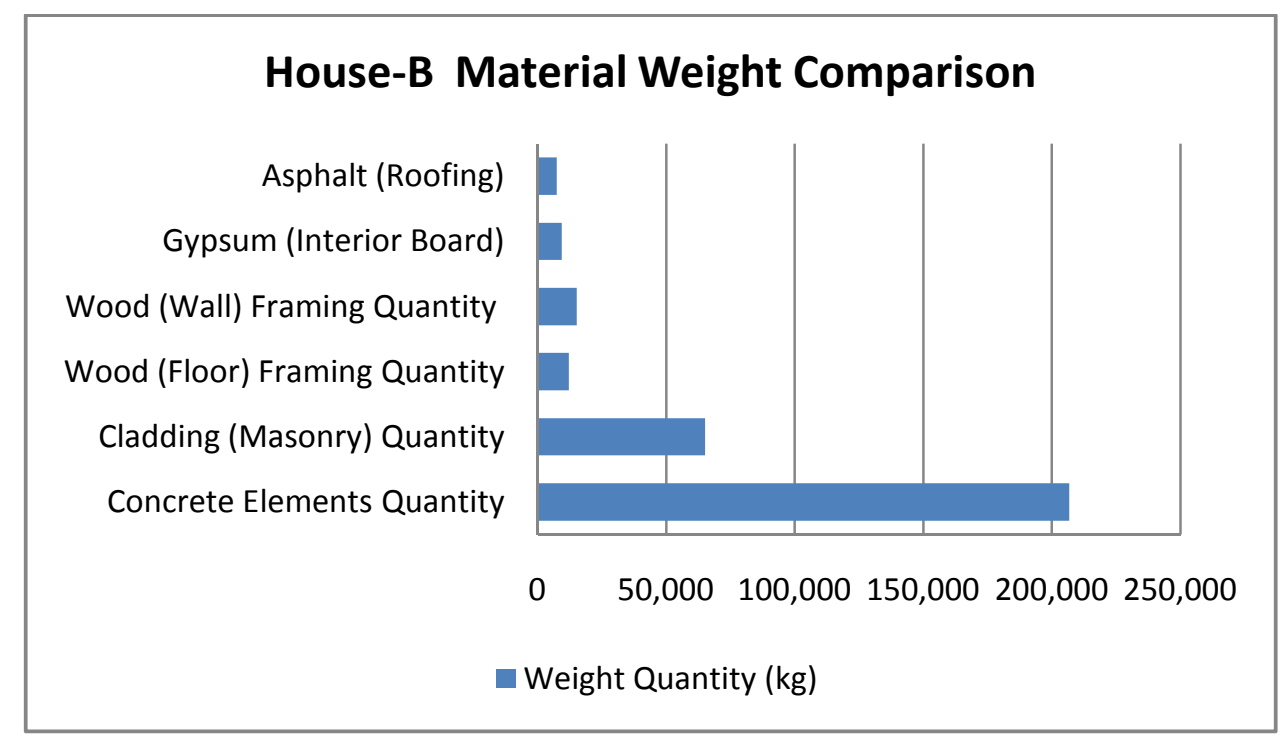

Figure 16: House-B Weight Summary

Given the information depicted in the bar chart in Figure 17, the composition of potential waste materials by weight over the total amount of material in House-B is generated in pie chart form in Figure 17 below. 


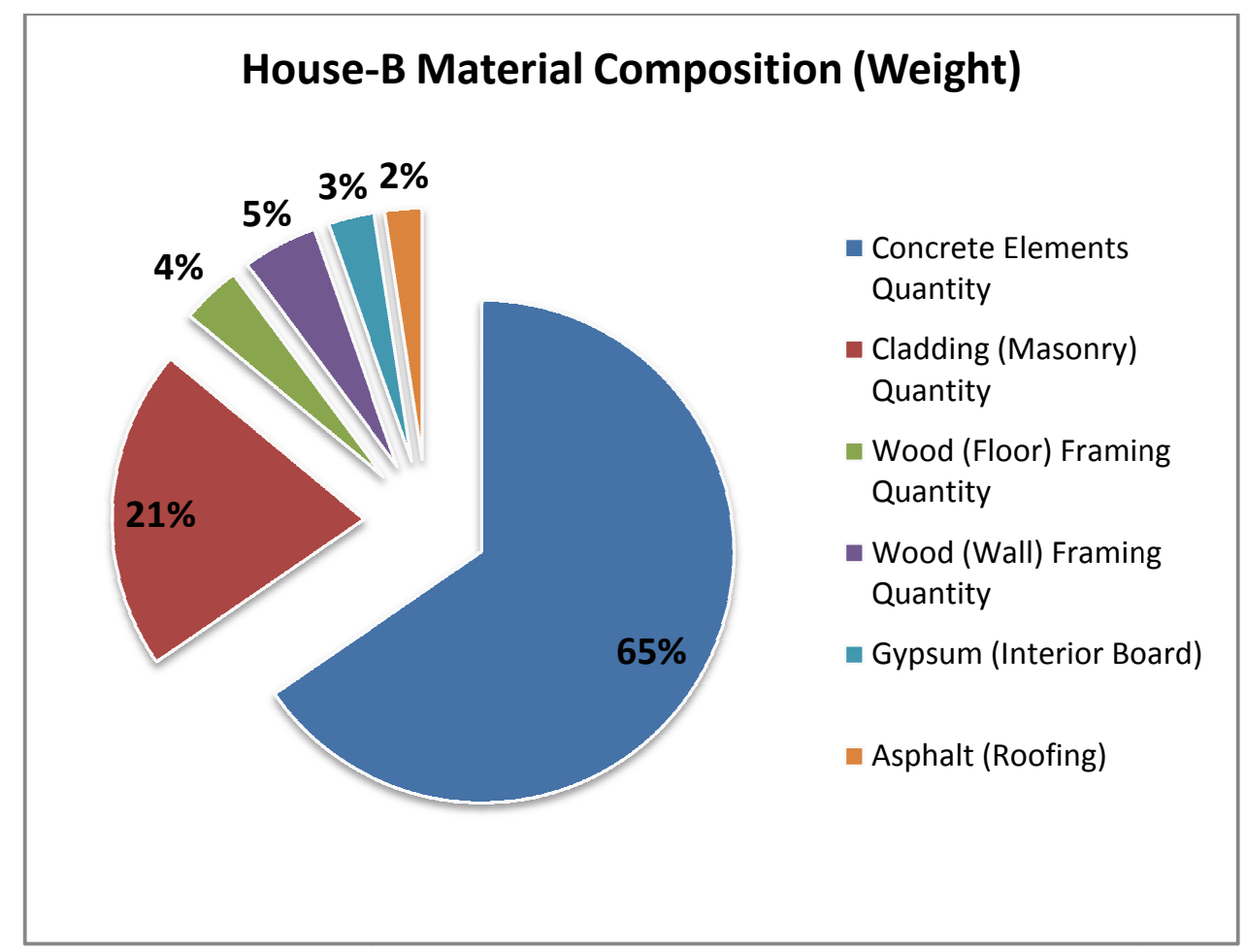

Figure 17: House-B Material Composition Percentages

Concrete used in the foundation of the house ranks as the highest in weight ratio at $65 \%$, and in a distant second, brick masonry material weight ratio is $21 \%$. The rest of the categories of materials fall relatively close together.

To gauge a truer picture of potential wood waste material quantity for House- $\mathrm{B}$, the walls and flooring portions are combined into one as they are the same material, although they represent different elements in the house. Accordingly, another figure was generated to show this method to reveal a more categorical data set (Figure 18). 


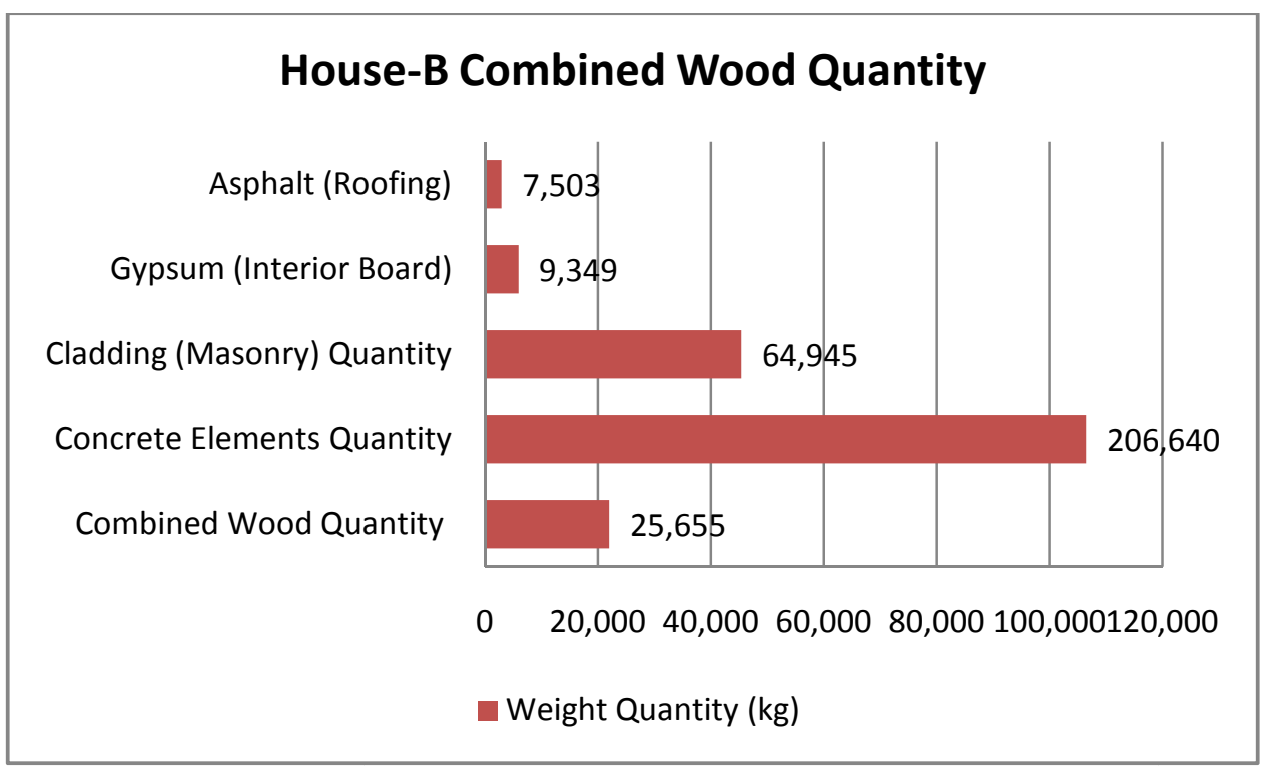

Figure 18: House-B Combined Wood Quantity

The combined wood portions added together include the elements (refer to Table 11 for original summary table): (1) Floor Framing and (2) Wall Framing, and is represented as "combined wood". The chart below shows the adjustments when wood material by weight is combined rather than separate as shown in Figure 17 above.

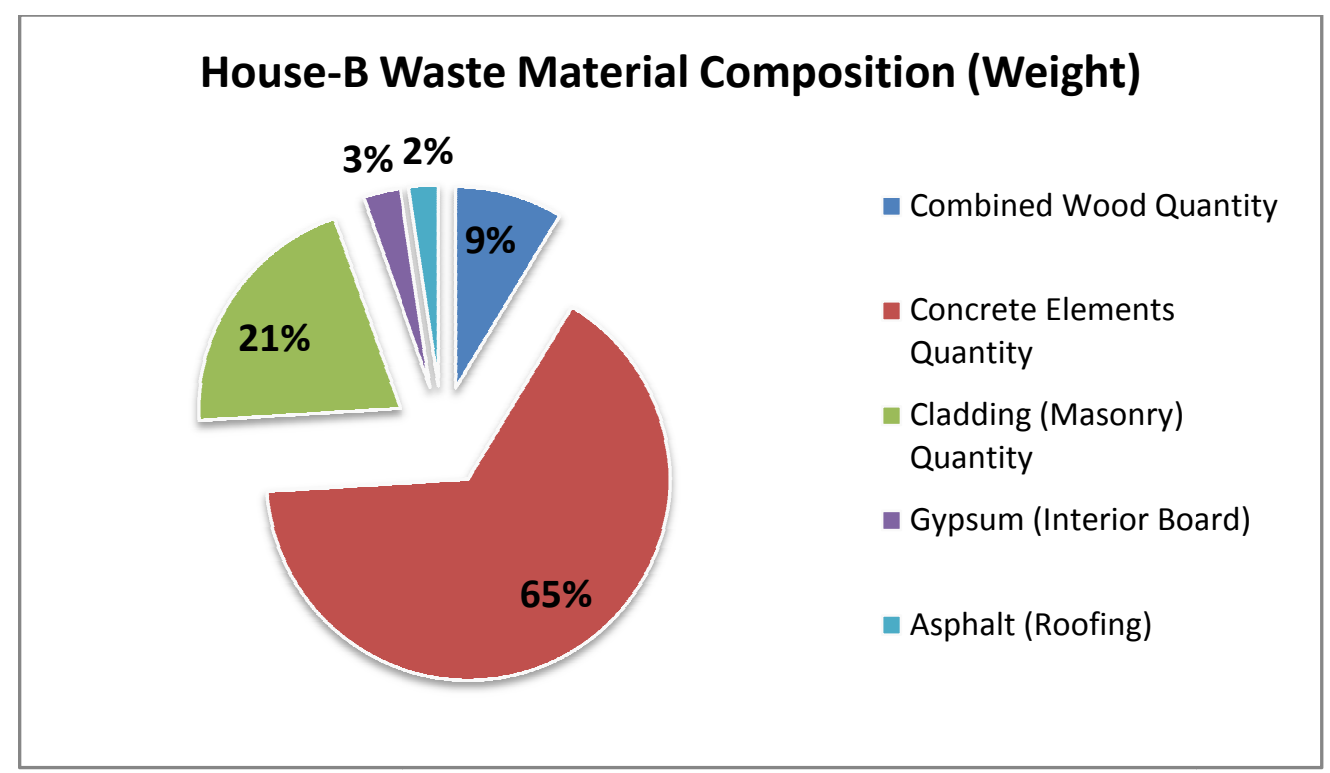

Figure 19: House-B Waste Material Composition 
With the adjustment, the ranking of wood remains in $3^{\text {rd }}$ place after concrete elements $\left(1^{\text {st }}\right)$ and masonry elements $\left(2^{\text {nd }}\right)$. As result of this method, we see wood represented as $9 \%$ of the total weighted material in the house, surpassing gypsum board and asphalt roofing significantly in comparison to Figure 17 where wood quantities were separated. Clearly concrete and brick masonry materials are much heavier in weight per unit area as opposed to another material for this house, and it was the same for House-A previously.

Again, concrete and masonry are potentially more wasteful than wood in House-B, just as it was with House-A. This is contrary to the literature sited specially CCA (1992), RCO (2006), and NRCan (2006) which indicate wood to be the top producer of waste. To investigate a potential source of difference in measurement used in literature, a volumetric measurement was used for House-A in concrete, masonry and wood that revealed a very different picture in terms of composition of waste in percentage (section 5.1.1.1). Such a method will also be used here for House-B with density of typical softwood $510 \mathrm{~kg} / \mathrm{m}^{3}$, concrete $2250 \mathrm{~kg} / \mathrm{m}^{3}$, and masonry 2000 $\mathrm{kg} / \mathrm{m}^{3}$.

If a volumetric unit is applied to concrete, masonry, and wood the results will amount to concrete waste above all at $91.8 \mathrm{~m}^{3}$, however much like House-A, wood waste becomes second at 50.3 $\mathrm{m}^{3}$, while masonry cladding would account for $32.5 \mathrm{~m}^{3}$. Clearly wood rises significantly when the unit of measurement is changed from weight to volume. This reveals a key point of measurement difference, and an insight into the potential method of wood estimates used in the case studies from CCA (1992), RCO (2006) and NRCan (2006). This will be further discussed in the analysis section.

The data generated in this section (5.2) for House-B and in section (5.1) for House-A represents step 1 of the 2-step process of the service life waste generation mentioned in the methodology 
(section 2.1). These data represents potential end of service life waste generation for both houses. In addition, step 2, the added waste accumulated over the 75-year service life period will also be evaluated for both houses in the following section.

\subsection{Service Life Waste Accumulation}

Figures 14 and 19 represent House-A and House-B potential end of service life (demolition) waste generation. The data generated in this section for House-A and House-B represents step 2 of the 2-step process of the total end of service life waste generation mentioned in the methodology. Also, in the methodology section it was determined that service life of 75 years for the two houses will be assumed for the purposes of this evaluation. This is using an extended life expectancy scenario, as surveyed data by Athena Institute (2004) revealed most houses last about 50 years, while some extend to 75 years (discussed in section 2.1.2).

According to the study materials of concrete, cladding (masonry), wood, gypsum and asphalt, only three material elements are particularly affected by the service life of the house which includes the foundation, cladding and exterior roofing. The other material elements excluded from this service life are wood (joists, studs, etc.) and interior gypsum board. These two materials typically do not have a different service life in residential housing with the exception of rare unforeseen problems that may occur such as mould growth, or structural problems. Therefore, the predicted service life of wood and interior gypsum is assumed same as the house service life of 75 years. This also reveals that the concrete (foundation), cladding and roofing are the three main elements of interest when it comes to individual service life of the element in residential housing. 
Six building materials life expectancy surveyed data references were referred to for this study regarding concrete foundation, brick cladding, and asphalt roofing, including surveys from CMHC (2000), Ontario Housing Corporation (CMHC, 2001) and National Association of Home Builders (NAHB, 2007) and the International Association of Certified Home Inspectors (InterNACHI, 2011).

\subsubsection{House-A}

Having estimated potential end of service life waste generation for House-A in section 5.1, the only remaining evaluation is to determine if any waste is accumulated from the three relevant waste material elements over a 75-year service for the house due to replacement. The three material elements are (1) concrete foundation, (2) brick cladding and (3) asphalt roofing.

According to the InterNACHI (2011) and NAHB (2007) surveys, the predicted service life of the concrete foundation (including slab, footing, and wall) is expected to last $100+$ years without rare any unforeseen problems. For brick veneer cladding and stone it is also expected to last $100+$ years. Therefore, the only material for House-A which is expected to have a differential service life than the 75-year service life of the house is the asphalt roofing.

The potential end of service life waste generation of asphalt roofing for House-A was 2,959 $\mathrm{kg}$ (see Table 9 and Figure 11), and the estimated life expectancy of asphalt roofing is estimated between 20-25 years, and 25 years is reported by InterNACHI (2011). Assuming a 25-year period, the asphalt roofing will need to be replaced 2 times after its initial installation during the 75-year service life of House-A, giving a total of $8,777 \mathrm{~kg}$ of asphalt roofing waste after 75 years. Consequently, this addition raises the total end of service life waste generation for House- $\mathrm{A}$, and the results are shown in Figure 20 below. 


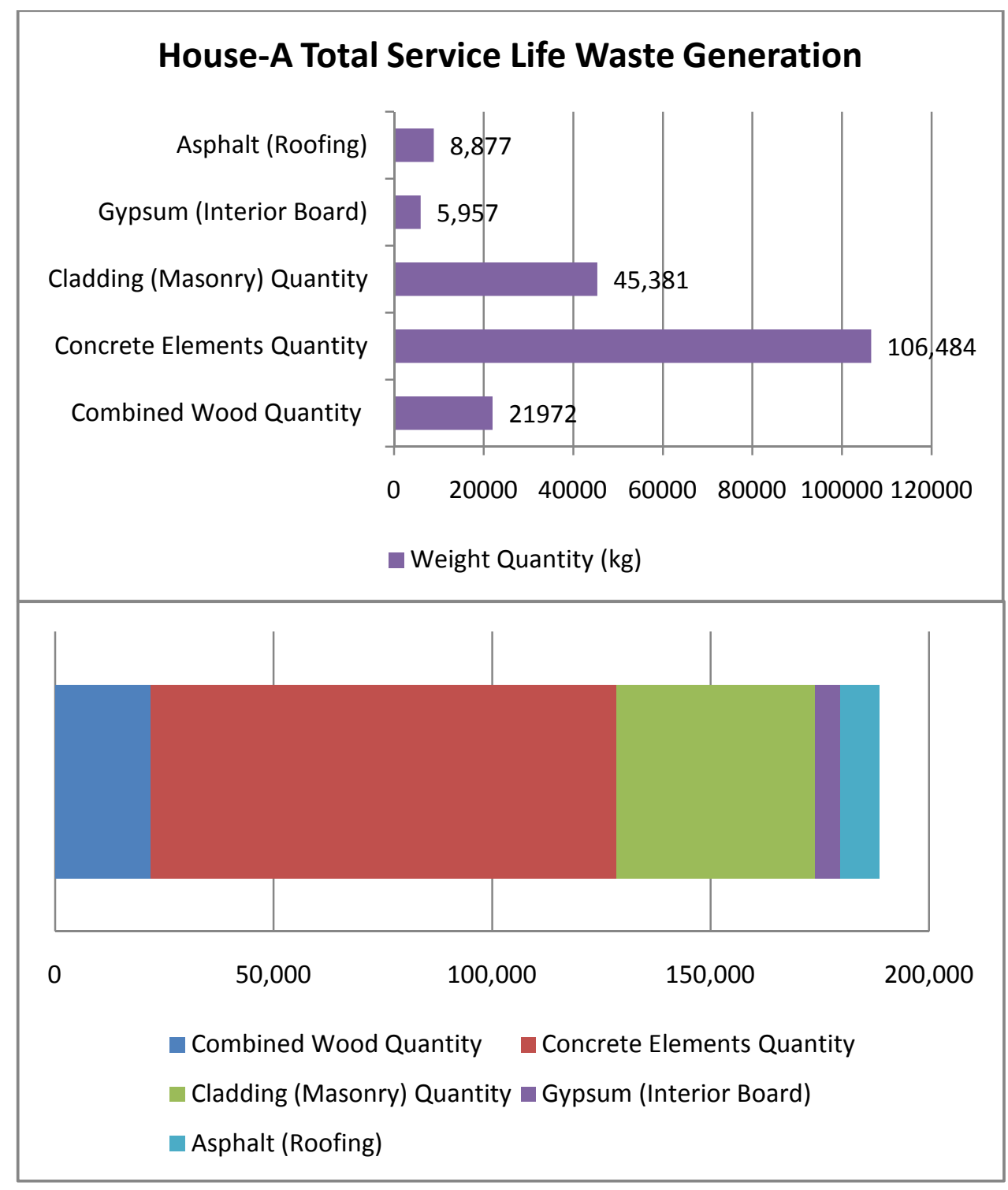

Figure 20: House-A Total End of Service Life Waste Generation

Therefore, the total end of service life waste generation for House-A is $188,673 \mathrm{~kg}$, while the end of service life waste generation was estimated as $180,669 \mathrm{~kg}$. The only difference between end of service life waste and total end of service life waste was the replacement of asphalt roofing two times, where the initial waste was $2,959 \mathrm{~kg}$ and with its replacement two times, that amount totaled to $8,877 \mathrm{~kg}$. The percentage of total end of service life waste generation of House- $A$ is shown in Figure 21 below. 
Due to the replacement of asphalt shingles, asphalt becomes $4^{\text {th }}$ most potential wasteful material moving above drywall over total service life waste generation for House-A.

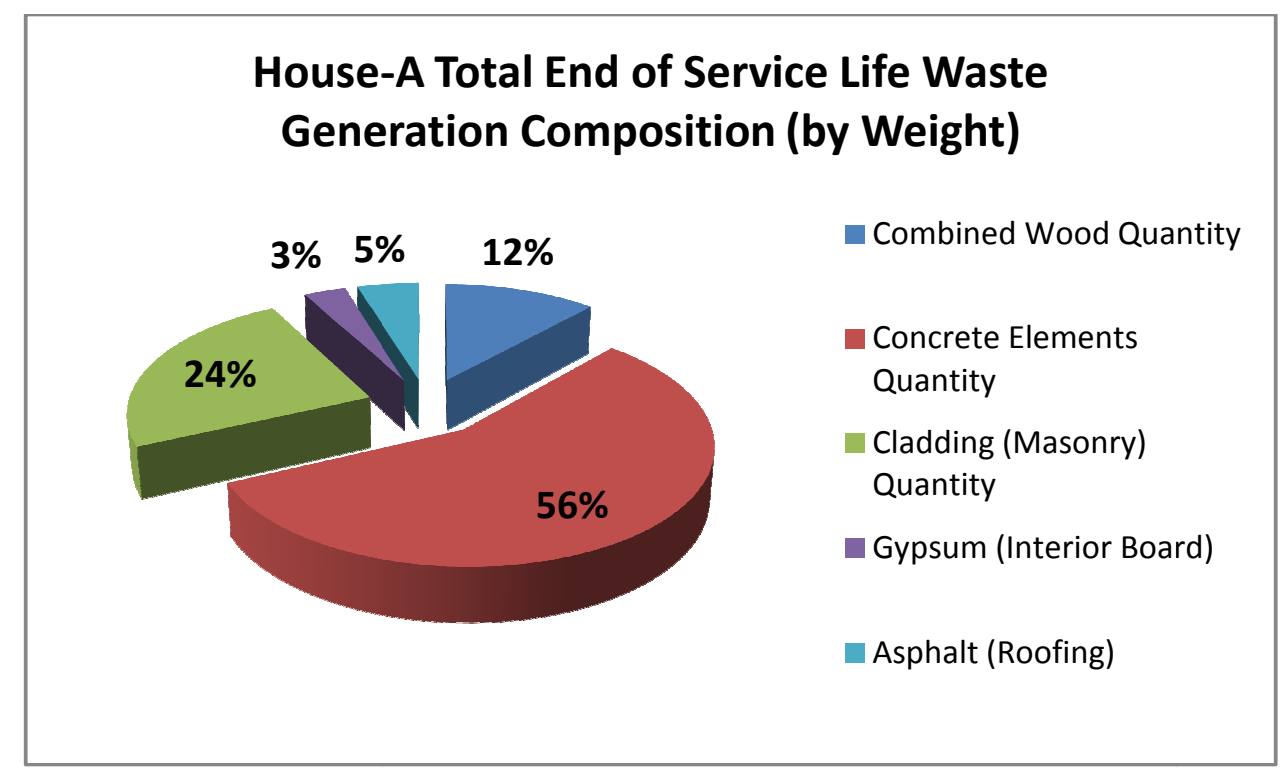

Figure 21: House-A Total Service Life Waste Generation Composition

\subsubsection{House-B}

All the parameters are identical for House-B as it was for House-A. Gypsum board and wood material elements are expected to last the 75-year service life of the house without any replacement. Concrete and brick masonry will last 100+ years, and therefore, the only material remaining material with a projected differential life expectancy is the asphalt roofing.

The total end of service life waste generation of asphalt for House-B was 7,503 kg (see Table 11 and Figure 18), and the life expectancy of asphalt roofing is 25 years, as discussed in the previous section, and according to InterNACHI (2011). Accordingly, the asphalt roofing will need 
to be replaced 2 times during the service life of House-B, giving a total of $22,509 \mathrm{~kg}$ of potential asphalt roofing waste material over a 75-year period. This result is shown in Figure 22 below.

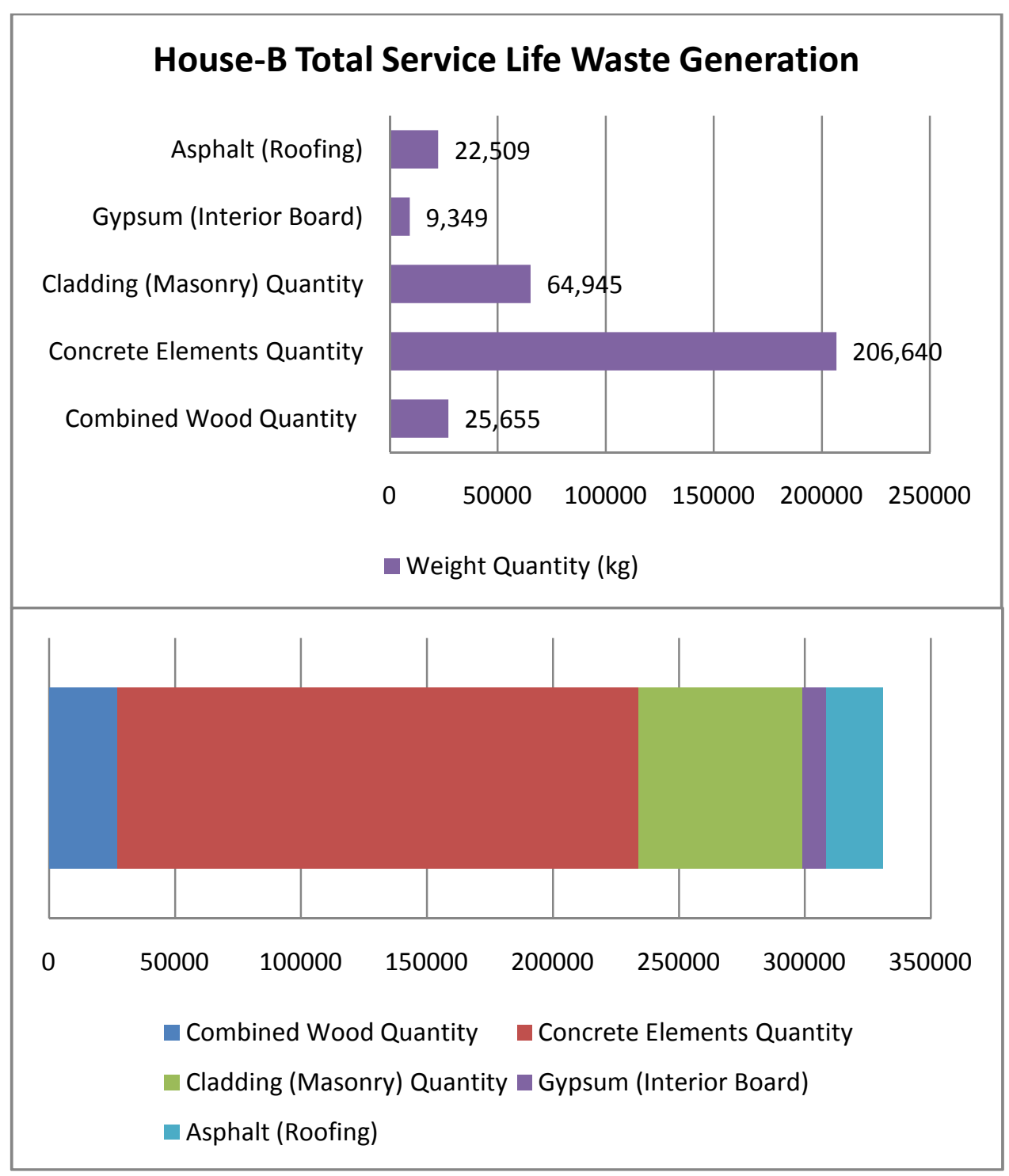

Figure 22: House-B Total End of Service Life Waste Generation

The total end of service life waste generation for House-B is $329,098 \mathrm{~kg}$, while the end of service life waste generation was estimated at $314,092 \mathrm{~kg}$. The only difference was in the addition of asphalt waste material due to it being replaced two times. The total end of service life waste generation percentage for House-B is shown in Figure 23 below. This figure differs 
slightly from Figure 19 which represents end of service life waste generation composition by weight. Due to the replacement of asphalt shingles, potential asphalt waste generation falls $4^{\text {th }}$ moving above drywall within the five waste material exactly like House-A.

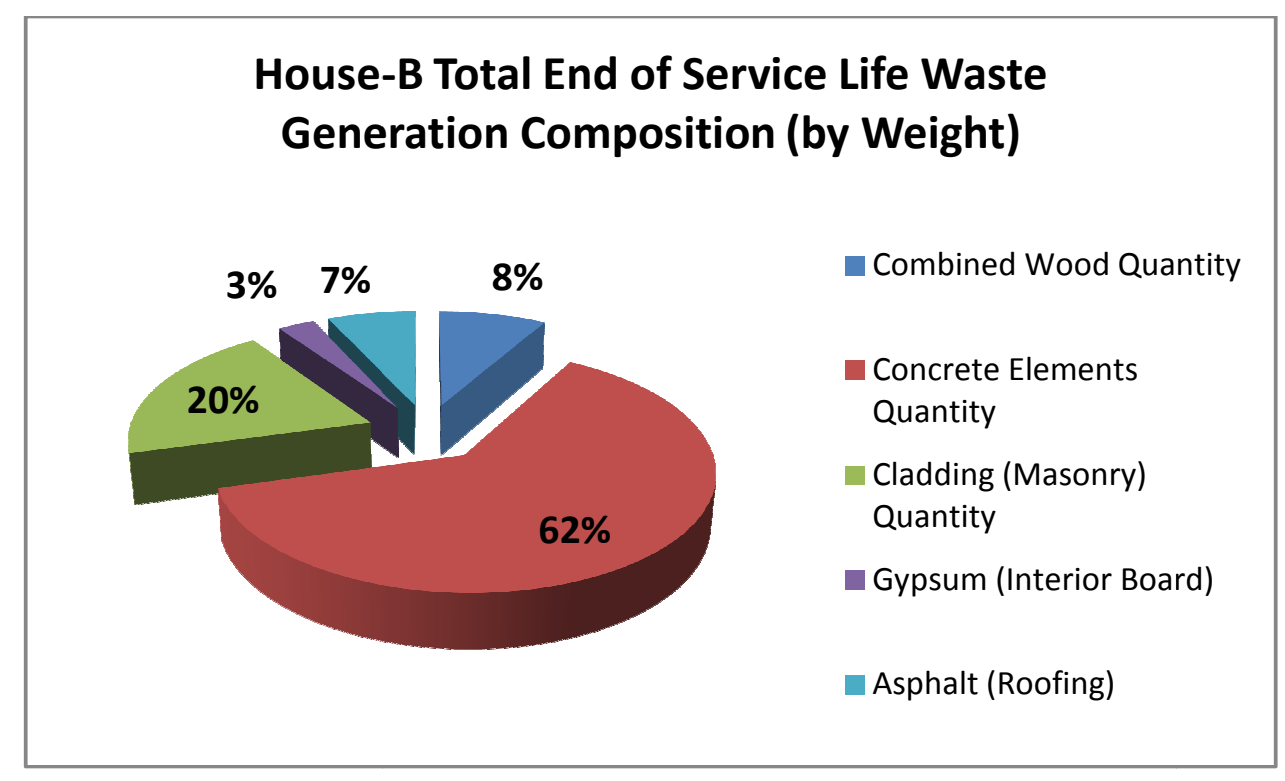

Figure 23: House-B Total Accumulation Composition

Clearly there is a similarity between House-A and House-B in potential waste generation. It is evident that both houses have a strong parallel between both end of service life waste generation (as done in section 5.1 for House-A and 5.2 for House-B), and total end of service life waste generation which accounts for asphalt replacement (as done in this section). Despite the difference between the two houses, the results are comparable by composition in percentage, however, not by weight. The weight was different mainly due to difference in design of the two houses.

Figures 21 (House-A) and 23 (House-B) may not be exact, but the similarity is evident and very important, and will be further discussed and compared in the next section (6.0). 


\subsubsection{Alternative Materials Life Expectancy}

House-A and House-B had very much the same construction and material use. The foundation was concrete, cladding was brick and roofing was asphalt. The concrete and brick perform well with a service life expectancy of $100+$ years. Another foundation option could be permanent wood foundation which can have a life expectancy between 62 to 75 years according to InterNACHI (2011). Although the life expectancy is not long as concrete foundation, the end of service life waste (by weight) generation of the house will be lower.

Alternative cladding options could be stucco (EIFS) or vinyl siding. The life expectancy of stucco is really unpredictable depending on the climate region. InterNACHI (2011) suggest it can last for 50 years, but in coastal humid climates life expectancy of 25 years should be more expected. Also, CMHC (2000) predicts a life expectancy of 21 years for stucco. Vinyl siding can also be a possible alternative cladding material other than brick. Vinyl has a life expectancy of 60 years according to InterNACHI (2011). Brick has a very long life expectancy of 100 years but the end of service life waste (by weight) generation will be much higher.

A possible alternative for roofing can be clay/concrete roofing rather than asphalt. Asphalt is expected to last about 25 years, while clay/concrete roofs can last from 80-100 years according to InterNACHI (2011).

Overall, the selection of building materials should focus on the expected service life of the house, and that will enable informed decisions making on whether to select a longer life expectancy material or a lower, but less wasteful material which may be the more optimal choice. For example, if the brick cladding were to get substituted with vinyl siding, the total material waste generated by vinyl would be less than the weight quantity of brick. To demonstrate this, a scenario of vinyl siding will be substituted for House-A and House-B to 
measure the impact of waste generation. Vinyl siding weight is approximately $2.37 \mathrm{~kg} / \mathrm{m}^{2}$ for typical thickness of $0.102 \mathrm{~cm}$ (CertainTeed, 2013)

For House-A, the end of service waste generation for brick was $45,381 \mathrm{~kg}$, over a total of $188,673 \mathrm{~kg}$, which is $24 \%$ of the total. Given the cladding area of $202 \mathrm{~m}^{2}$ for House-A, the total waste generation from vinyl siding at the end of service life will amount to $478 \mathrm{~kg}$. However, life expectancy is estimated at 60 -years and thus a replacement will be need during the houses 75 year service life. Accordingly, the total end of service life waste generation from vinyl siding for House-A is $956 \mathrm{~kg}$. This is only $2 \%$ of brick, and brings the total end of service life waste generation for House-A to $144,284 \mathrm{~kg}$. This substitution of vinyl cladding can potentially reduce total waste generation by almost $24 \%$ from the original brick cladding.

The same process is applied to House-B, with a cladding area of $312 \mathrm{~m}^{2}$, the end of service life waste generation amounts to $739 \mathrm{~kg}$. This then amounts to $1,478 \mathrm{~kg}$ as the total end of service life waste generation due to a replacement at year 60 . The end of service waste generation for brick was $64,945 \mathrm{~kg}$, over a total of $329,098 \mathrm{~kg}$, which is $20 \%$ of the total. Vinyl siding is just over $2 \%$ of brick, and brings the total end of service life waste generation for House-A to $265,631 \mathrm{~kg}$. Substitution of vinyl cladding can potentially reduce total waste generation by almost $20 \%$ from the original brick cladding.

In these substitution scenarios for House-A and House-B, the weight composition percentage of concrete would rise considerably. When plotted into a graph, the composition percentage is dominated by concrete and cladding becomes negligible. The results of the two houses are depicted in the graph below, and clearly show effect of changing cladding from brick to vinyl siding. 


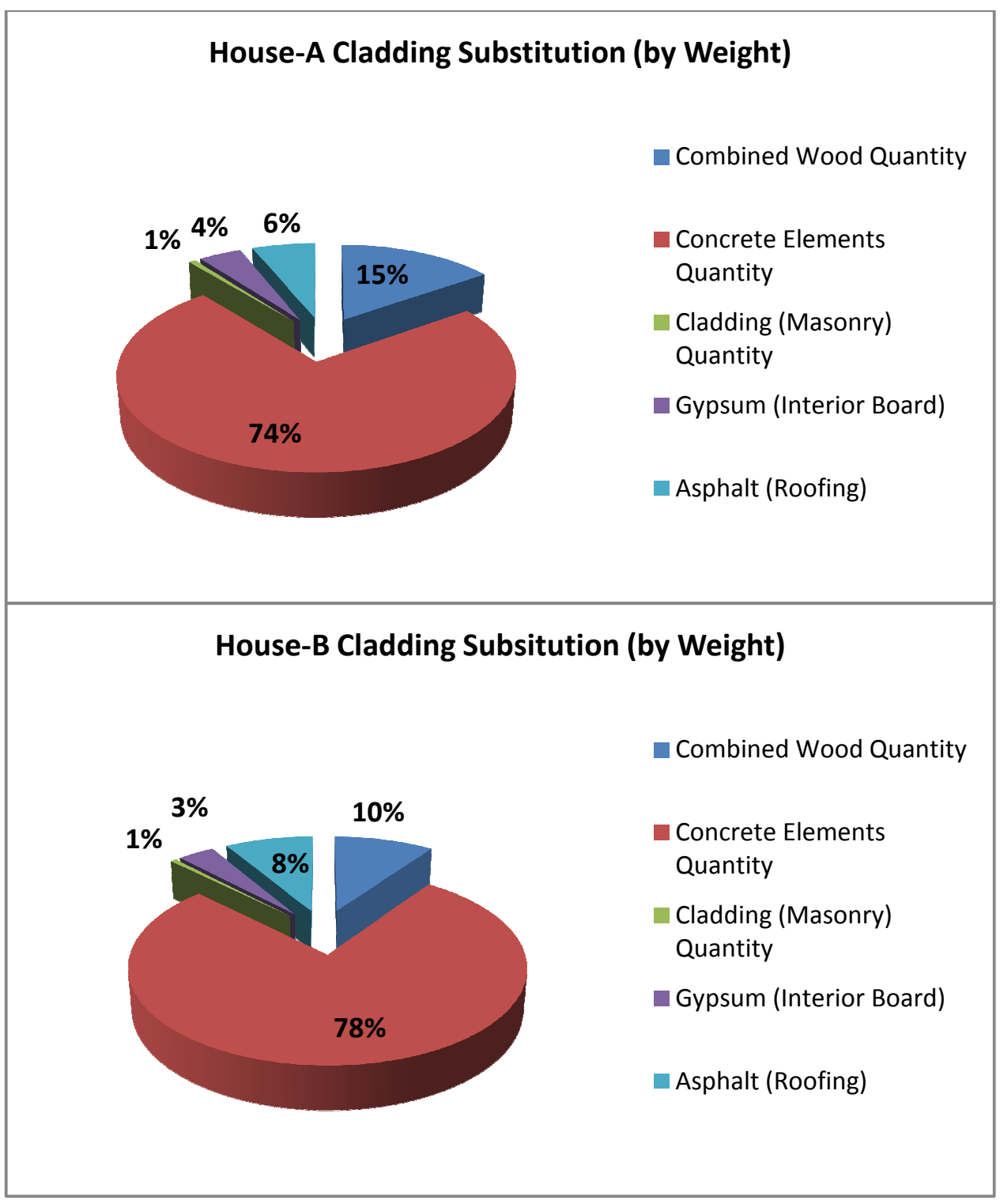

Figure 24: Effect of Vinyl Siding Substitution for Brick Cladding

As mentioned, concrete becomes the dominant total end of service life waste generation for both houses representing between 74 to 78 percent of the total potential waste. Vinyl siding significantly reduces the total potential waste. 


\subsection{Results and Analysis}

The total end of service life waste generation for House-A and House-B were determined in the previous section. This was accomplished by measuring the end of service life waste generation (step 1), as well any additional waste accumulation from replacement over the 75-year service life (step 2). It was found (through step 2) that only asphalt roofing accumulated additional waste contributing to the total end of service life waste generation. It was also found that the two houses had very similar waste composition by weight, but not so much in terms of total waste generation by quantity $(\mathrm{kg})$. Such would be the case given the difference between the two houses in configuration, mainly size and spacing. In fact, despite the clear differences between the two houses (listed in Appendix C, also discussed in section 6.2), the overall composition of weight by percentage was very similar which strengthens the results and consistency.

What the results of the two houses reveal is that specific ratios of waste material can be anticipated for residential houses at the end of its service life, and the associated material that will contribute to waste, regardless of the configuration it may have. What this study certainly proved is that concrete and wood, which is used is almost all residential homes, can potentially be major contributors of waste material for the existing housing stock in the near future.

House-A gross floor area (GFA) is $189 \mathrm{~m}^{2}$ and House-B is $296 \mathrm{~m}^{2}$ respective to their configuration. House-A total service life waste generation was 188,673 kg, approximately 189 metric tonnes. This generates waste of $31,445 \mathrm{~kg} /$ person considering the 6 possible people who may occupy the building. In comparison, House-B total service life waste generation is 329,098 kg, about 329 metric tonnes. This generates to waste of $54,849 \mathrm{~kg} /$ person. House-B continues to be the greater producer of potential waste in total, and per occupant. The normalization of each specific material to the GFA is depicted in chart form below. 


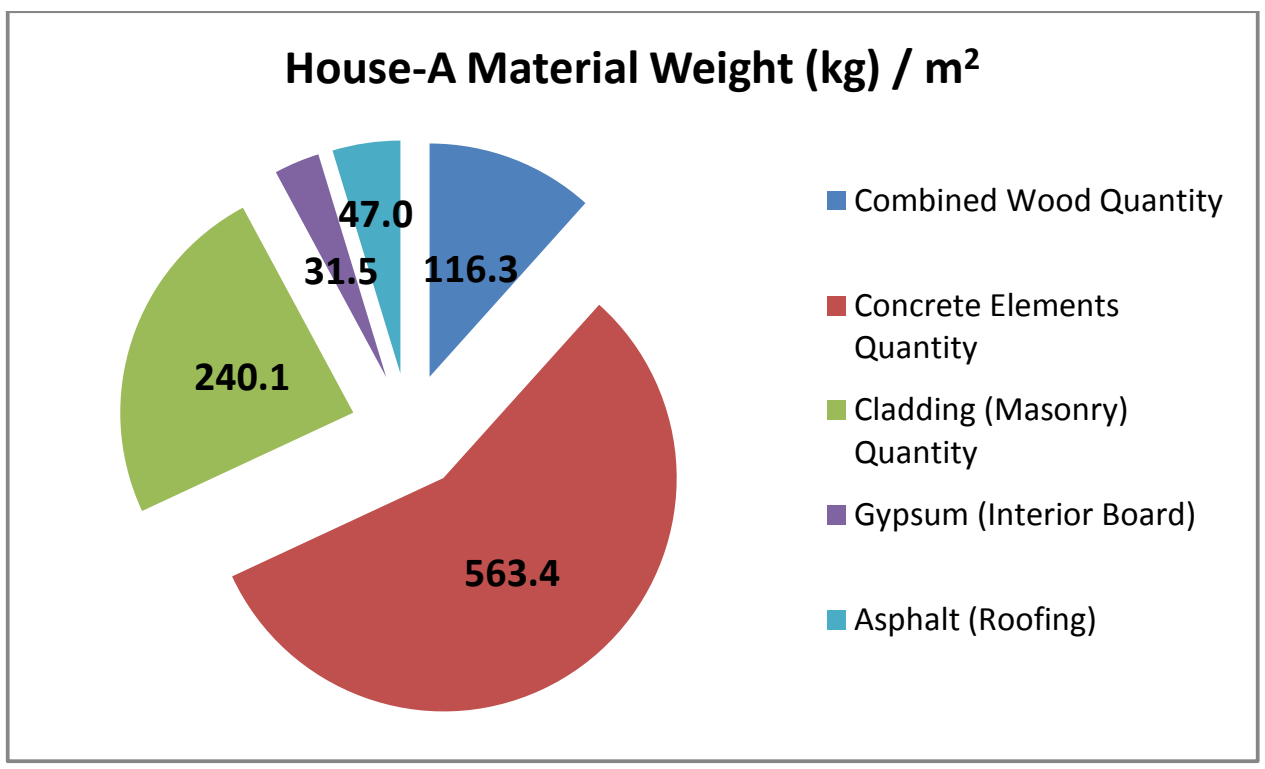

Figure 25: House-A Waste Material Normalization

The summation of the five materials makes up the total end of service life waste generation, which is $998 \mathrm{~kg} / \mathrm{m}^{2}$ of waste for House-A and $1,118 \mathrm{~kg} / \mathrm{m}^{2}$ of waste for House-B. Overall, House$B$ is a greater generator of potential end of service life waste surpassing House-A by $120 \mathrm{~kg} / \mathrm{m}^{2}$. This is anticipated given the GFA of House-B is 1.5 times greater than House-A. The ranking of the waste per $\mathrm{m}^{2}$ is identical to the percentage that was determined in the previous section.

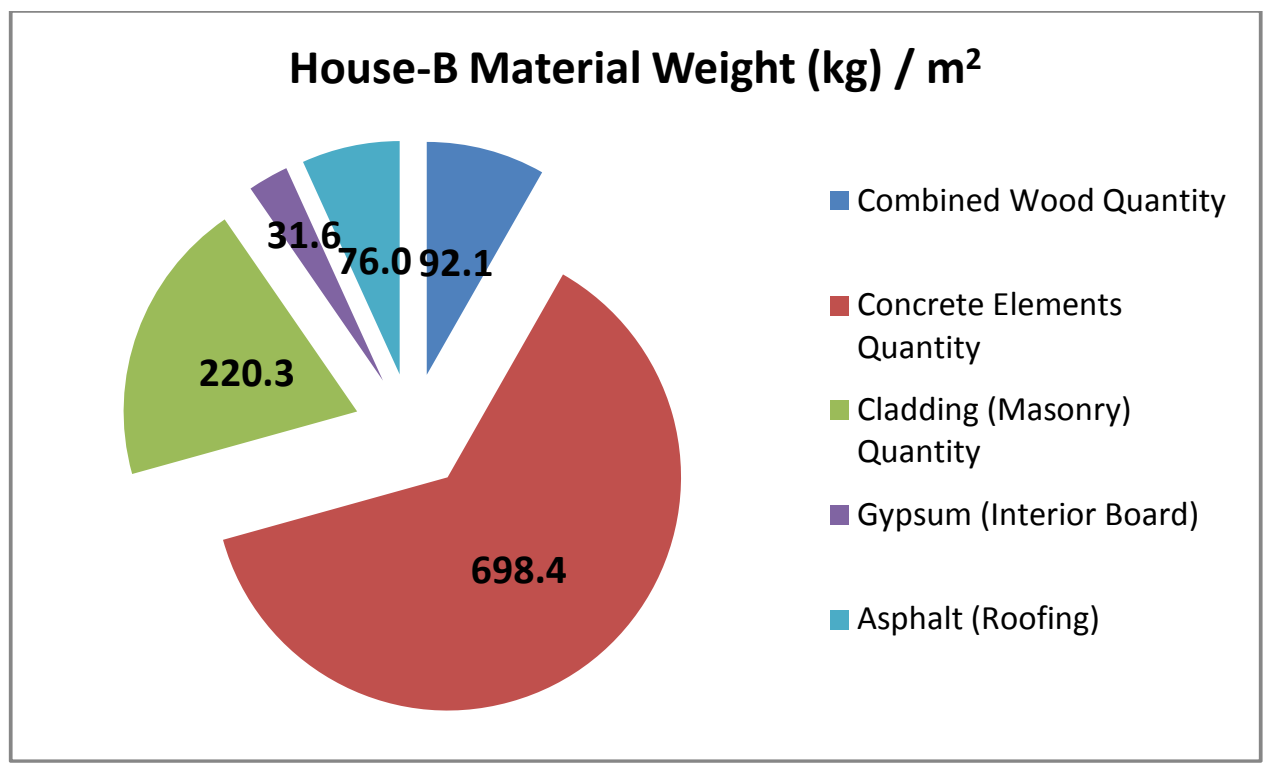

Figure 26: House-B Waste Material Normalization 


\subsection{Literature and Study Results}

The key information determined in this study is the percentage composition (by kg weight) of potential waste that can be expected at the end of service life for residential houses in Canada. The most wasteful materials found in literature included concrete, brick masonry, wood, gypsum and asphalt roofing.

In the literature review section (section 3.0), case studies of residential waste by CCA (1992), RCO (2006) and NRCan (2006) was presented and discussed. CCA (1992) study showed that $30 \%$ of general construction waste was attributed to wood. Placing second was rubble (concrete and brick masonry) at $23.9 \%$, and then building material (mix of asphalt, shingles, and tar paper products) at $18.7 \%$ (see Figure 3 section 3.1.1). However, this formulation was in regards to waste generated during the construction process, and the waste during the demolition process revealed wood waste at even a higher percentage of $51 \%$ and rubble at $24.7 \%$ (Figure 4 , section 3.1.1).

Moreover, NRCan (2006) also reported similar numbers and placed wood as the highest C \& D waste material at $26 \%$, while drywall at $10 \%$ and asphalt roofing at $12 \%$. The concentration of wood waste was also the message given by RCO (2006) and its many case studies, and some were discussed in section 3.1.2. All these three reports place emphasis on wood waste in residential housing.

Furthermore, many researchers in literature including Lu and Yuan (2011), Faniran and Caban (1998), Rounce (1998), focus on wood waste minimization in construction during the construction process and give minimal attention to waste generated during demolition at the end service life for buildings. Given this was the focus of $C \& D$ waste status from literature and 
reports, it seemed more prudent to consider waste at the end of service life for housing. This was precisely done in section 5.0 to quantify specific waste material mentioned and concentrated in literature (e.g. wood, concrete, masonry, gypsum and asphalt) for 2 residential houses in Ontario. This study revealed wood was not the most wasteful material by weight at the end of service life for the 2 houses. Rather it was concrete and brick masonry material which was much higher and will potentially generate more waste. If the total end of service waste generation is compared for the two houses, the following is observed as depicted in Figure 27.

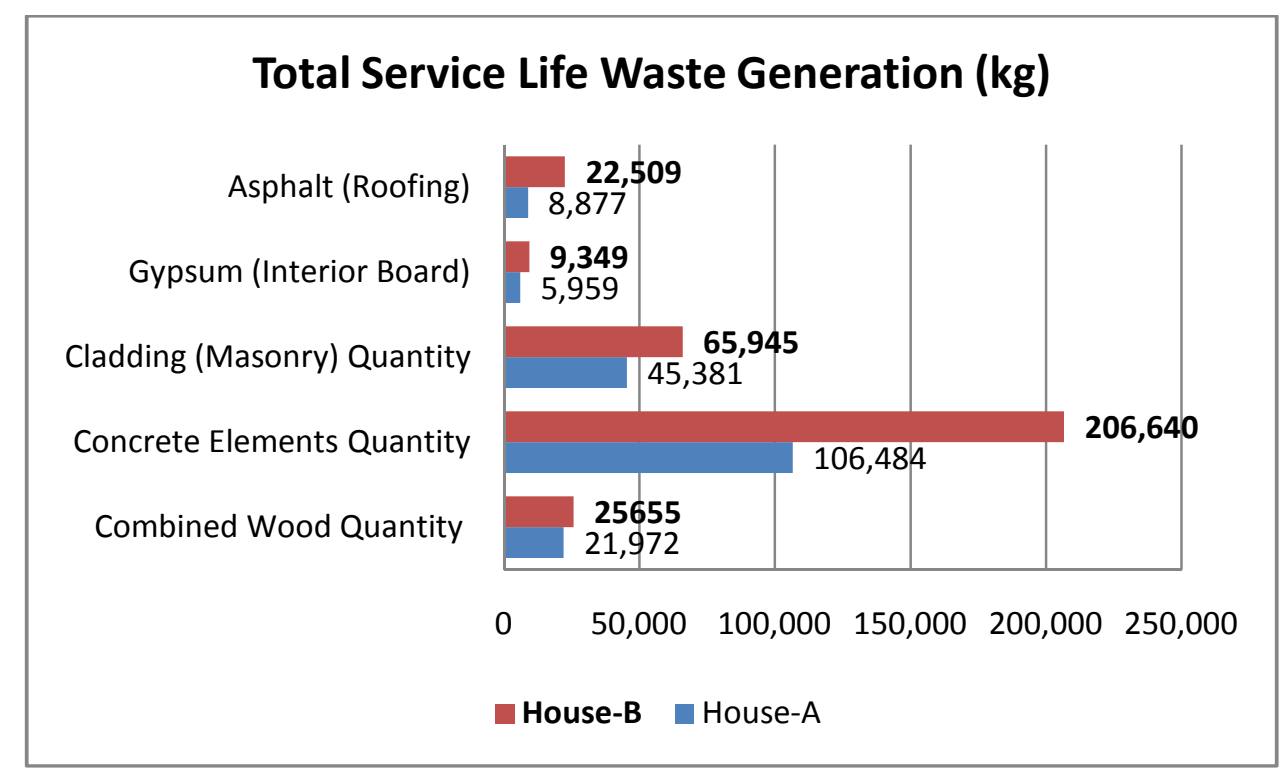

Figure 27: House-A and House-B Potential Total Service Life Waste Generation

The five potential waste materials in weight comparison are similar in rank but not so close in relation to total waste. As mentioned earlier, this is mainly due to the difference in configuration rather than construction type, which is very much similar for both houses. It is important to note here that both houses excluded the quantity of wood use for roof rafters, so the combined wood quantity would be slightly higher, perhaps by a percentage or two in composition. The ranges for the between the houses in percentage are as follows: concrete is between $56-62 \%$, masonry is between $20-24 \%$, wood is between $8-12 \%$, asphalt is between $5-7 \%$, and gypsum is $3 \%$. 


\subsubsection{Demolition Waste Generation}

Step 1 of the 2-step process of measuring waste generation was completed in section 5.1 for House-A, and section 5.2 for House-B. Step 1 was the end of service life waste generation which is potential demolition waste that can be anticipated when the house will be demolished. The demolition waste data from CCA (1992) and NRCan (2006) is listed in Table 13, along with the comparable data from this study.

Table 13: Study Results Comparison to CCA and NRCan

\begin{tabular}{|l|c|c|c|c|c|}
\hline Element & House-A & House-B & Range (A \& B) & CCA (1992) & NRCan (2006) \\
\hline Wood & 12 & 9 & $9-12$ & 51 & 26 \\
\hline Concrete & 58 & 65 & $58-65$ & $24.7^{*}$ & 9 \\
\hline Masonry (brick) & 25 & 21 & $21-25$ & $24.7^{*}$ & 3 \\
\hline Gypsum Drywall & 3 & 3 & 3 & $7.9^{\star \star}$ & 10 \\
\hline Asphalt & 2 & 2 & 2 & $7.9^{\star \star}$ & 12 \\
\hline
\end{tabular}

*24.7 does not represent concrete or masonry distinctly, it is a combination of the two materials

${ }^{* *} 7.9$ is assumed to be gypsum and asphalt material in combination with other material (CCA study

not does indicate this directly)

We see from this table that the numbers reported as demolition waste generation from CCA and NRCan do not match at all to the study Houses A and B. Given that the housing industry has not changed in any significant way either in construction method or material use, the conflicting data from CCA and NRCan is strange. Concrete and masonry quantity for the study houses fall between $83-86 \%$, whereas the CCA study suggests the combination of the two represents $24.7 \%$. If date of data is recognized as a possible source of difference, note that in 1992 the demolition waste for wood was very high at $51 \%$, and this decreased to $26 \%$ in 2006 . One possible reason could be the awareness of wood waste in the 90's caused a major concern in the construction industry. This in turn helped change the industry norm and strategies to minimize wood waste were implemented. Another possible reason for this discrepancy may be that the measurement was done in volume ratio, not weight. However, NRCan clearly reports it as a weight ratio, and CCA report seems to suggest it was done by volume ratio although there 
is nothing definite to suggest it as either volume or weight. Nevertheless, a volumetric measurement was done for the two study houses in section 5.1.1.1 (House-A) and section 5.2.1.1 (House-B). What was interesting is that wood waste (ranked $3^{\text {rd }}$ ) became very similar to concrete waste when measured in volume. In fact for House-A the difference was $4 \mathrm{~m}^{3}$, while for House-B it was much greater at $40 \mathrm{~m}^{3}$.

Furthermore, the demolition waste data by CCA (1992) varied in sampling across different sectors such as residential and commercial, as well as high-rise and renovation projects. If such was the case, concrete waste should certainly have been much greater if commercial buildings were included. Nevertheless, the results of this research from House-A and House-B suggest an anticipated range of waste composition between key waste materials for residential housing can potentially be expected from demolition. Although the two sample houses used for the study were very different in configuration, the similarities in the results despite its differences give it strength. The percentage (by weight) used in this chart is the end of service life waste generation, another words demolition waste, that can be anticipated from current residential housing stock in Canada. It does not include total end of service life waste generation.

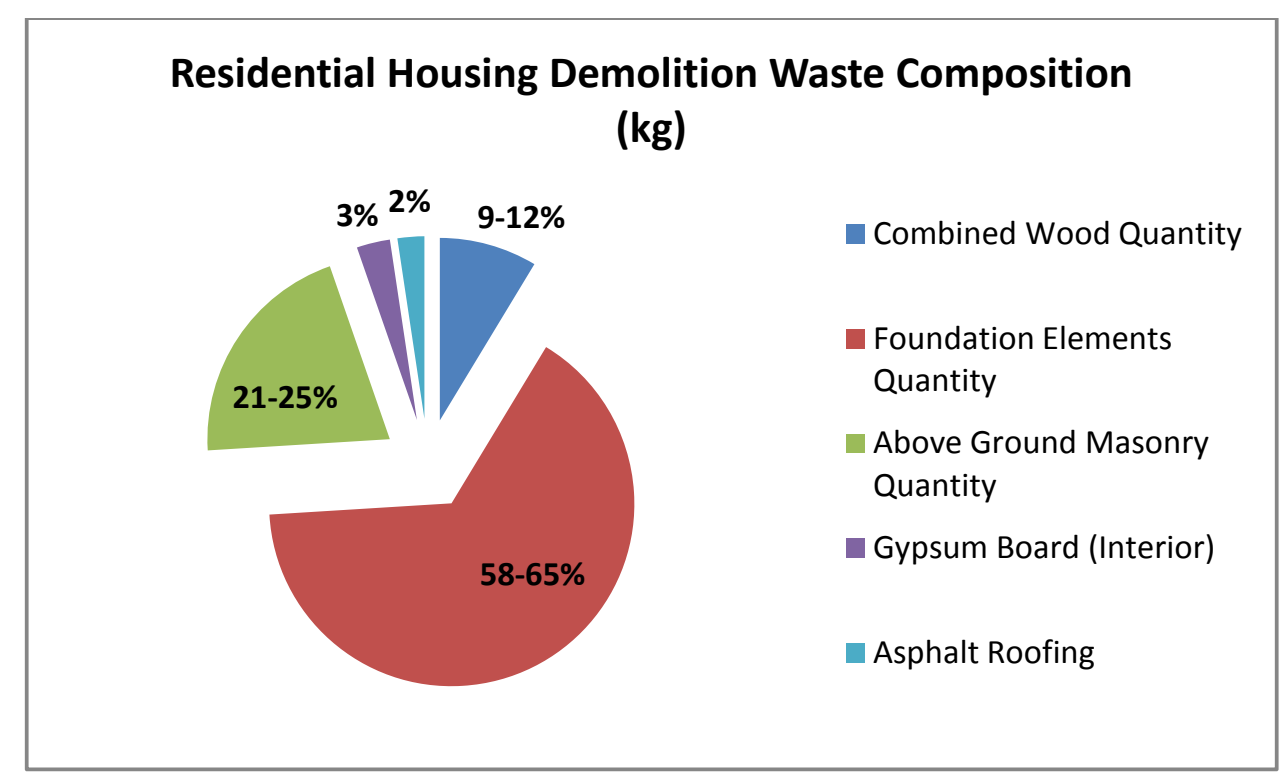


Figure 28: Residential Housing Demolition Waste Composition Percentage by Weight

This material composition (percentage) does reveal an accurate, not precise, quantity of waste that can be anticipated in common low-rise residential homes. This is important because the current housing stock in Canada is very similar (as discussed in section 2.1.) to the two houses used in this research.

\subsection{Waste Diversion Outlook}

The theory used to combat waste is the application of the 3R's principle (reduce, reuse and recycle) in descending order, as discussed section 2.3. Literature focuses on potential wood waste minimization in the residential $C \& D$ industry. The findings of this study implies the contrary, much more focus needs to be placed on potential concrete waste. If one considers the potential waste at the end of service life for residential houses, concrete is perhaps the highest contributor to solid waste. Certainly this study proves such can be the case when existing housing stock are demolished in the near future. The most common foundation for residential houses is concrete based. In effect, much like wood has been the focus since the early 90 's, concrete needs to be the focus moving forward from present time. The focus should be reduction of concrete by design, reuse of concrete at the end of service life for houses, and recycling of concrete when excess amounts are retrieved from building sites.

Currently, researchers such as Gull (2011) and Hoffman (2012) affirm the reliability of recycled concrete as aggregate for new concrete, granular base for infrastructure and buildings. In fact, this application has been in use for very long due to its practical application (CCA, 1992).

Furthermore, concrete use in low-rise residential houses is predominately in the foundation, and roughly $60 \%$ of the potential waste generation from a house is concrete, as shown in the two 
study houses. One important observation was that House-A had a much lower concrete content (in the foundation) as opposed to House-B. Such was the case despite the two houses incorporating 3 bedrooms, for a total of 6 occupants. The building coverage for House-B $\left(123 \mathrm{~m}^{2}\right)$ was 2.8 times greater than House-A $\left(353 \mathrm{~m}^{2}\right)$. This is indicating the use of design issues to reduce potential waste generation. In effect, a home designed for 6 occupants is far more waste efficient if it is built as a 2-storey home rather than a single storey. Clearly this is the case with the two study houses where House-A generated 31,445 kg/person and House-B generated $54,849 \mathrm{~kg} /$ person of potential waste.

Design for Deconstruction is also an effective way to reduce waste. In 2006, CSA released its Guidelines for design disassembly and adaptability of buildings to identify design approaches and potential waste reduction solutions. The principle is to design for deconstruction to allow for disassembly at the end of the service life of buildings. The issue with disassembly and almost with all other waste diversion strategies is the cost. The net cost of deconstruction and demolition can vary but demolition can be much cheaper, given the low tipping costs at landfills. Guy (2011) gives this expression as follows:

Net costs $=($ Deconstruction + Disposal + Processing $)-($ Contract Price + Salvage Value $)$ Demolition Costs $=($ Demolition + Disposal $)-($ Contract Price $)$

Notice the extra cost of processing is not needed for demolition, while the benefit of salvaged material is possible for deconstruction work. Deconstruction feasibility depends heavily on the value of salvaged material/products, which can vary from one project to another. 
Wood was relatively low in solid waste by weight between the two houses. Permanent Wood Foundations (PWF), which has a life expectancy of 75 years according to InterNACHI (2011), may be a possible alternative to the common concrete foundation. This will certainly reduce a house's waste generation significantly, mainly by reducing potential concrete waste which can represent around $60 \%$ by weight for common residential homes.

Reduction of wood waste is very practical, specifically in the design phase, before reuse or recycling comes into play. Designers can use many strategies, and one concept is smart (or advanced) framing, which is common in the industry. Smart framing involves using a $2 \times 6$ frame at 24 inches on centre with single top plates and headers, as opposed to standard framing where $2 \times 4$ frame at 16 inches on centre with double top plates, three stud corners, and double headers are used (Lstiburek, 2010). According to Building Science Corporation (2010), smart framing can also be cheaper because lumber use is reduced by 5 to $10 \%$, and it uses $3 \%$ less wood pieces while the framing factor if reduced from typical $25 \%$ for standard framing to $15 \%$ for smart framing.

NRCan (2006) lists some constraints to waste recycling as low cost of dumping waste into landfills, contamination in waste materials, minimal value of salvageable waste, and infrastructure and proximity to processing plants. Also, consider Regulations 102 and 103 discussed in sub-section 1.1.2, and the minimum requirement of projects to be $2000 \mathrm{~m}^{2}$ in floor area to be obligated to do a waste audit and waste reduction work plan. Studies in 1992 (CCA) up to 2006 (NRCan) placed much emphasis on minimizing wood waste, however, moving on forward from 2013 should focus on potential concrete waste minimization using design strategies to better combat potential end of service life (demolition) waste generation. 


\subsection{Conclusion}

The fact that $C \& D$ waste is a major topic of concern today is attested by many researchers including Lu and Yuan (2011), Yuan and Shen (2010), Monahan and Powell (2012), and others. Some studies suggest that up to $40 \%$ of wastes in global landfills are C \& D waste material (Nitivattananon and Borongan, 2007). Given the magnitude of such a global impact, Yuan and Shen (2010) further mention that research into C \& D waste reduction and management must be the focus moving forward.

RCO (2006) suggests Canada's total C \& D waste accumulation is expected to be around 12.5 million tonnes (metric) annually, which equates to $1.07 \mathrm{~kg}$ waste per capita/day, and that accounts for approximately 25 percent of solid waste material in landfills. Furthermore, NRCan (2006) predicted 4.2 million tonnes of waste in landfills are attributed to the residential sector (NRCan, 2006). In comparison, the United States generates roughly 136 million tonnes of C \& D waste annually, which represents 30 percent of their solid waste in landfills, and that produces $1.24 \mathrm{~kg}$ waste per capita/day, considering a population of over 300 million (Guy \& Gibeau, 2003). These statistics certainly show the magnitude of C \& D waste generation and the needed research to deal with waste generation and ultimate minimization.

Literature gives much attention to $C$ \& $D$ waste reduction planning in the design phase and construction phase, where Shen and Tam (2002) suggest waste management should stream into project management. However, it seemed prudent to consider waste where it would be

most generated, which is the demolition phase. Furthermore, reports by CCA (1992), RCO (2006) and NRCan (2006) point to wood as the most wasteful material in residential construction. The main intent of this study was to evaluate if such was the case with residential houses, and whether demolition waste confirmed the observation made by CCA, RCO and 
NRCan. With this objective in mind, two low-rise residential houses were chosen to determine the potential end of service life waste generation.

House-A was a two-storey house with a total GFA of $189 \mathrm{~m}^{2}$, whereas House-B was a bungalow with $296 \mathrm{~m}^{2}$ GFA. The total service life waste accumulation for House-A was determined as $188,673 \mathrm{~kg}$ (189 metric tonnes) and for House-B it was $329,098 \mathrm{~kg}$ (329 metric tonnes). This equated to $31,445 \mathrm{~kg} /$ person potential waste generation, and $998 \mathrm{~kg} / \mathrm{m}^{2}$. By comparison, House-B generated 55,172 kg/person, and $1,111 \mathrm{~kg} / \mathrm{m}^{2}$. Although House-B (bungalow) produces about 1.75 times more waste in total weight $(\mathrm{kg})$ than House-A (two-storey house), the normalized waste rate depicts a much more relative and accurate measurement. Overall, the two study houses showed that a two-storey house could be far more waste efficient from a end of service life waste generation perspective than a single-storey house in its equivalent, as both houses support 6 occupants.

Despite the differences, the composition percentage of waste generation (by weight) from the two houses are relatively similar and comparable, although there were major differences in design, size, and space between the two houses. The potential end of service life (demolition) waste generation range determined from House-A and House-B is presented in Figure 29 below. If these findings are compared to CCA (1992), RCO (2006) and NRCan (2006), the results are contrary to the notion that wood waste is the most wasteful material in the residential construction industry. The results show concrete is in fact potentially the most wasteful material at the end of service life (demolition stage) for residential houses. One of the possible reasons for this discrepancy may be the unit of measurement for the studies in literature. When this is converted into volumetric unites $\left(\mathrm{m}^{3}\right)$, the result are slightly more compatible with literature. 


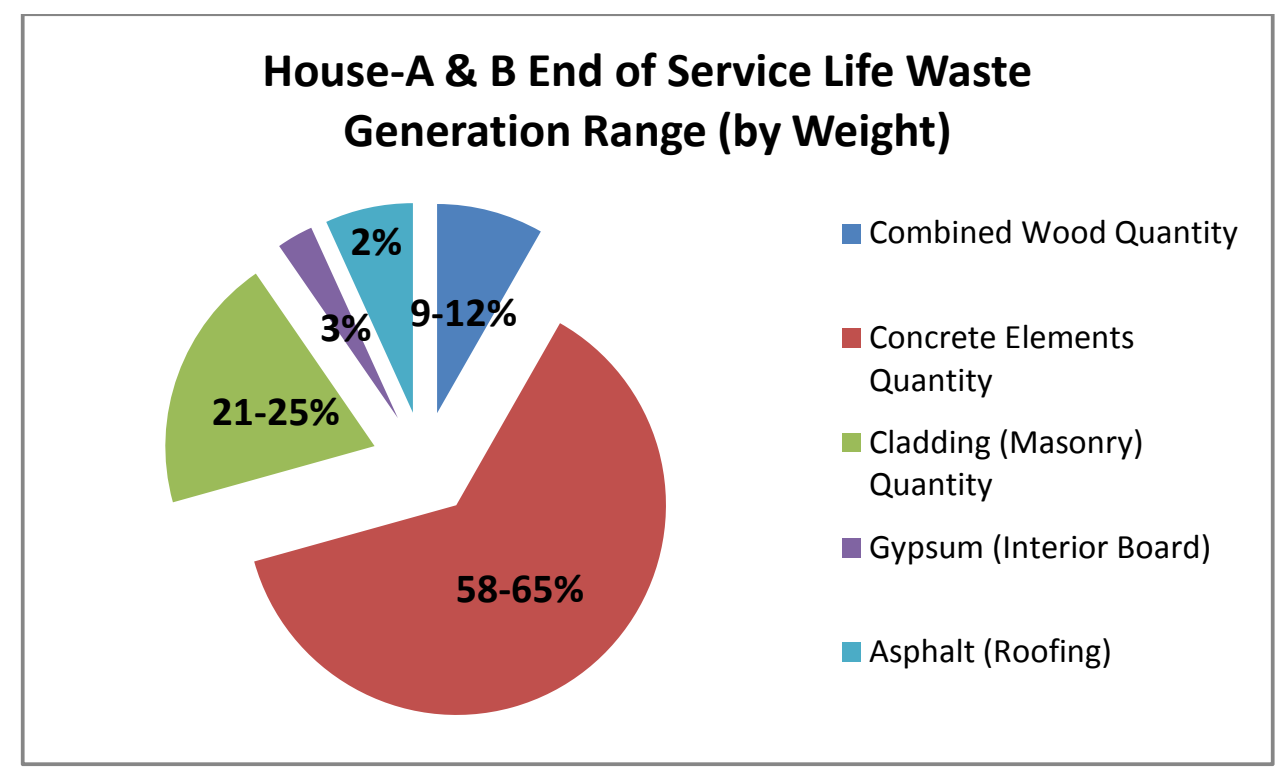

Figure 29: End of Service Life Waste Generation Composition Range (kg) for Houses

Potential concrete waste for House-A amounts to $47.3 \mathrm{~m}^{3}$, wood to $43 \mathrm{~m}^{3}$, while masonry cladding would account for $22.7 \mathrm{~m}^{3}$. House-B was concrete waste above all at $91.8 \mathrm{~m}^{3}$, wood becomes second at $50.3 \mathrm{~m}^{3}$, while masonry cladding at $32.5 \mathrm{~m}^{3}$. What this volumetric measurement (detailed in section 5.1.1.1 and 5.2.2.1) shows is the clear distinction of concrete and wood potentially being the most wasteful material, and which may have been the method used by the reports done by CCA (1992) and others. This and other possible reasons where further discussed in section 6.1 .

\subsection{Environmental Impact}

The materials subject to the study were concrete, brick, drywall, asphalt and wood. It was touched upon in the introduction that energy consumption in $C$ \& $D$ waste and its impact on climate change is not as apparent as it is in building operation energy consumption. To better understand the potential impact C \& D waste can have on energy use and climate change, the associated energy and emissions impact for the 5 materials will be briefly touched upon conceptually. 
Energy and emissions is a key factor in environmental impact measurement as it contributes to global warming and $\mathrm{CO}_{2}$ concentration in the atmosphere, which has a direct affect on climate change. Energy that is predicted over a products lifecycle, that being raw extraction, manufacturing and transportation, are commonly classified as embodied energy, given in $\mathrm{MJ} / \mathrm{kg}$. This energy use is then attributed to the amount of $\mathrm{CO}_{2}$ that is released in the process, given in $\mathrm{kg} \mathrm{CO}_{2} / \mathrm{kg}$. Many factors alter such calculations such as location, infrastructure, manufacturing process and others. Therefore, it should not be taken as complete and precise estimations, rather an indication.

According to GreenSpec (2012), the embodied energy given for 'cradle to gate' estimations is listed Table 14 for the 5 materials.

Table 14: Energy and Emissions of Waste Materials (Source: GreenSpec, 2012)

\begin{tabular}{|l|c|c|c|}
\hline Material & Energy (MJ/kg) & Carbon E $(\mathbf{k g C O} / \mathbf{k g})$ & Density $\left(\mathbf{k g} / \mathbf{m}^{3}\right)$ \\
\hline Concrete & 1.11 & 0.159 & 2400 \\
\hline Brick & 3.0 & 0.24 & 1700 \\
\hline Wood (softwood) & 7.4 & 0.45 & 510 \\
\hline Gypsum Board & 6.75 & 0.38 & 800 \\
\hline Asphalt & 11.3 & 0.30 & - \\
\hline
\end{tabular}

The embodied energy $(\mathrm{MJ} / \mathrm{kg}$ ) values above where estimated in UK and are comparable to values derived by Athena Institute of North America (2012). By comparison, concrete is estimated at $0.93 \mathrm{MJ} / \mathrm{kg}$, brick at $2.29 \mathrm{MJ} / \mathrm{kg}$, wood at $5.24 \mathrm{MJ} / \mathrm{kg}$, gypsum board at $7.94 \mathrm{MJ} / \mathrm{kg}$, and asphalt shingles at $14.57 \mathrm{MJ} / \mathrm{kg}$ (Athena Institute, 2012).

At first glance it seems that concrete is much better in energy use than the rest of the materials due to low $1.11 \mathrm{MJ}$ per kg energy consumption. However, upon closer look we see that it is a weight ratio (per $\mathrm{kg}$ ) energy consumption, and in that regards concrete is the most dense of the 5 materials. On top of that, concrete material has the most mass in the two houses in total end 
of service life waste generation, as it represents 56-62\% (Figures 21 and 23) of the total mass of materials. As a result, the embodied energy intensity of concrete is greater in the overall $\mathrm{CO}_{2}$ emissions than the other 4 materials. Conversely, wood has the highest $\mathrm{kgCO}_{2}$ concentration per kg material, but due to its lower density and relative to the other materials, its effect is not as significant as concrete or brick considering that it is $9-12 \%$ of the total mass.

By weight ratio and quantity, concrete and brick have the greatest environmental impact as it releases the most $\mathrm{CO}_{2}$ emissions into the atmosphere due to the greater total mass of potential waste material for the two houses of this study. Thus, the impact on climate change is most felt from concrete. This also emphasizes the focus placed on concrete moving forward from the waste evaluation, as it is was found to be the most wasteful material at the end of service life.

\subsection{Recommendations and Future Study}

The summation of this study suggests the need to look into $C \& D$ generation at the end of service life (demolition stage) of houses, and not just during construction. Certainly the design phase strategies and construction phase waste management are critical for minimizing waste, as referenced in literature. However, to determine a more effective method to minimize waste generation, potential end of service life demolition waste should be a strong focus. This study determined the end of service life waste generation gave better insight into the potential waste generation that may be encountered in the demolition stage of residential houses. The need therefore, to consider where potential waste material will end up at the end of the service life (often the landfill) of a house deserves much greater attention than the material waste factor during the construction phase. 
Thus the findings of this study suggest the main target for designers is to build knowing concrete will potentially be the greatest producer of waste in residential housing, not wood, and what strategies can be employed to ensure the around $60 \%$ (concrete use by weight) of the total material in a house is not dumped into a landfill at the end of the service life of the house. Past literature in the 90's and last decade have focused on wood waste, and now the recommendation from this study is to focus on concrete use in residential houses, and how to deal with the vast amount of potential concrete waste that will be generated when the existing housing stock are demolished in the near future. Essentially a shift in focus from wood to concrete is most appropriate moving forward.

In terms of future research, a comprehensive study dealing with alternative material use and specific design for residential houses along with the embodied energy use is a potential topic of research. In this research, one construction type of housing was studied but all different types of residential homes need to be looked at and evaluated to measure and determine which type of housing is best from a waste generation perspective. In this study, embodied energy was touched upon briefly as it was not the focus of this study, however, a further study can investigate much deeper into this matter and produce a much more comprehensive report focusing on energy use and consumption. Also, all waste that is generated is either landfilled, recycled or reused based on available technology, facilities and infrastructure in accordance to regulations, and this can also serve part of a further study. 


\section{Appendix A - House A Information}

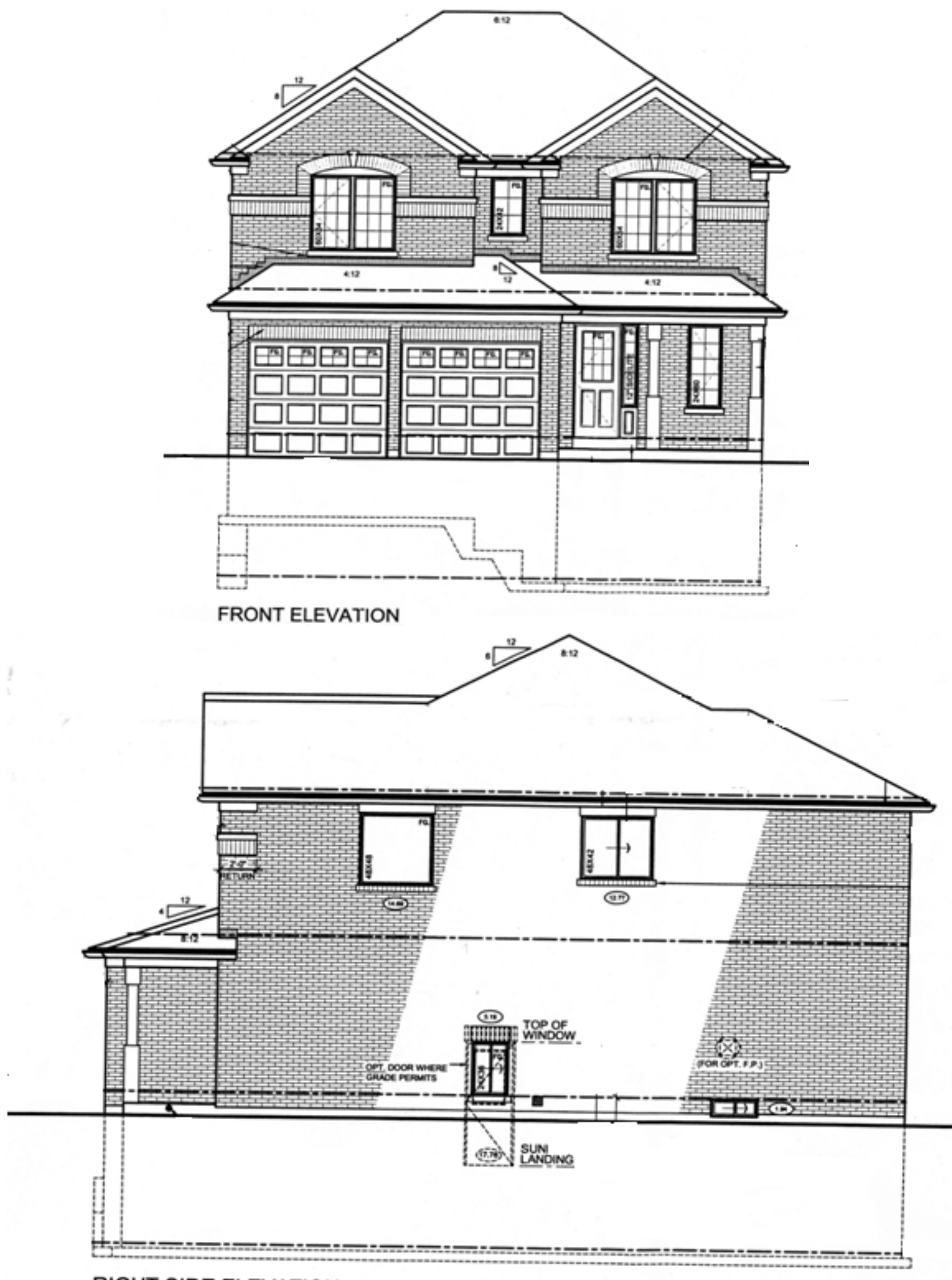

RIGHT SIDE ELEVATION 

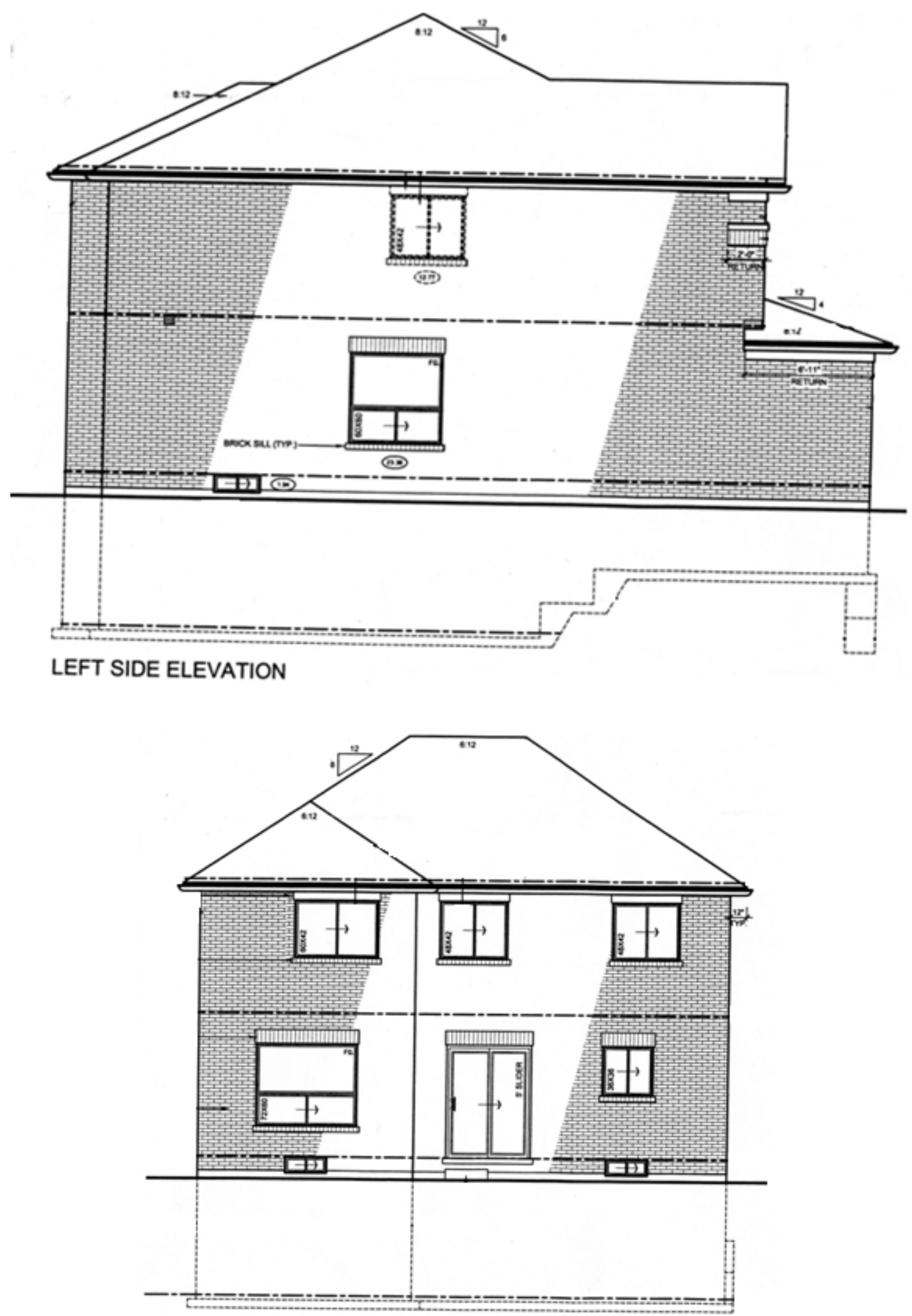

REAR ELEVATION 


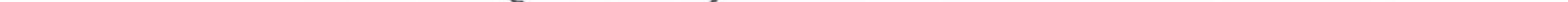


$(w 9.01), 5 \varepsilon$

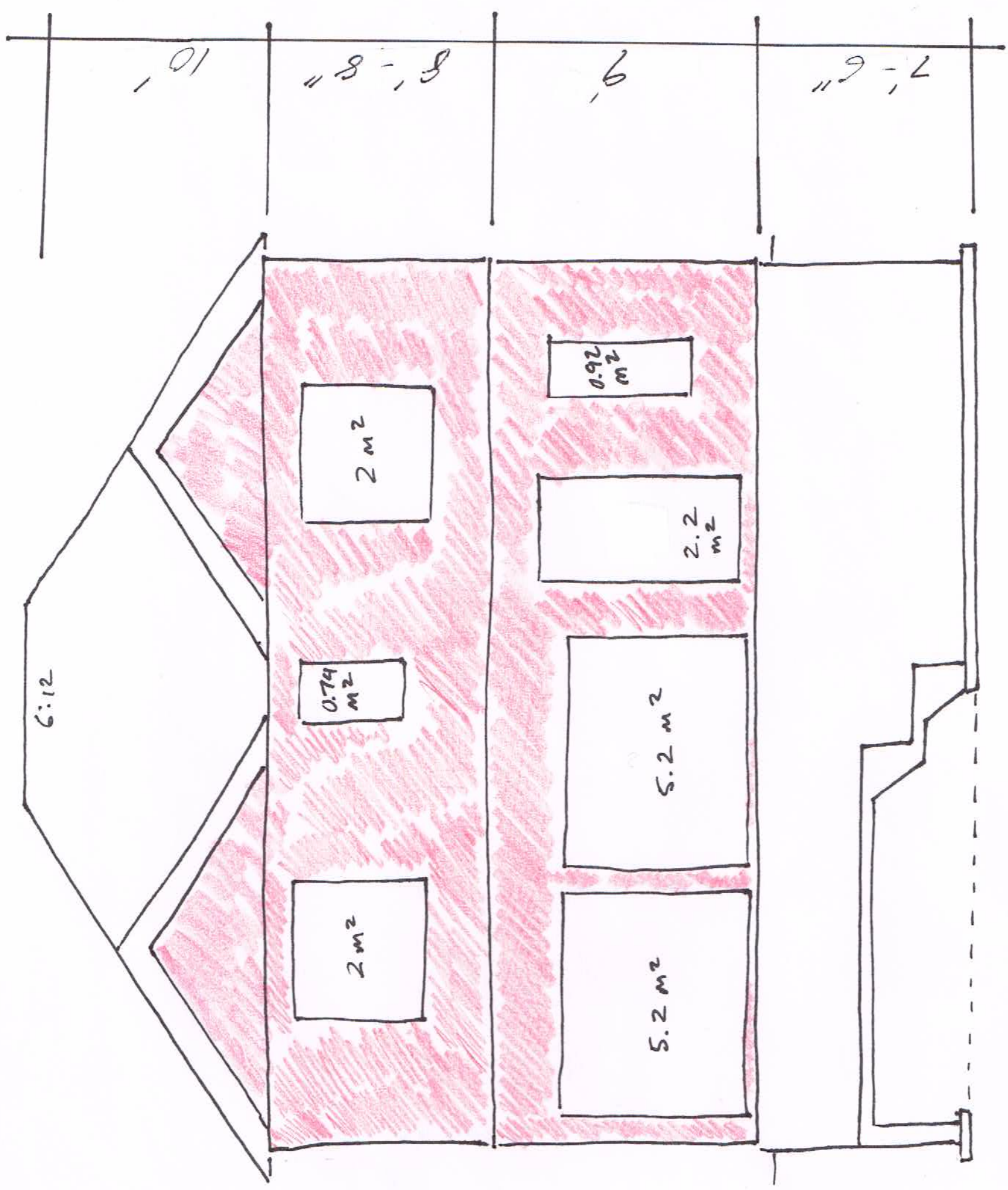




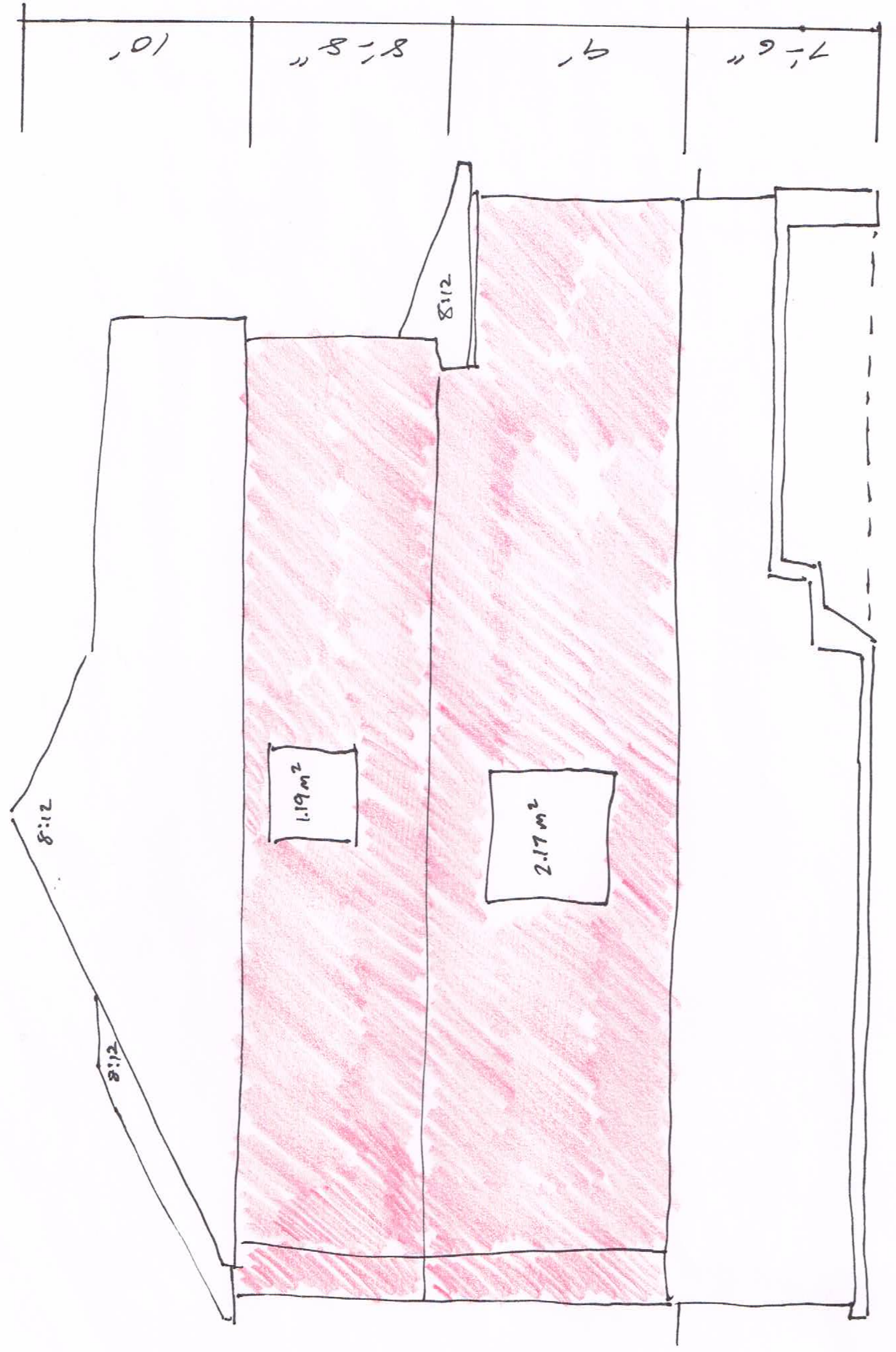



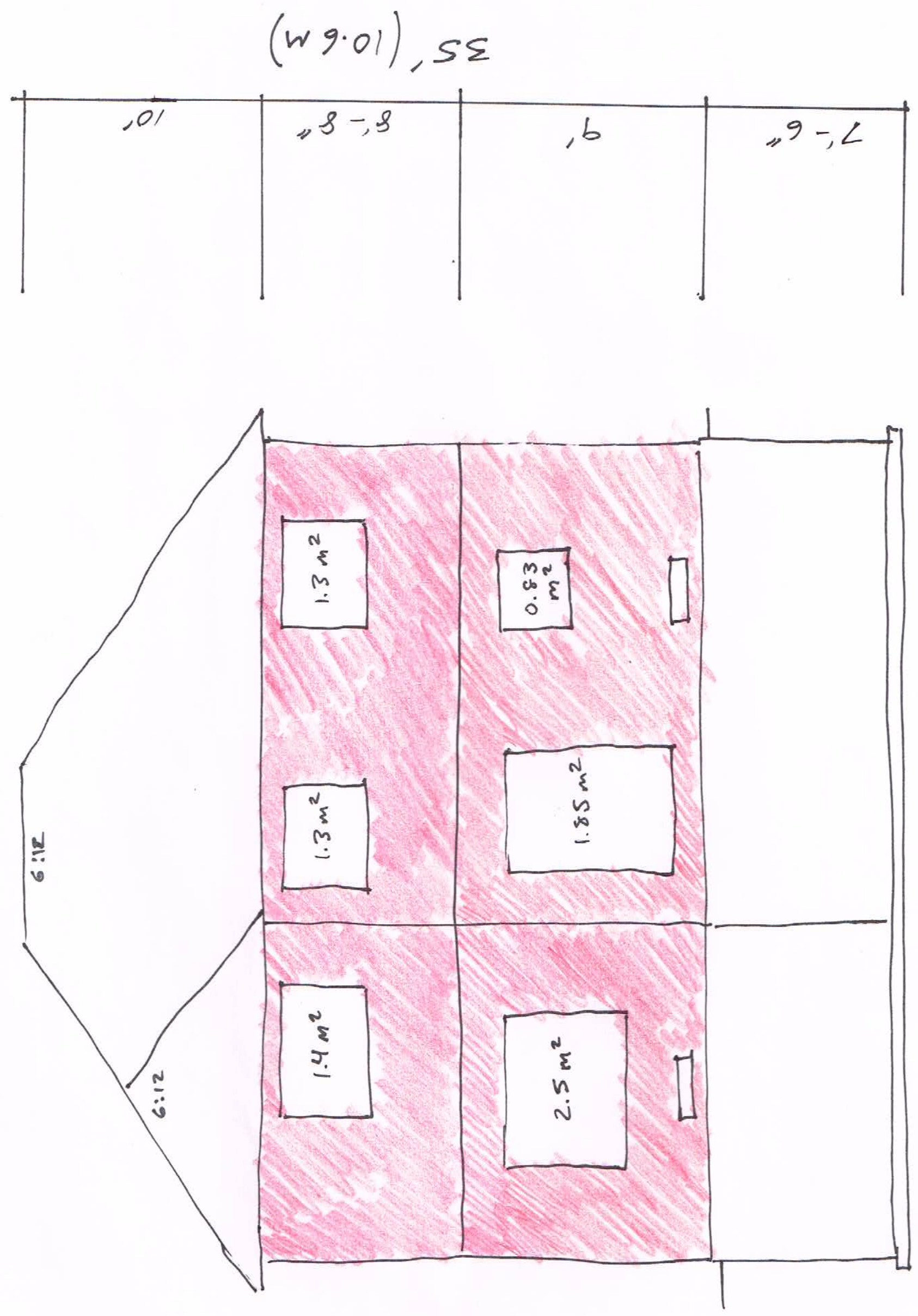


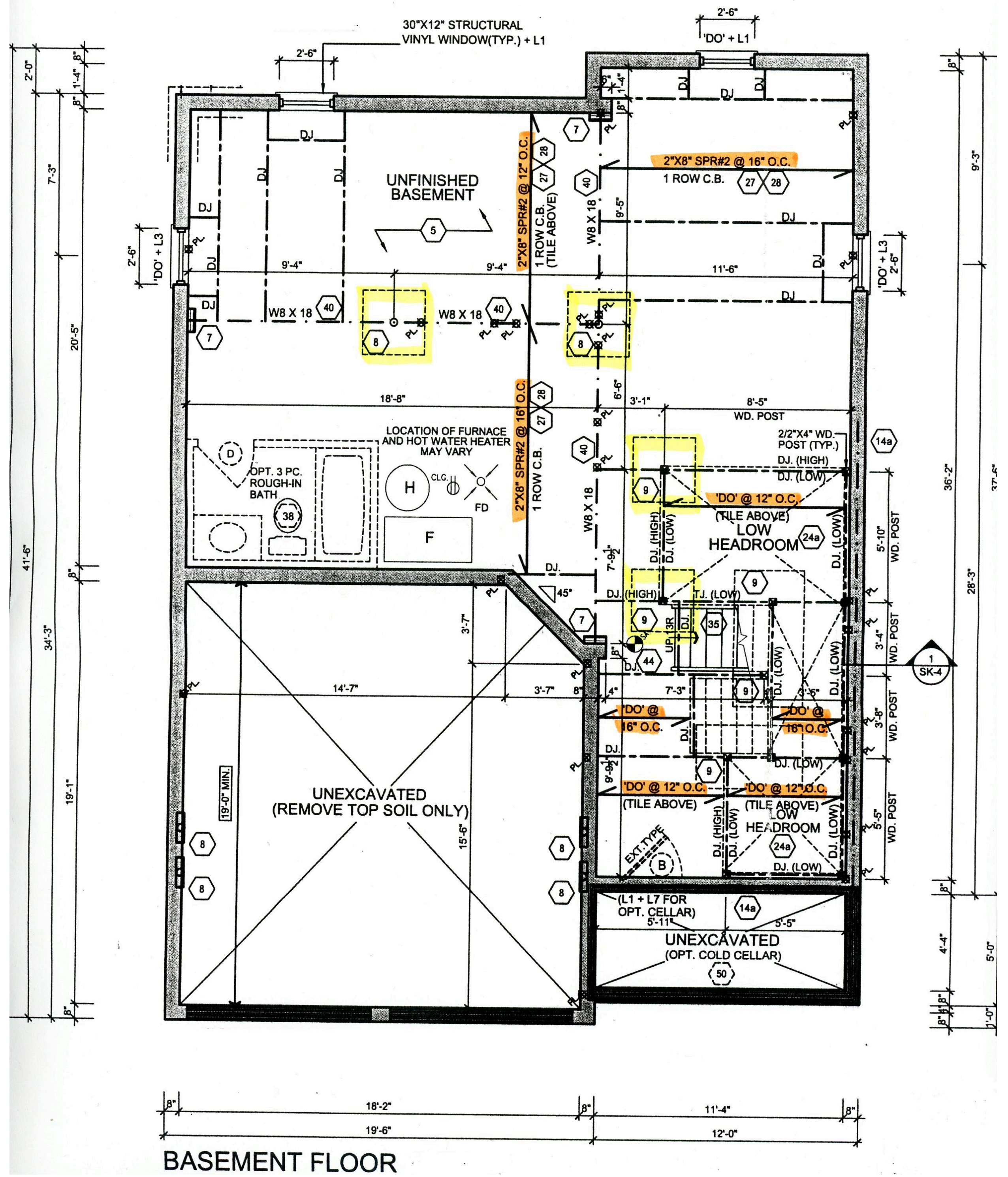



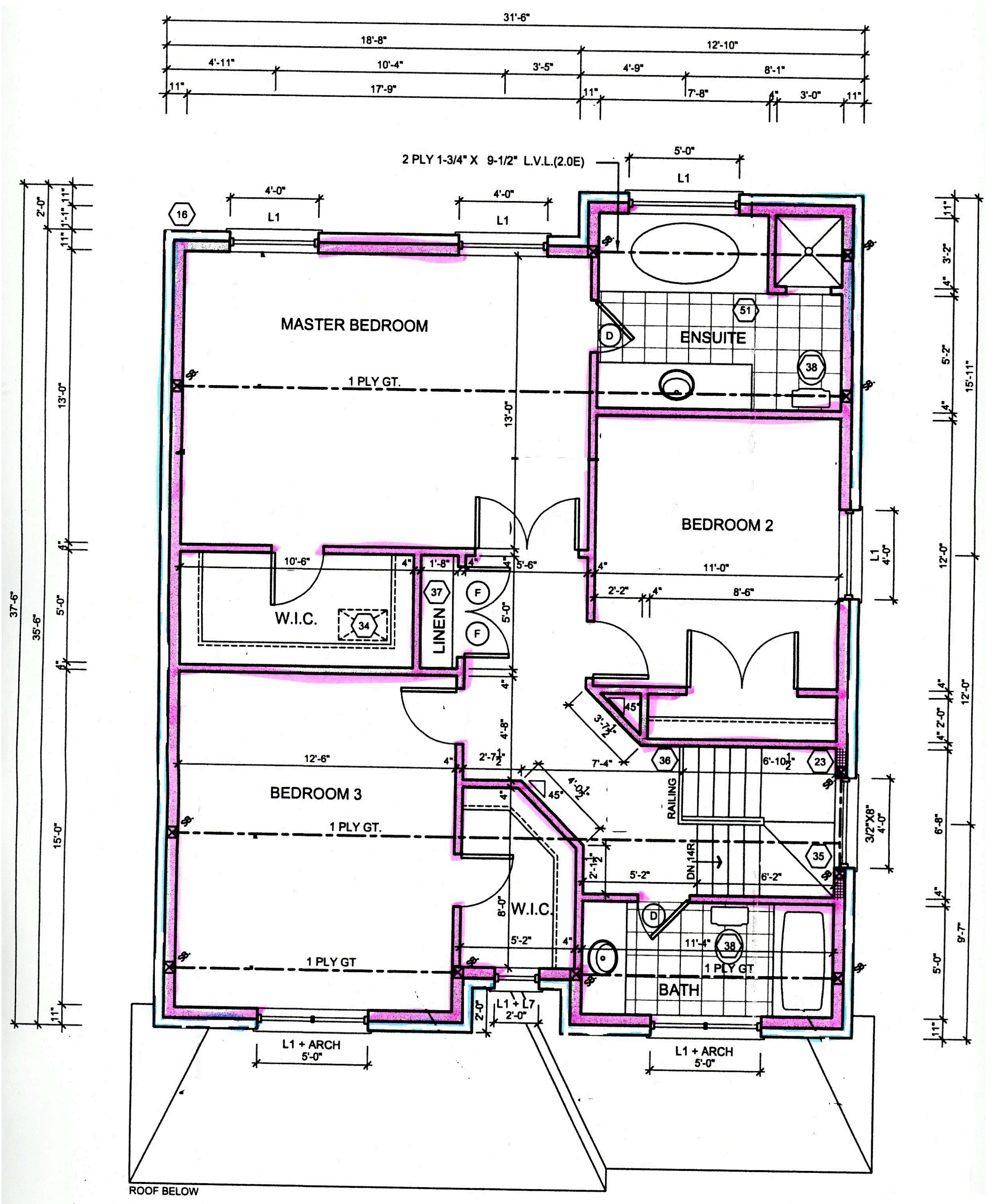

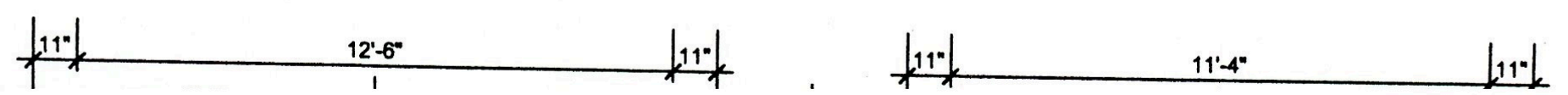




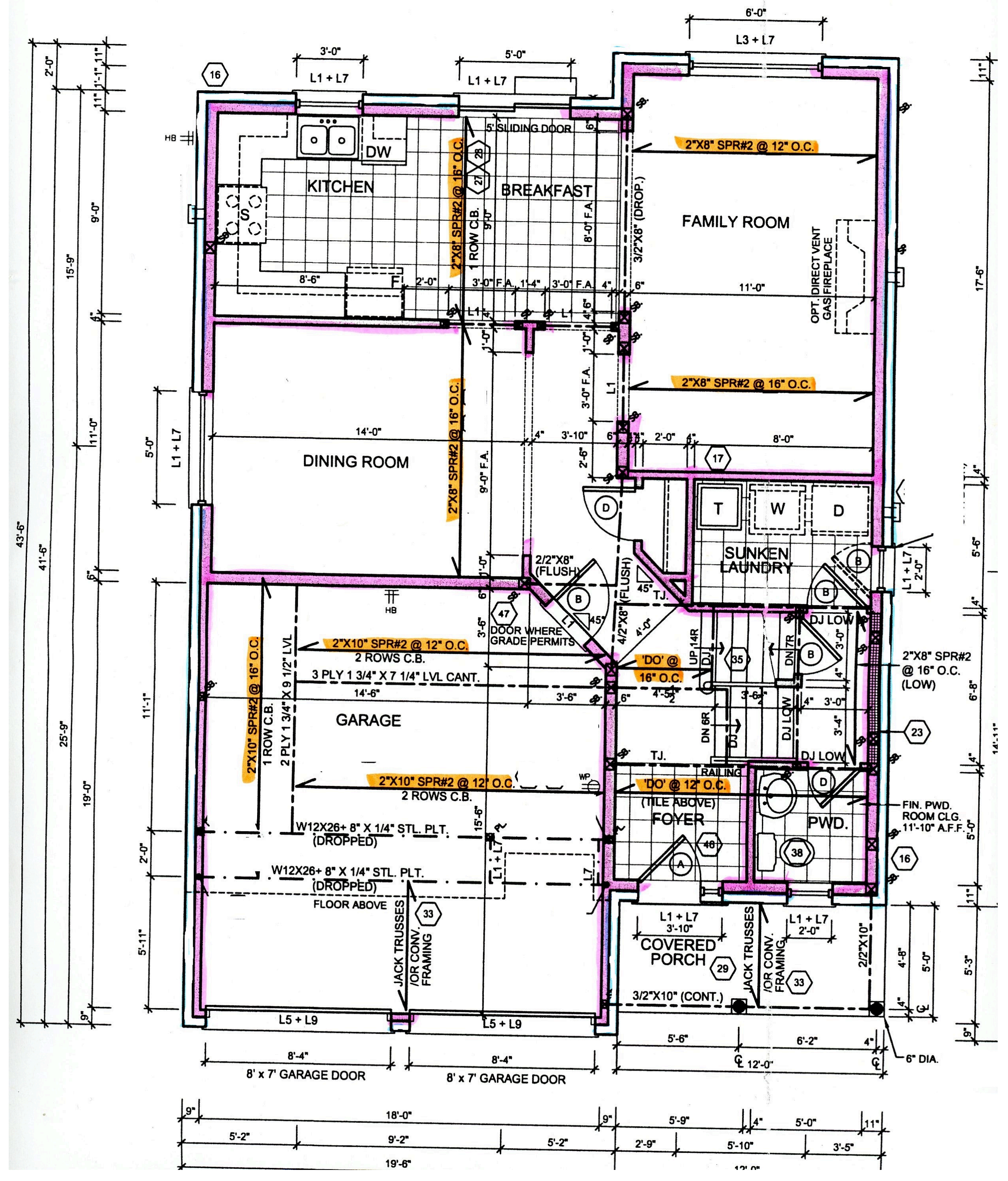




\section{House-A: Material Quantity and Weight}

\begin{tabular}{|c|c|c|}
\hline \multicolumn{3}{|c|}{ Concrete Elements } \\
\hline Element & Quantity $\left(m^{3}\right)$ & Weight $\left(\mathrm{kg}^{\star}\right)^{\star \star}$ \\
\hline Footing (15MPa) & 6 & 13,500 \\
\hline Column Footing (15MPa) & 1 & 2250 \\
\hline Walls (15 MPa) & 27 & 60,750 \\
\hline Basement and Cellar Slab (15MPa) & 8 & 18,000 \\
\hline Garage Slab (32MPa) & 3 & 6750 \\
\hline Interior Curb and Door Sills (15Mpa) & 0.22 & 490 \\
\hline Porch Slab (32MPa) & 1 & 2250 \\
\hline Grade Beam (32MPa) & 1 & 2250 \\
\hline Pre-cast Concrete Step & 0.071 & 160 \\
\hline Total & 47.3 & 106,484 \\
\hline
\end{tabular}

\begin{tabular}{|c|c|c|}
\hline \multicolumn{3}{|c|}{ Cladding (Masonry) } \\
\hline Element & Quantity & Weight $(\mathrm{kg})$ \\
\hline 90 mm Brick Veneer* & $202\left(m^{2}\right)$ & 41,417 \\
\hline 100 mm Concrete Blocks ${ }^{* *}$ & $13\left(m^{2}\right)$ & 1905 \\
\hline Stone Sills $100 \mathrm{~mm} \times 150 \mathrm{~mm}^{\star \star \star}$ & $29(\mathrm{~m})$ & 1143 \\
\hline Stone Headers $100 \mathrm{~mm} \times 200 \mathrm{~mm}^{* * * *}$ & $11(\mathrm{~m})$ & 590 \\
\hline Total & & 45,381 \\
\hline \multicolumn{3}{|c|}{$\begin{array}{l}\text { "some sources say } 39 \mathrm{lbs} / \mathrm{ft}^{2} \text { or } 42 \mathrm{lbs} / \mathrm{ft}^{2}, 42 \mathrm{lbs} / \mathrm{ft} 2 \text { is used for the calculation } \\
{ }^{* \star} \text { assumed as } 30 \mathrm{lbs} / \mathrm{ft}^{2} \text {, source: Florida Building Code } \\
{ }^{* * \star} \text { assumed as } 39.4 \mathrm{~kg} / \mathrm{m} \text {, source: TecCast Traditional Cills } \\
{ }^{* * \star} \text { assumed as } 53.6 \mathrm{~kg} / \mathrm{m} \text {, source: TecCast Traditional Cills }\end{array}$} \\
\hline
\end{tabular}

\begin{tabular}{|c|c|c|}
\hline \multicolumn{3}{|c|}{ Wood Ground Floor Framing } \\
\hline Element & Quantity & Weight (kg) \\
\hline Sill Plate $38 \times 89 \mathrm{~mm}\left(2 " x 4^{\prime \prime}\right)^{\star \star}$ & $50(\mathrm{~m})$ & 95 \\
\hline Beam Strap 19x89mm (1"x4") & $32(\mathrm{~m})$ & 53 \\
\hline \multicolumn{3}{|l|}{ Header Joists } \\
\hline $2 \times 8 \times 10^{\prime}(38 \times 184 \times 3050 \mathrm{~mm})^{\star \star \star}$ & 4 (pcs) & 48 \\
\hline 2x8x12' (38x184x3660mm) & 5 (pcs) & 71.8 \\
\hline $2 \times 8 \times 14$ ' (38x184x4270mm) & 1 (pcs) & 16.8 \\
\hline \multicolumn{3}{|l|}{ Common Joists } \\
\hline 2x8x8' (38x184x2440mm) & 37 (pcs) & 354 \\
\hline $2 \times 8 \times 10^{\prime}(38 \times 184 \times 3050 \mathrm{~mm})$ & 15 (pcs) & 180 \\
\hline $2 \times 8 \times 12^{\prime}(38 \times 184 \times 3660 \mathrm{~mm})$ & 13 (pcs) & 187 \\
\hline
\end{tabular}




\begin{tabular}{|c|c|c|}
\hline $2 \times 8 \times 14{ }^{\prime}(38 \times 184 \times 4270 \mathrm{~mm})$ & 92 (pcs) & 1542 \\
\hline $2 \times 8 \times 10$ ' (38x184x3050mm) & 4 (pcs) & 48 \\
\hline \multicolumn{3}{|l|}{ Bridging } \\
\hline 2"x2" (38x38mm) 300 O.C. ${ }^{\star \star \star \star}$ & 36 (sets) & 21 \\
\hline 2"x2" (38x38mm) 400 O.C. & 49 (sets) & 40 \\
\hline \multicolumn{3}{|l|}{ Strapping } \\
\hline 1"x3" (19x64mm) ${ }^{\star \star \star \star \star ~}$ & $12(\mathrm{~m})$ & 19 \\
\hline \multicolumn{3}{|l|}{ Sheathing } \\
\hline 5/8" (15.9mm) Sheathing ${ }^{* * * * * *}$ & 41 (shts) & 1271 \\
\hline Total & & 3,946 \\
\hline
\end{tabular}

\begin{tabular}{|c|c|c|}
\hline \multicolumn{3}{|c|}{ Wood Second Floor Framing } \\
\hline Element & Quantity & Weight (kg) \\
\hline Wood Column 140x140mm (6"x6") & 2 & 59 \\
\hline Beam Strap 19x89 (1"x4") & $22(\mathrm{~m})$ & 36 \\
\hline \multicolumn{3}{|l|}{ Header Joists } \\
\hline $2 \times 8 \times 12^{\prime}(38 \times 184 \times 3660 \mathrm{~mm})$ & 5 (pcs) & 72 \\
\hline \multicolumn{3}{|l|}{ Common Joists ${ }^{\star \star \star \star \star}$} \\
\hline 2x8x8' (38x184x2440mm) & 18 (pcs) & 172 \\
\hline $2 \times 8 \times 10^{\prime}(38 \times 184 \times 3050 \mathrm{~mm})$ & 16 (pcs) & 192 \\
\hline $2 \times 8 \times 12 '(38 \times 184 \times 3660 \mathrm{~mm})$ & 40 (pcs) & 575 \\
\hline $2 \times 8 \times 14$ ' (38x184x4270mm) & 40 (pcs) & 669 \\
\hline $2 \times 8 \times 10^{\prime}(38 \times 184 \times 3050 \mathrm{~mm})$ & 6 (pcs) & 158 \\
\hline \multicolumn{3}{|l|}{ Bridging } \\
\hline 2"x2" (38x38mm) 300 O.C. ${ }^{\star \star \star \star \star \star ~}$ & 18 (sets) & 10 \\
\hline 2"x2" (38x38mm) 400 O.C. & 76 (sets) & 59 \\
\hline \multicolumn{3}{|l|}{ Sheathing } \\
\hline 5/8" (15.9mm) Sheathing ${ }^{\star \star \star \star \star \star *}$ & 41 (shts) & 1271 \\
\hline Total & & 3,273 \\
\hline \multicolumn{3}{|c|}{ 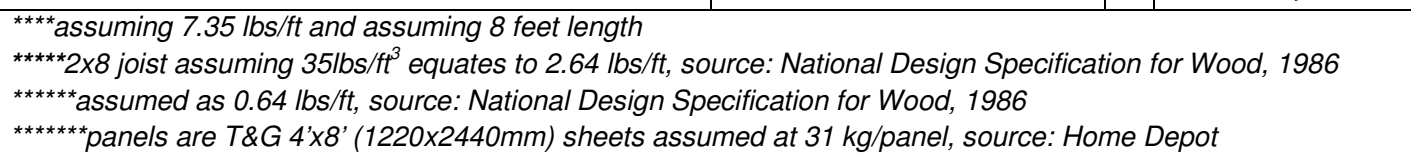 } \\
\hline
\end{tabular}

\section{Wood Basement Wall Framing}

\begin{tabular}{|l|c|c|}
\hline Element & Quantity & Weight $(\boldsymbol{k g})$ \\
\hline Plates (interior) 38x89mm (2"x4") & $13(\mathrm{~m})$ & 28 \\
\hline Studs (interior) 38x89x2440mm (2"x4"x8') & $12(\mathrm{pcs})$ & 56 \\
\hline
\end{tabular}




\begin{tabular}{|c|c|c|}
\hline Wood Solid Bearing 38x89x2440 (2"x4"x8') & 5 (pcs) & 23 \\
\hline Wood Solid Bearing 38x140x2440 (2"x6"x8') & 5 (pcs) & 36 \\
\hline Wood Strapping 38x89mm (2"x4") & $159(\mathrm{~m})$ & 303 \\
\hline Lintels 38x184x2440 (2"x8"x8') & 4 (pcs) & 38 \\
\hline Total & & 484 \\
\hline \multicolumn{3}{|c|}{$\begin{array}{l}{ }^{*} 1.28 \mathrm{lbs} / \mathrm{ft} \text {, source: National Design Specification for Wood, } 1986 \\
\star * 2 \mathrm{lbs} / \mathrm{ft} \text {, source: National Design Specification for Wood, } 1986 \\
\star * \star 35 \mathrm{lbs} / \mathrm{ft} \mathrm{t}^{3} \text { equates to } 2.64 \mathrm{lbs} / \mathrm{ft} \text {, source: National Design Specification for Wood, } 1986\end{array}$} \\
\hline
\end{tabular}

\begin{tabular}{|c|c|c|}
\hline \multicolumn{3}{|c|}{ Wood Ground Floor Wall Framing } \\
\hline Element & Quantity & Weight (kg) \\
\hline \multicolumn{3}{|l|}{ Plates } \\
\hline Exterior 38x89 (2"x4") ${ }^{*}$ & $35(\mathrm{~m})$ & 147 \\
\hline Exterior $38 \times 140(2 " \times 6 ")^{* *}$ & $151(\mathrm{~m})$ & 990 \\
\hline Interior 38x89 (2"x4") & $70(\mathrm{~m})$ & 294 \\
\hline Interior 38x140 (2"x6") & $45(\mathrm{~m})$ & 296 \\
\hline \multicolumn{3}{|l|}{ Studs $s^{\star * \star}$} \\
\hline Exterior 38x89 (2"x4") & 30 (pcs) & 139 \\
\hline Exterior 38x140 (2"x6") & 173 (pcs) & 1,256 \\
\hline Interior 38x89 (2"x4") & 75 (pcs) & 348 \\
\hline Interior 38x140 (2"x6") & 51 (pcs) & 370 \\
\hline \multicolumn{3}{|l|}{ Wall Bracing } \\
\hline Exterior 38x89x4270 (2"x8"x14') & 18 (pcs) & 302 \\
\hline Interior 38x89x4270 (2"x8"x14') & 8 (pcs) & 134 \\
\hline Backing 38x89mm (2"x4") & $38(\mathrm{~m})$ & 160 \\
\hline Wood Solid Bearing 38x89x2440mm (2"x4"x8') & 30 (pcs) & 140 \\
\hline Wood Solid Bearing 38x140x2440mm (2"x6"x8') & 65 (pcs) & 472 \\
\hline \multicolumn{3}{|l|}{ Lintels } \\
\hline 38x184x2440mm (2"x8"x8') & 17 (pcs) & 163 \\
\hline $38 \times 184 \times 3050 \mathrm{~mm}\left(2 " x 8 " x 10^{\prime}\right)$ & 10 (pcs) & 120 \\
\hline $38 \times 184 \times 3660 \mathrm{~mm}(2 " x 8 " \times 12 ')$ & 3 (pcs) & 43 \\
\hline $38 \times 235 \times 3050 \mathrm{~mm}\left(2^{\prime \prime} \times 10^{\prime \prime} \times 10^{\prime}\right)^{\star \star \star \star \star}$ & 3 (pcs) & 46 \\
\hline $38 \times 235 \times 3660 \mathrm{~mm}(2 " \times 10 " \times 12$ ') & 3 (pcs) & 55 \\
\hline $38 \times 286 \times 2440 \mathrm{~mm}\left(2^{\prime \prime} \times 12^{\prime \prime} \times 8^{\prime}\right)^{\star \star * \star \star \star}$ & 3 (pcs) & 45 \\
\hline LVL at Garage Front 45x235x2440mm & 2 (pcs) & 20 \\
\hline LVL at Garage Door 45×235×3050mm & 4 (pcs) & 48 \\
\hline LVL at Garage Front $45 \times 235 \times 6100 \mathrm{~mm}$ & 2 (pcs) & 48 \\
\hline Total & & 5636 \\
\hline \multicolumn{3}{|c|}{ 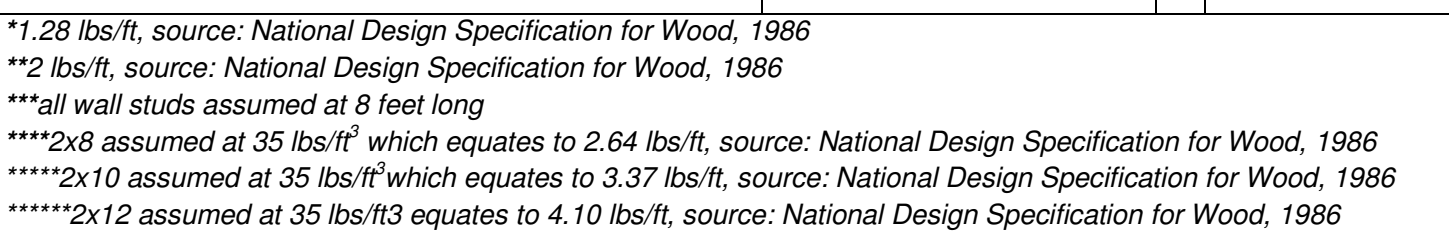 } \\
\hline
\end{tabular}




\begin{tabular}{|c|c|c|}
\hline \multicolumn{3}{|c|}{ Wood Second Floor Wall Framing } \\
\hline Element & Quantity & Weight (kg) \\
\hline \multicolumn{3}{|l|}{ Plates } \\
\hline Exterior 38x140 (2"x6") ${ }^{*}$ & $135(\mathrm{~m})$ & 886 \\
\hline Interior 38x89 (2"x4") & $140(\mathrm{~m})$ & 588 \\
\hline \multicolumn{3}{|l|}{ Studs ${ }^{\star \star *}$} \\
\hline Exterior 38x140 (2"x6") & 164 (pcs) & 1190 \\
\hline Interior 38x89 (2"x4") & 156 (pcs) & 724 \\
\hline \multicolumn{3}{|l|}{ Wall Bracing ${ }^{\star \star \star \star}$} \\
\hline Exterior 38x89x4270 (2"x8"x14') & 12 (pcs) & 201 \\
\hline Interior 38x89x4270 (2"x8"x14') & 8 (pcs) & 134 \\
\hline Backing 38x89mm (2"x4") & $75(\mathrm{~m})$ & 315 \\
\hline Wood Solid Bearing 38x140x2440mm (2"x6"x8') & 20 (pcs) & 145 \\
\hline \multicolumn{3}{|l|}{ Lintels } \\
\hline 38x184x2440mm (2"x8"x8') & 9 (pcs) & 86 \\
\hline $38 \times 184 \times 3050 \mathrm{~mm}\left(2 " \times 8 " \times 10^{\prime}\right)$ & 3 (pcs) & 36 \\
\hline $1 / 2^{\prime \prime}(12.7 \mathrm{~mm})$ Wall Sheathing $\left(4^{\prime} \times 8^{\prime}\right)^{\star \star \star \star \star}$ & 80 (shts) & 1423 \\
\hline 3/8" (9.5mm) Plywood Roof Sheathing & 80 (shts) & 1231 \\
\hline Total & & 6959 \\
\hline \multicolumn{3}{|c|}{ 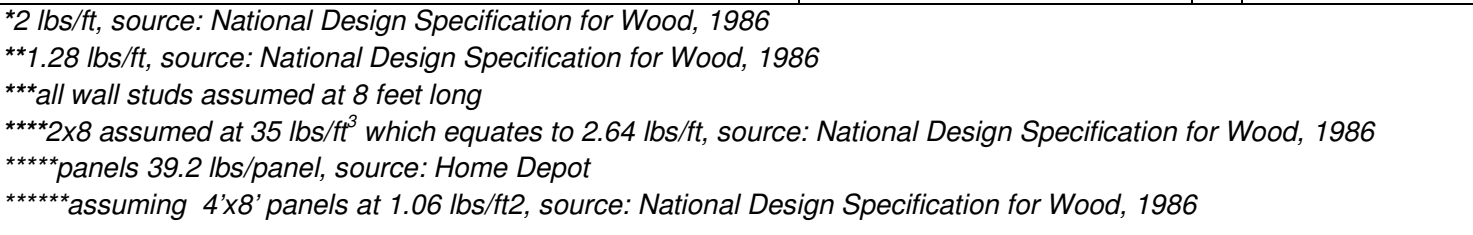 } \\
\hline
\end{tabular}

\section{Gypsum}

With the floor area being $189 \mathrm{~m}^{2}$, and a ceiling height of 8 feet, a factor of 3.4 (to estimate the total interior gypsum board required per $\mathrm{ft}^{2}$ of flooring area) was used which was retrieved from a local Toronto drywall tapping company (Drywall Installation and Taping Service Toronto, 2011). Accordingly, the total gypsum need for House-A is as follows:

Total Area of Interior Gypsum Board Installation (ft $\left.{ }^{2}\right): 6,898$

Total Number of Panels (4'x8'): 216

The weight per panel for typical sheetrock drywall is $60.8 \mathrm{lbs} /$ panel, which equates to $1.9 \mathrm{lbs} / \mathrm{ft}^{2}$ of drywall (Home Depot, 2011). Therefore, the total weight allocated to gypsum board panels for 
House-A is $13,132 \mathrm{lbs}$, which is $5957 \mathrm{~kg}$. Although this a general estimation of the required interior gypsum board needed for House-A, whereby using a ratio (3.4) to the floor area, such as estimation is fairly accurate and is commonly used in the industry (Drywall Installation and Taping Service Toronto, 2011).

\section{Asphalt Roofing}

The estimation for asphalt roofing used for the roof of House-A is also calculated in a similar factored method. The specifications of House-A provides the weight ratio for the asphalt singles to be $30.5 \mathrm{~kg} / \mathrm{m}^{2}$, which is representative of typical asphalt shingles used in the industry (Boise Cascade, 2011). Given the three different roof slopes of House-A, the total area per slope was calculated and the total roofing area was determined using a slope rake factor as shown in Table 10 (Sentrigard, 2012). Given the weight ratio of $30.5 \mathrm{~kg} / \mathrm{m}^{2}$, and the total area needed for shingles is $97 \mathrm{~m}^{2}\left(1,048 \mathrm{ft}^{2}\right)$, the total asphalt shingles weight for House-A is 2,959 kg. 
House-A Quantity Recap

\begin{tabular}{|c|c|c|}
\hline $\begin{array}{l}\text { Cast-In-Place } \\
\text { Concrete }\end{array}$ & & \\
\hline $\begin{array}{l}15 \mathrm{MPa} \text { Foundation } \\
\text { Footing }\end{array}$ & $\begin{array}{l}55 \times 0.48 \times 0.16=4.2 \\
(+1.4)\end{array}$ & $6 \mathrm{~m} 3$ \\
\hline $\begin{array}{l}15 \mathrm{MPa} \text { Column } \\
\text { Footing } \\
\end{array}$ & $\begin{array}{l}1 \times 1 \times 0.46=0.46 \\
(+0.62)\end{array}$ & $1 \mathrm{~m} 3$ \\
\hline $\begin{array}{l}15 \mathrm{MPa} \text { Basement } \\
\text { Wall }\end{array}$ & $\begin{array}{l}50.26 \times 2.26 \times 0.20= \\
22.7\end{array}$ & \\
\hline $15 \mathrm{MPa}$ Cellar Wall & $\begin{array}{l}4.66 \times 2.14 \times 0.20=2 \\
(+0.06)\end{array}$ & \\
\hline $15 \mathrm{MPa}$ Garage Wall & $\begin{array}{l}11.5 \times 1.23 \times 0.20=2.84 \\
(+0.16)\end{array}$ & \\
\hline $\begin{array}{l}\text { Total in Foundation } \\
\text { Wall }\end{array}$ & & $27 \mathrm{~m} 3$ \\
\hline $\begin{array}{l}15 \mathrm{MPa} \text { Basement } \\
\text { Slab }\end{array}$ & $14 \times 10.75 \times 0.08(-4.3)$ & $7.65 \mathrm{~m} 3$ \\
\hline $15 \mathrm{MPa}$ Cellar Slab & $1.34 \times 2.78 \times 0.08$ & $0.30 \mathrm{~m} 3$ \\
\hline 32 MPa Garge Slab & $5.5 \times 5.95 \times 0.1$ & $3 \mathrm{~m} 3$ \\
\hline $32 \mathrm{MPa}$ Proch Slab & $3.10 \times 1.66 \times 0.13$ & $1 \mathrm{~m} 3$ \\
\hline 32 Mpa Grade Beam & $5.5 \times 0.25 \times 0.20$ & $1 \mathrm{~m} 3$ \\
\hline 15 MPa Door Sills & $2 \times 0.29 \times 0.15$ & $0.2 \mathrm{~m} 3$ \\
\hline
\end{tabular}




\begin{tabular}{|l|l|l|l|l|l|l|}
\hline $\begin{array}{l}\text { Brick Veneer / } \\
\text { Masonry }\end{array}$ & & & & & & \\
\hline & & $51 \times$ & & & & \\
\hline & 2.75 & & & $141 \mathrm{~m} 2$ & \\
\hline & & & & & & \\
\hline & & $46 \times$ & & & $121 \mathrm{~m} 2$ & \\
\hline & 2.65 & & & $(-59)$ & $202 \mathrm{~m} 2$ & \\
\hline & & & & & & \\
\hline Stone Sirst Floor & & $1.72 \times 6$ & & & & \\
\hline & & $1.03 \times 1$ & & & & \\
\hline & $1.26 \times$ & & & & \\
\hline & 14 & & & & & \\
\hline Stone Headers & & $2.76 \times 2$ & & & & \\
\hline & & $1.31 \times 1$ & & & & \\
\hline & & $2.03 \times 2$ & & & $11 \mathrm{~m}$ & \\
\hline
\end{tabular}

\begin{tabular}{|c|c|c|}
\hline Wood Recap & & \\
\hline $\begin{array}{l}\text { Basement Wal } \\
\text { Framing }\end{array}$ & & \\
\hline & $38 \times 89$ plates & $13 \mathrm{~m}$ \\
\hline & $38 \times 89 \times 2440$ studs & 12 pcs \\
\hline & $38 \times 89 \times 2440$ wood & 5 pcs \\
\hline & $38 \times 89$ strapping & $159 \mathrm{~m}$ \\
\hline & $38 \times 184 \times 2440$ lintels & 4 pcs \\
\hline First Floor Fran & & \\
\hline & Sill Plate & $50 \mathrm{~m}$ \\
\hline & Beam Strap & $32 \mathrm{~m}$ \\
\hline Header Joist & & \\
\hline & $38 \times 184 \times 3050$ & 4 pcs \\
\hline & $38 \times 184 \times 3660$ & 5 pcs \\
\hline & $38 \times 184 \times 4270$ & $1 \mathrm{pcs}$ \\
\hline Common Joist & & \\
\hline & $38 \times 184 \times 2440$ & 37 pcs \\
\hline & $38 \times 184 \times 3050$ & $15 \mathrm{pcs}$ \\
\hline & $38 \times 184 \times 3660$ & 13 pcs \\
\hline
\end{tabular}




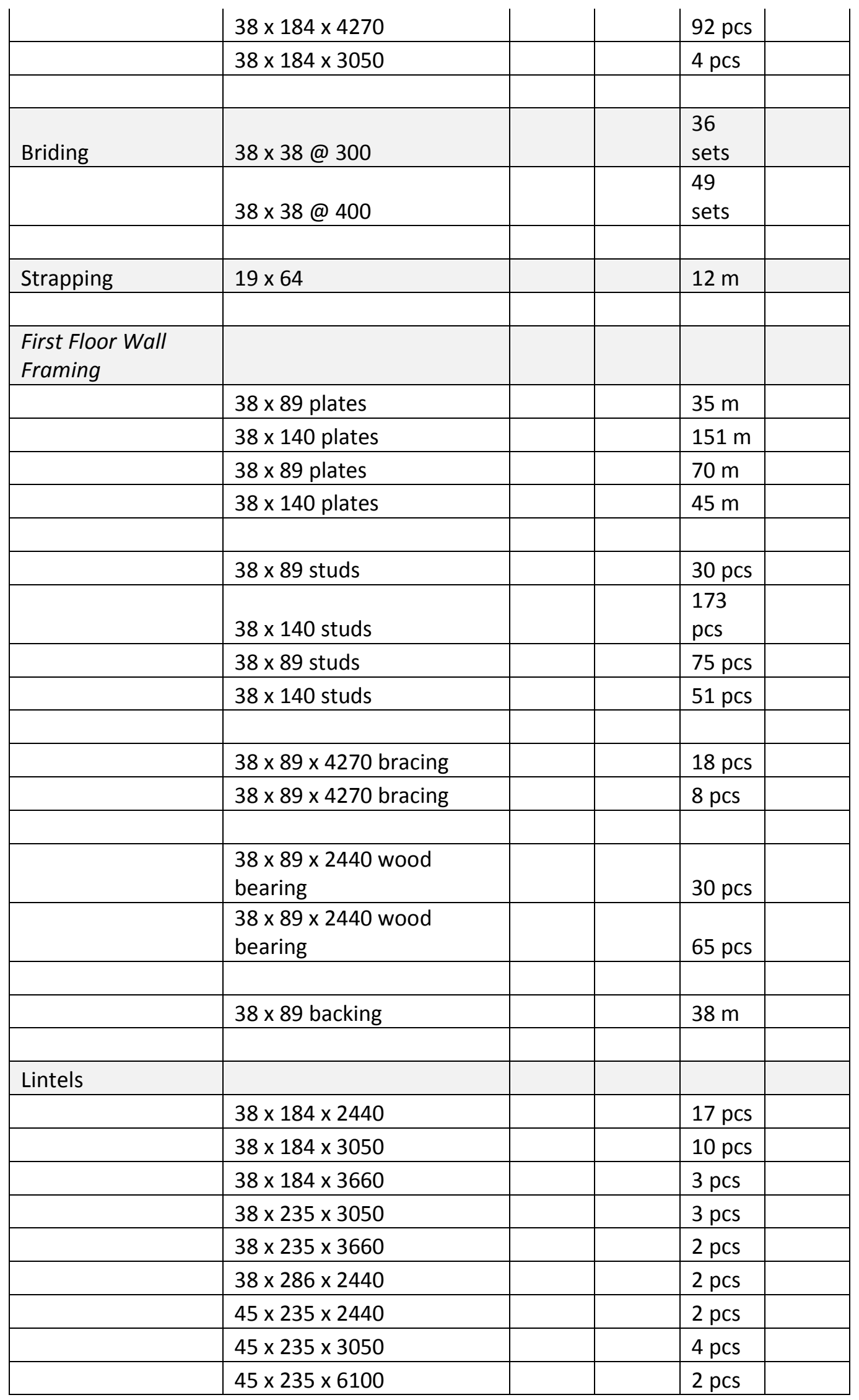




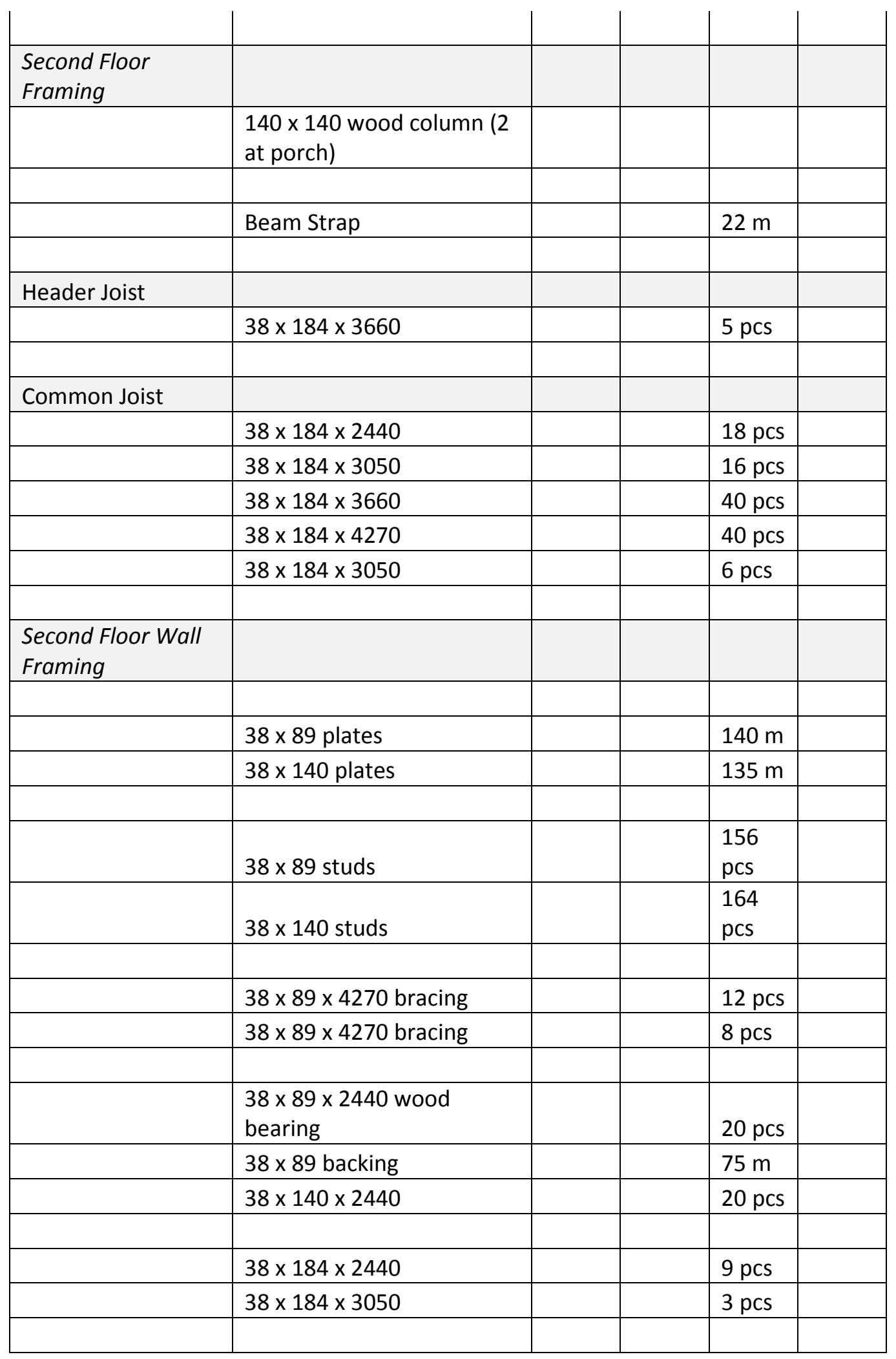




\section{Appendix B: House-B Information}

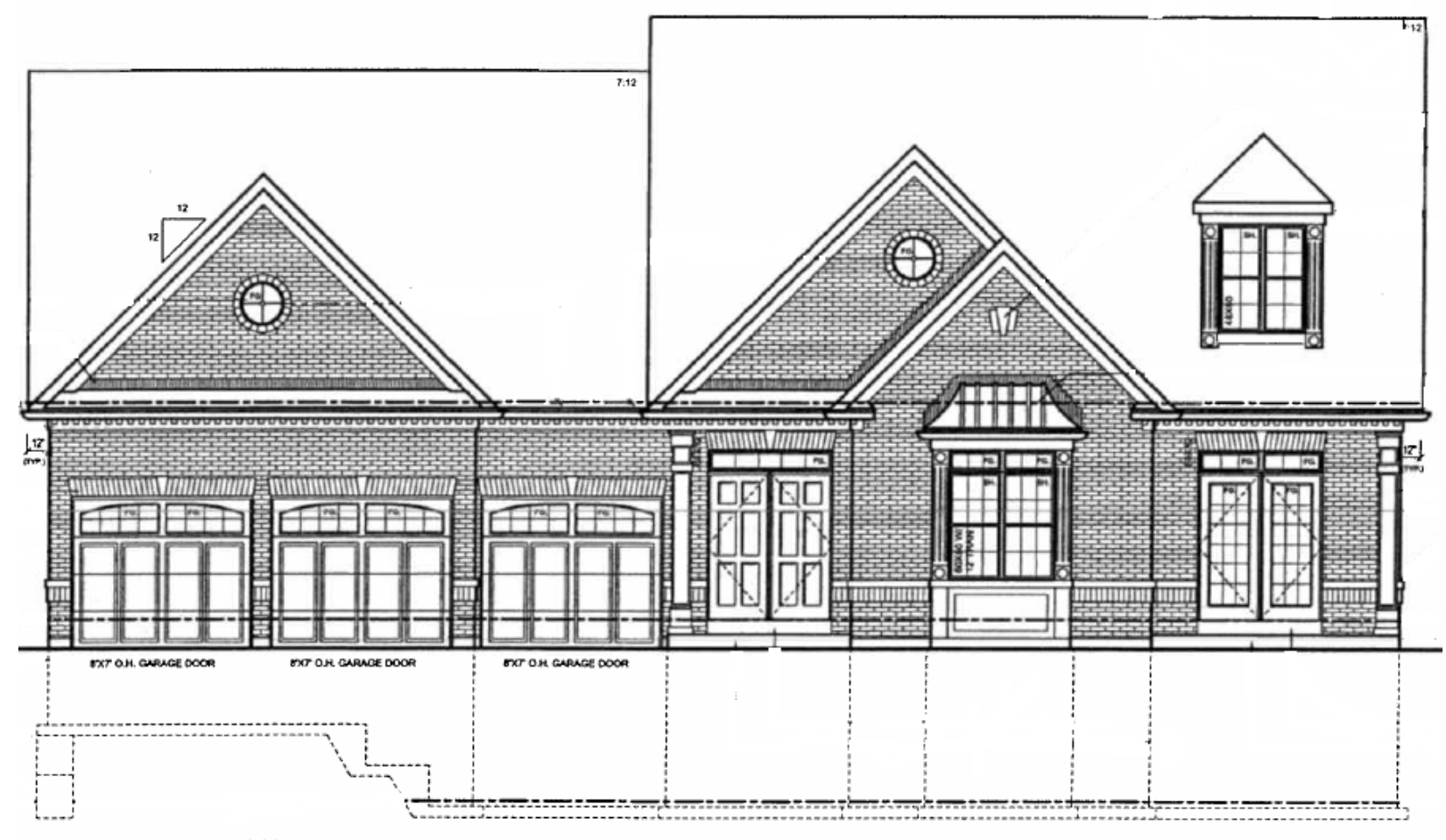

FRONT ELEVATION

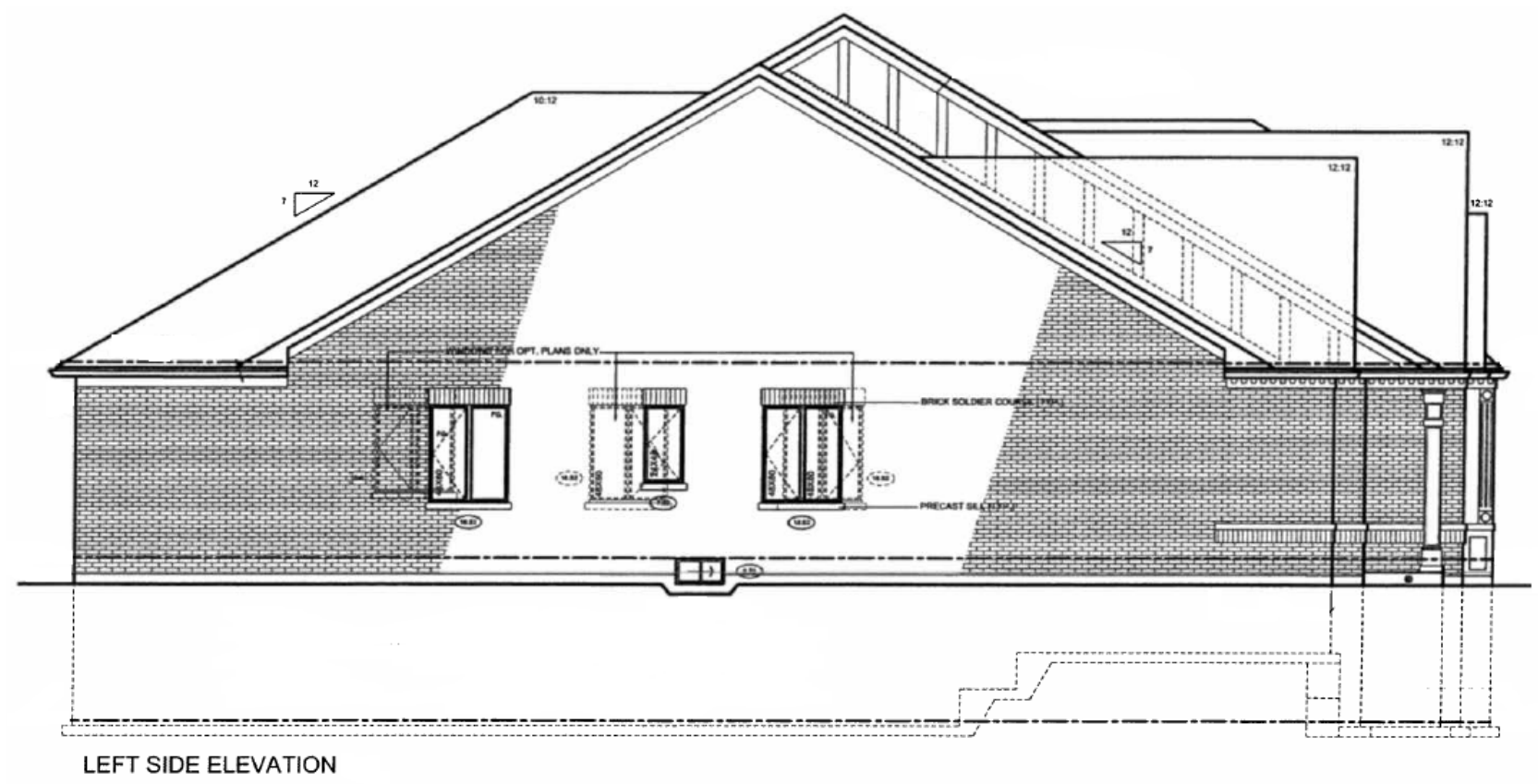



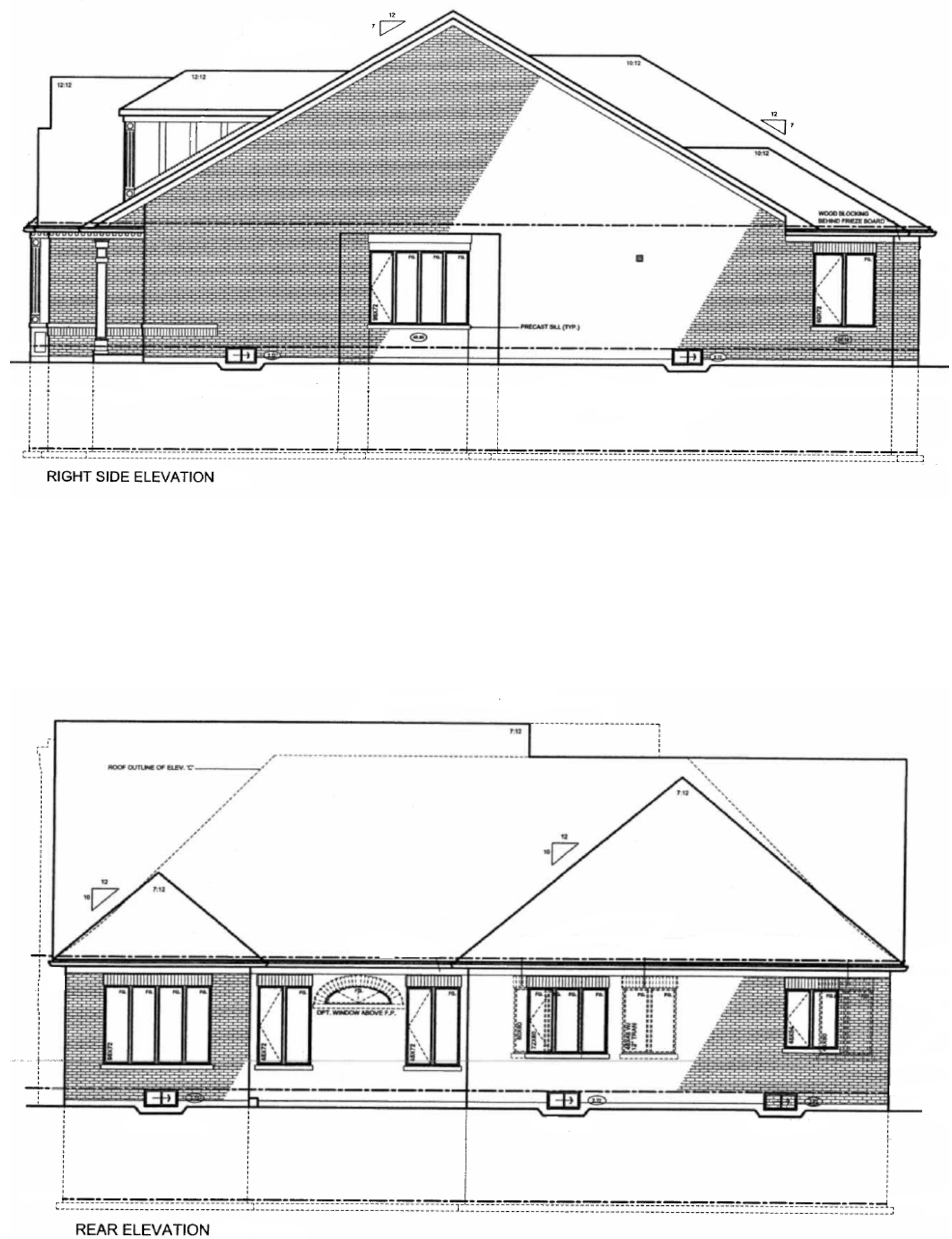


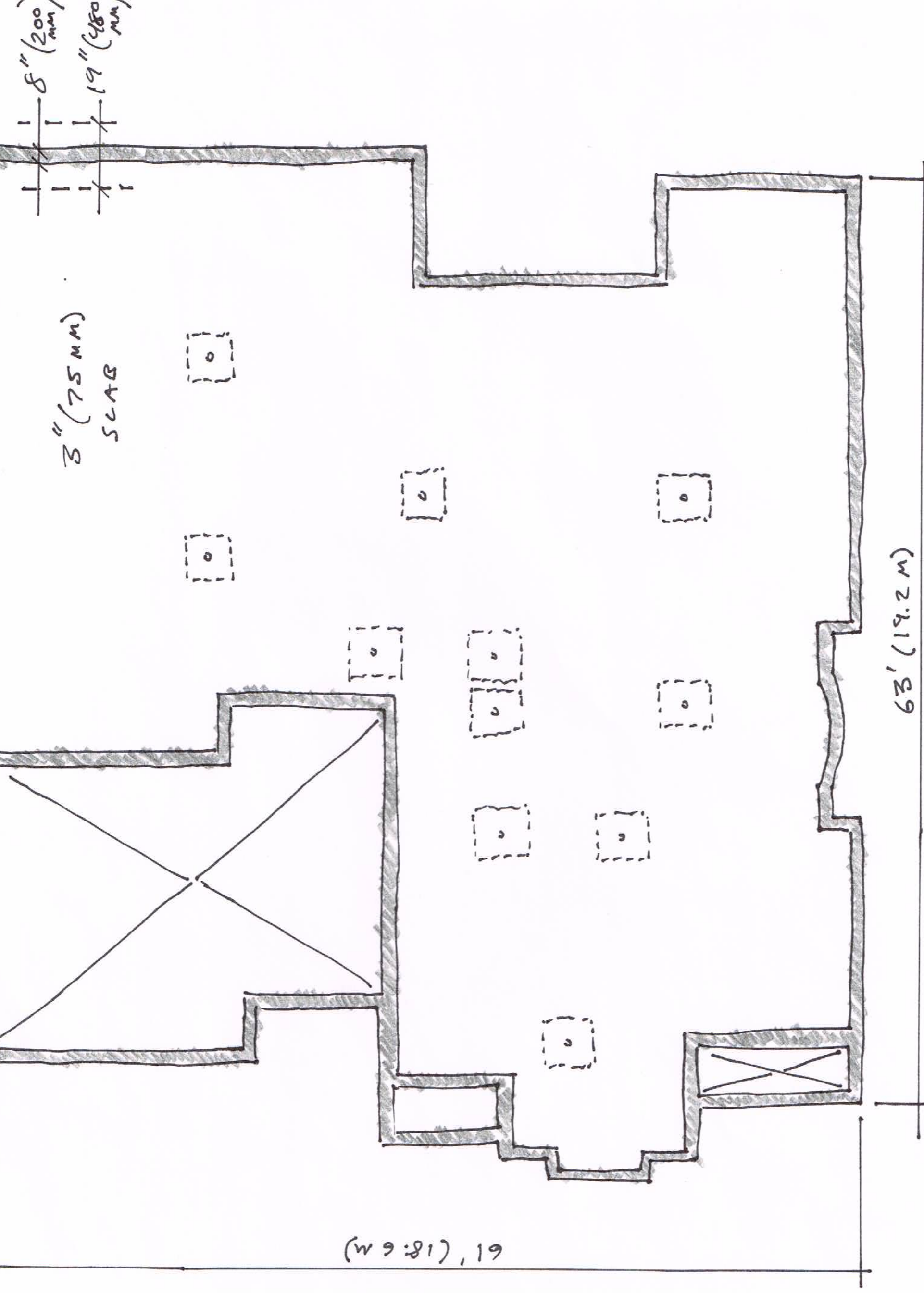


$(w 8.01), 558$

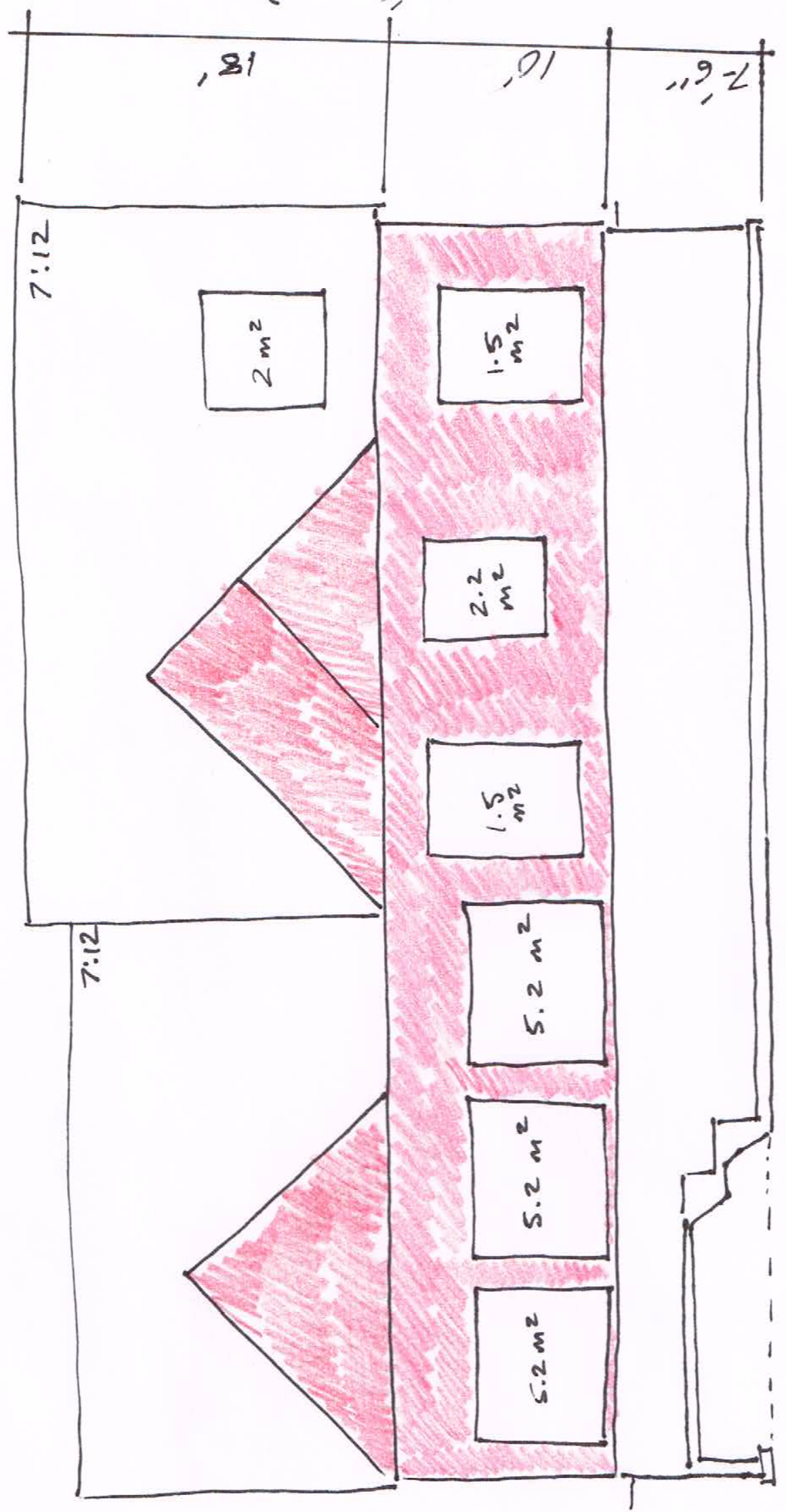



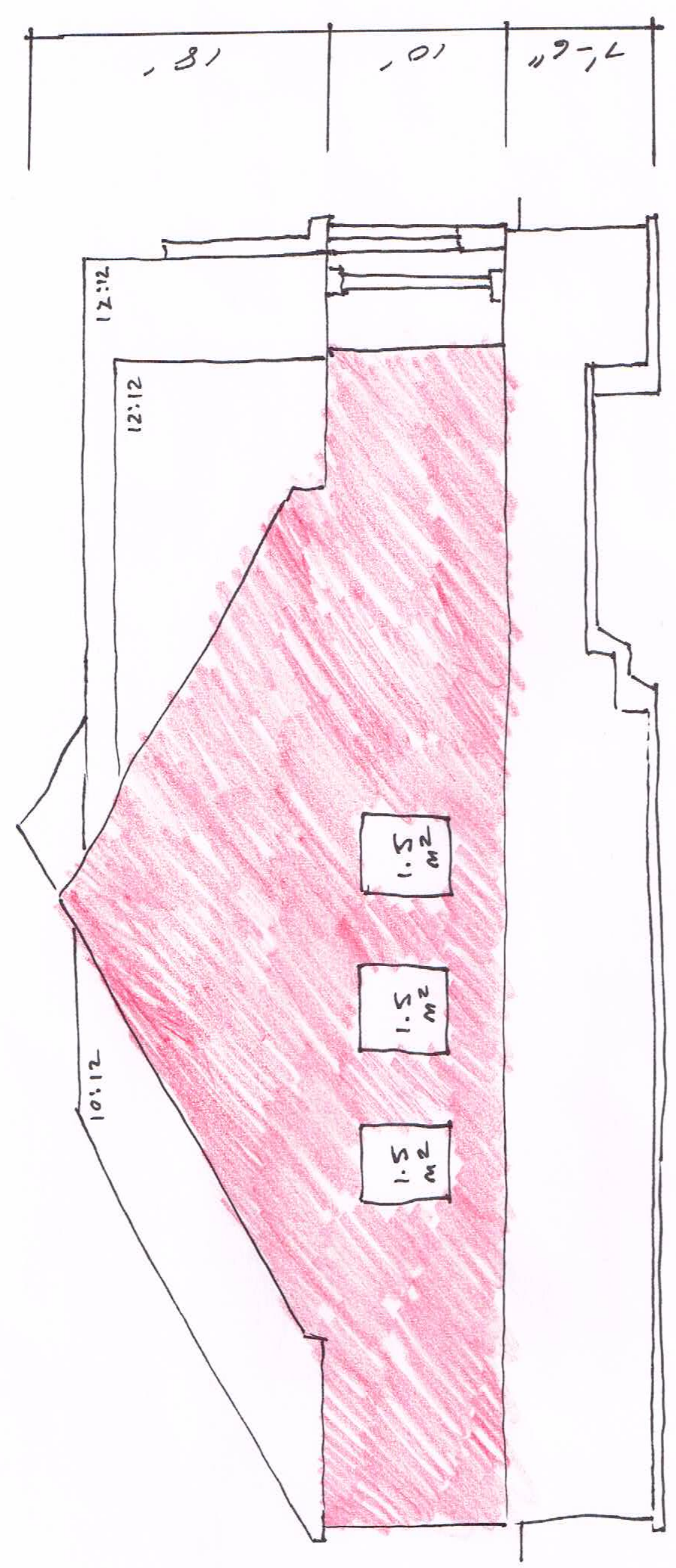

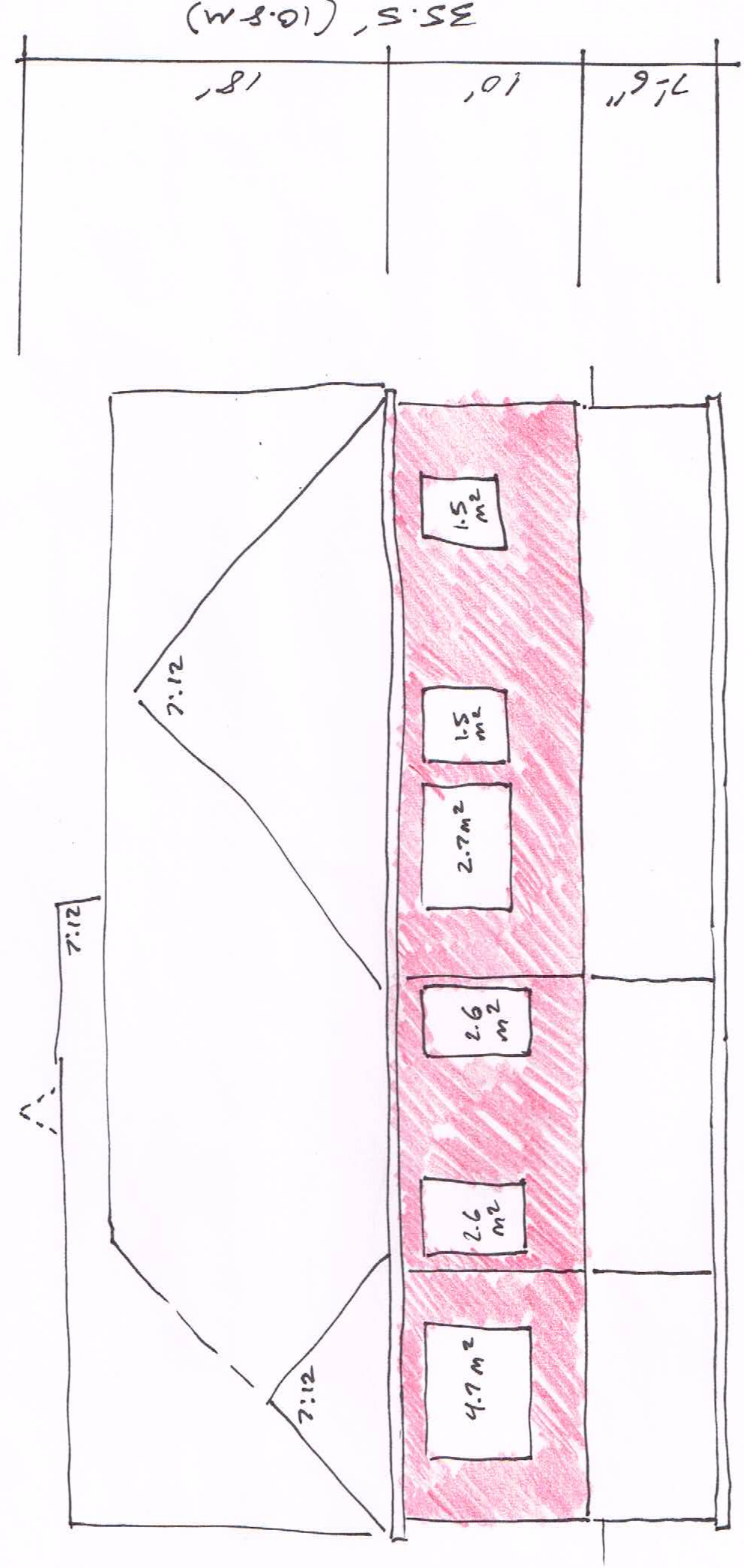


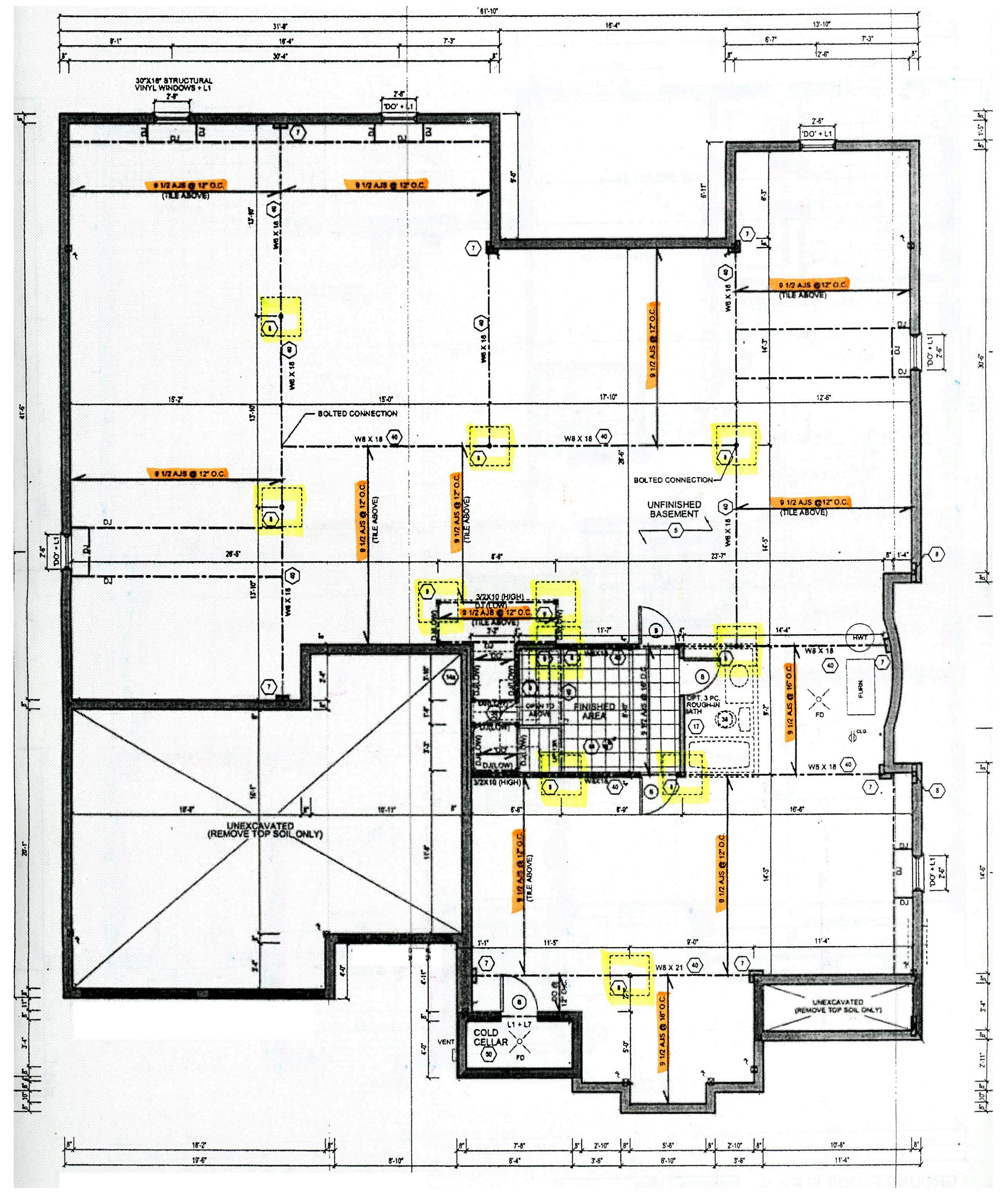




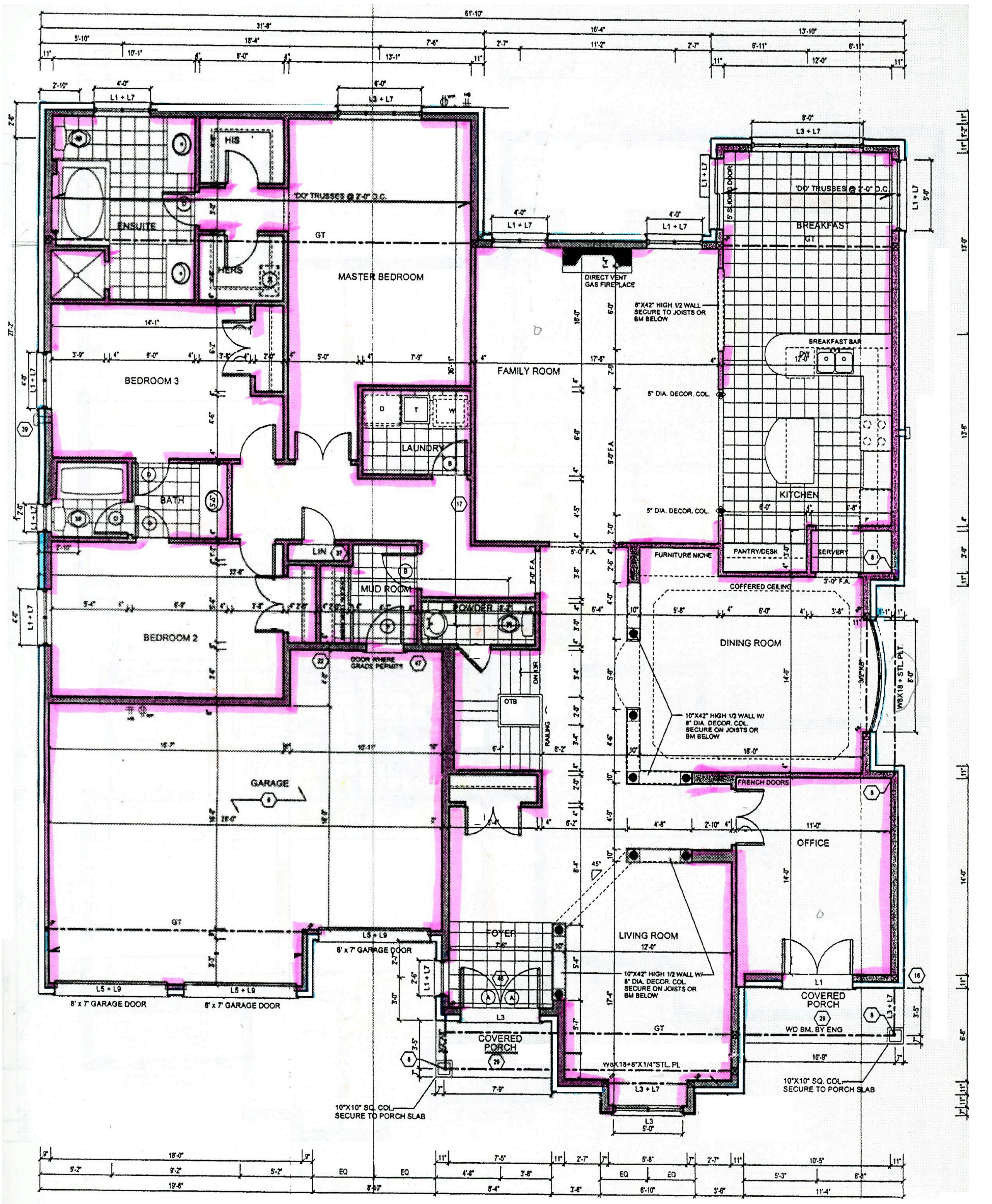




\section{House-B: Material Quantity and Weight}

\begin{tabular}{|c|c|c|}
\hline \multicolumn{3}{|c|}{ Concrete Elements } \\
\hline Element & Quantity $\left(m^{3}\right)$ & Weight $\left(\mathrm{kg}^{\star}\right)^{\star \star}$ \\
\hline Footing (15MPa) & 7 & 15,750 \\
\hline Column Footing (15MPa) & 6.2 & 13,950 \\
\hline Walls (15 MPa) & 44.4 & 99,900 \\
\hline Basement and Cellar Slab (15MPa) & 21.8 & 49,050 \\
\hline Garage Footing (15MPa) & 1.4 & 3,150 \\
\hline Garage Wall (15Mpa) & 4.2 & 9,450 \\
\hline Garage Slab (32MPa) & 5.2 & 11,700 \\
\hline Door Sills (15Mpa) & 0.1 & 225 \\
\hline Porch Slab (32MPa) & 1.3 & 2,925 \\
\hline Total & 91.6 & 206,640 \\
\hline
\end{tabular}

\begin{tabular}{|c|c|c|}
\hline \multicolumn{3}{|c|}{ Cladding (Masonry) } \\
\hline Element & Quantity & Weight (kg) \\
\hline 90 mm Brick Veneer* & $312\left(m^{2}\right)$ & 63,973 \\
\hline $100 \mathrm{~mm}$ Concrete Blocks ${ }^{\star *}$ & $1\left(\mathrm{~m}^{2}\right)$ & 145 \\
\hline Stone Sills $100 \mathrm{~mm} \times 150 \mathrm{~mm}^{\star * * *}$ & $21(\mathrm{~m})$ & 827 \\
\hline Total & & 64,945 \\
\hline \multicolumn{3}{|c|}{$\begin{array}{l}\text { *assumed as } 44 \mathrm{lbs} / \mathrm{ft}^{2} \text { is used for the calculation } \\
{ }^{* \star} \text { assumed as } 30 \mathrm{lbs} / \mathrm{ft}^{2} \text {, source: Florida Building Code } \\
{ }^{* \star *} \text { assumed as } 39.4 \mathrm{~kg} / \mathrm{m} \text {, source: TecCast Traditional Cills }\end{array}$} \\
\hline
\end{tabular}

\begin{tabular}{|c|c|c|}
\hline \multicolumn{3}{|c|}{ Wood Ground Floor Framing } \\
\hline Element & Quantity & Weight (kg) \\
\hline Sill Plate $38 \times 89 \mathrm{~mm}(2 " x 4 ")^{*}$ & $88(\mathrm{~m})$ & 165 \\
\hline \multicolumn{3}{|l|}{ Beam Straps Stock Lengths (Joists) } \\
\hline $2 \times 10 \times 88^{\prime}(38 \times 235 \times 2440 m m)^{\star *}$ & 7 (pcs) & 96 \\
\hline $2 \times 10 \times 10 \prime(38 \times 235 \times 3050 \mathrm{~mm})$ & 56 (pcs) & 957 \\
\hline $2 \times 10 \times 12$ ' (38x184x3660mm) & 9 (pcs) & 184 \\
\hline $2 \times 10 \times 14^{\prime}(38 \times 184 \times 4270 \mathrm{~mm})$ & 42 (pcs) & 1005 \\
\hline $2 \times 10 \times 16$ ' (38x184x4880mm) & 179 (pcs) & 4897 \\
\hline \multicolumn{3}{|l|}{ Bridging } \\
\hline 2"x2" (38x38mm) 300 O.C.*** & 436 (sets) & 126 \\
\hline 2"x2" (38x38mm) 400 O.C. & 26 (sets) & 10 \\
\hline Sheathing & & \\
\hline
\end{tabular}




\begin{tabular}{|c|c|c|}
\hline 5/8" (15.9mm) Sheathing**** & 98 (shts) & 3,038 \\
\hline Total & & 10,478 \\
\hline \multicolumn{3}{|c|}{$\begin{array}{l}{ }^{*} / \mathrm{umber} \text { (joists, studs and sill plates) assumed at } 35 \mathrm{lbs} / \mathrm{ft}^{3} \text {, source: National Design Specification for Wood, } 1986 \\
{ }^{* *} 2 \times 10 \text { joist assuming } 35 \mathrm{lbs} / \mathrm{ft}^{3} \text {, equates to } 3.37 \mathrm{lbs} / \mathrm{ft} \text {, source: National Design Specification for Wood, } 1986 \\
{ }^{* * *} \text { assumed as } 0.64 \mathrm{lbs} / \mathrm{ft} \text {, source: National Design Specification for Wood, } 1986 \\
{ }^{* * * *} \text { panels are 4'x8' (1220x2440mm) sheets assumed at } 31 \mathrm{~kg} / \text { panel, source: Home Depot }\end{array}$} \\
\hline
\end{tabular}

\begin{tabular}{|c|c|c|}
\hline \multicolumn{3}{|c|}{ Wood Wall Framing } \\
\hline Element & Quantity & Weight (kg) \\
\hline \multicolumn{3}{|l|}{ Plates } \\
\hline \multicolumn{3}{|l|}{ Exterior 38x89 (2"x4")* } \\
\hline Exterior $38 \times 140(2 " \times 6 ")^{* *}$ & $1028(\mathrm{~m})$ & 3,059 \\
\hline Interior 38x89 (2"x4") & $1004(\mathrm{~m})$ & 1,912 \\
\hline Interior 38x140 (2"x6") & $109(\mathrm{~m})$ & 324 \\
\hline Interior 38x235 (2"x10") & $70(\mathrm{~m})$ & 351 \\
\hline Interior 38x140 (2"x6") & 18 (pcs) & 131 \\
\hline \multicolumn{3}{|l|}{ Studs } \\
\hline Interior 38x140x2440 (2"x6"x8') & 46 (pcs) & 334 \\
\hline Wood Strapping 38x89 (2"x4") & $931(\mathrm{~m})$ & 3,657 \\
\hline Lintels 38x184x2440 (2"x4"x8') & 5 (pcs) & 23 \\
\hline Exterior $38 \times 140(2 " x 6 ")^{\star * *}$ & 361 (pcs) & 2,620 \\
\hline Interior 38x89 (2"x4") $)^{\star \star \star}$ & 407 (pcs) & 1,890 \\
\hline Interior 38x140 (2"x6") $)^{* \star *}$ & 18 (pcs) & 131 \\
\hline Exterior 38x89x4270mm (2'x4"14') & 27 (pcs) & 219 \\
\hline Interior 38x89x4270mm (2'x4"14') & 18 (pcs) & 146 \\
\hline Backing 38x89 (2"x4") & $5.5(\mathrm{~m})$ & 10 \\
\hline $38 \times 184 \times 2440 \mathrm{~mm}\left(2^{\prime \prime} \times 8 " \times 10^{\prime}\right)^{\star * \star *}$ & 5 (pcs) & 60 \\
\hline 38x184x3050mm (2"x8"x12') & 4 (pcs) & 57 \\
\hline $38 \times 184 \times 3660 \mathrm{~mm}\left(2^{\prime \prime} \times 10^{\prime \prime} \times 8^{\prime}\right)^{* * * * *}$ & 2 (pcs) & 25 \\
\hline $38 \times 235 \times 3050 \mathrm{~mm}\left(2 " \times 10 " \times 10^{\prime}\right)$ & 4 (pcs) & 61 \\
\hline $38 \times 235 \times 3660 \mathrm{~mm}$ (2"x10"x12') & 3 (pcs) & 55 \\
\hline $38 \times 286 \times 2440 \mathrm{~mm}\left(2{ }^{\prime \prime} \times 12 " \times 10^{\prime}\right)^{\star \star \star \star \star * \star}$ & 6 (pcs) & 112 \\
\hline Total & & 15,177 \\
\hline \multicolumn{3}{|c|}{ 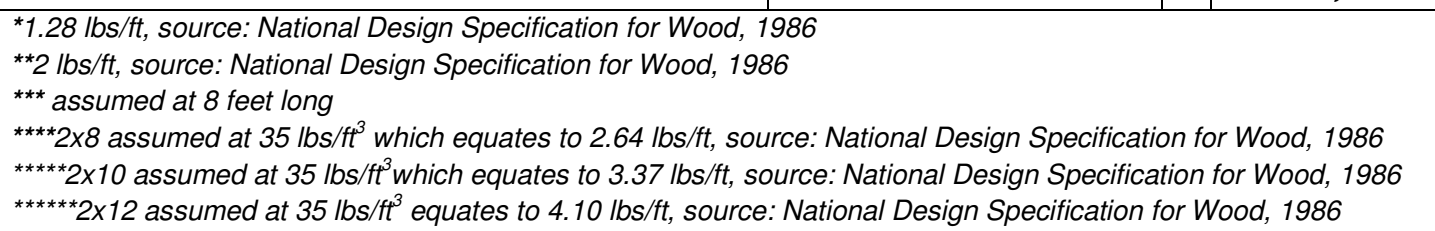 } \\
\hline
\end{tabular}




\section{Gypsum}

Gypsum board $13 \mathrm{~mm}\left(1 / 2^{\prime \prime}\right)$ is estimated for House-B accordingly by the known information:

Total Floor Area $\left(f^{2}\right): 3189$

Ceiling Height (ft): 8

A factor of 3.4 in reference to the floor area and ceiling was used, identical to House-A (Drywall Installation and Taping Service Toronto, 2011). Thus, the total gypsum need for House-B is as follows:

Total Area of Interior Gypsum Board Installation (ft'): 10,842

Total Number of Panels (4'x8'): 339

Accordingly, the weight per panel for typical sheetrock drywall is $60.8 \mathrm{lbs} /$ panel, which equates to $1.9 \mathrm{lbs} / \mathrm{ft}^{2}$ of drywall (Home Depot, 2011). Therefore the total weight allocated to gypsum board panels for House-B is $20,611 \mathrm{lbs}$, which is $9349 \mathrm{~kg}$.

\section{Asphalt Roofing}

The estimation for the asphalt sheathing used for the roof of House-B is calculated in an identical manner to House-A. The specifications of House-B lists weight ratio for the asphalt shingles as $30.5 \mathrm{~kg} / \mathrm{m}^{2}$. Given the different slopes of the roof for House-B, the total area per slope was calculated and the total roofing area was determined using a slope rake factor as shown in the Table 12 (Sentrigard, 2012). With the weight ratio of $30.5 \mathrm{~kg} / \mathrm{m}^{2}$, and the total area needed for shingles is $246 \mathrm{~m}^{2}\left(2,654 \mathrm{ft}^{2}\right)$, the total asphalt shingles weight for House- $B$ is 7,503 $\mathrm{kg}$. 
[House-B Quantity Recap]

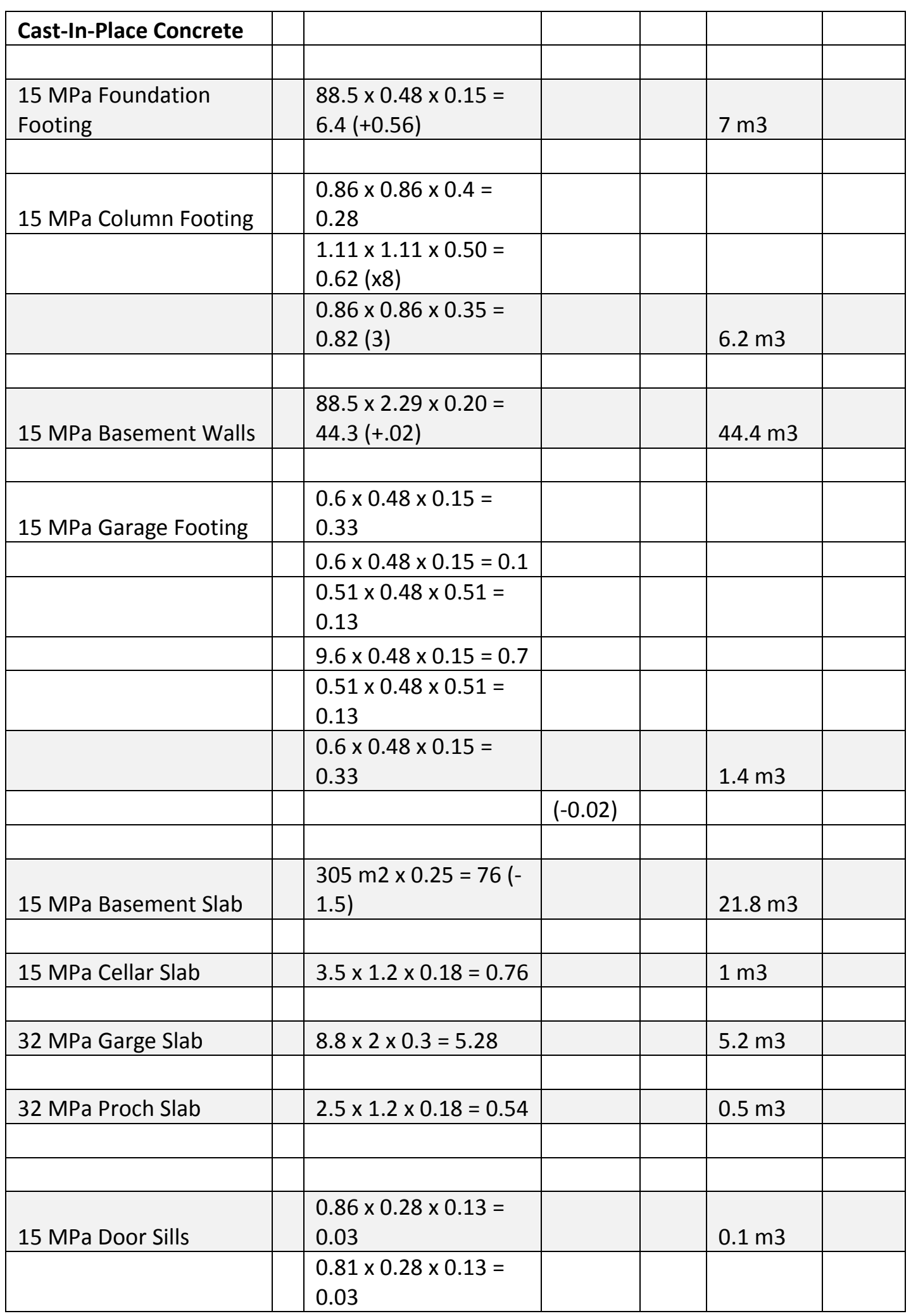




\begin{tabular}{|l|l|l|l|l|l|}
\hline Brick Veneer / Masonry & & & & & \\
\hline & & & & & \\
\hline First Floor & & $325-13=$ & & $312 \mathrm{~m} 2$ & \\
\hline & & & & & \\
\hline Stone Sills & & & & $21 \mathrm{~m}$ & \\
\hline & & & & & \\
\hline Concrete Blocks & & & & $1 \mathrm{~m}$ & \\
\hline
\end{tabular}

\begin{tabular}{|c|c|c|c|}
\hline Wood Rec & & & \\
\hline \multicolumn{4}{|c|}{ First Floor Framing } \\
\hline & Sill Plate & $88 \mathrm{~m}$ & \\
\hline & Beam Strap & $116 \mathrm{~m}$ & \\
\hline \multicolumn{4}{|c|}{ Header Joist } \\
\hline & $38 \times 235 \times 2440$ & 7 pcs & \\
\hline & $38 \times 235 \times 3050$ & 4 pcs & \\
\hline & $38 \times 235 \times 3660$ & 3 pcs & \\
\hline & $38 \times 235 \times 4270$ & 3 pcs & \\
\hline \multicolumn{4}{|c|}{ Common Joist } \\
\hline & $38 \times 235 \times 3050$ & 52 pcs & \\
\hline & $38 \times 235 \times 3660$ & $6 \mathrm{pcs}$ & \\
\hline & $38 \times 235 \times 4270$ & 39 pcs & \\
\hline & $38 \times 235 \times 4880$ & 179 pcs & \\
\hline \multirow[t]{2}{*}{ Briding } & 38 x $38 @ 300$ & 436 sets & \\
\hline & 38 x $38 @ 400$ & 26 sets & \\
\hline Strapping & $19 \times 64$ & $931 \mathrm{~m}$ & \\
\hline \multicolumn{4}{|c|}{$\begin{array}{l}\text { First Floor Wall } \\
\text { Framing }\end{array}$} \\
\hline & $38 \times 89$ plates & $109 \mathrm{~m}$ & \\
\hline & $38 \times 140$ & $1028 \mathrm{~m}$ & \\
\hline & $38 \times 89$ & $1004 \mathrm{~m}$ & \\
\hline & $38 \times 189$ & $70 \mathrm{~m}$ & \\
\hline & $38 \times 140$ studs & 46 pcs & \\
\hline & $38 \times 140$ studs & 361 pcs & \\
\hline & $38 \times 89$ studs & 407 pcs & \\
\hline
\end{tabular}




\begin{tabular}{|l|l|l|l|l|l|} 
& $38 \times 140$ studs & & & $18 \mathrm{pcs}$ & \\
\hline & & & & & \\
\hline & $38 \times 89 \times 4270$ & & & $27 \mathrm{pcs}$ & \\
\hline & $38 \times 89 \times 4270$ & & & $18 \mathrm{pcs}$ & \\
\hline & & & & & \\
\hline & $38 \times 89$ backing & & & $5.5 \mathrm{~m}$ & \\
\hline Lintels & & & & & \\
\hline & & & & & \\
\hline & $38 \times 138 \times 3050$ & & & $5 \mathrm{pcs}$ & \\
\hline & $38 \times 138 \times 3660$ & & & $4 \mathrm{pcs}$ & \\
\hline & $38 \times 235 \times 2440$ & & & $2 \mathrm{pcs}$ & \\
\hline & $38 \times 235 \times 3050$ & & & $4 \mathrm{pcs}$ & \\
\hline & $38 \times 235 \times 4270$ & & & $3 \mathrm{pcs}$ & \\
\hline & $38 \times 235 \times 4270$ & & & $6 \mathrm{pcs}$ & \\
\hline & $38 \times 184 \times 2440$ & & & $5 \mathrm{pcs}$ & \\
\hline & & & & \\
\hline
\end{tabular}




\section{Appendix C}

\begin{tabular}{|l|c|c|c|}
\hline Component & House-A & House-B & Difference \\
\hline Bldg. Coverage & $123 \mathrm{~m}^{2}\left(1321 \mathrm{ft}^{2}\right)$ & $353 \mathrm{~m}^{2}\left(3801 \mathrm{ft}^{2}\right)$ & House-B 2.8 times larger \\
\hline GFA & $189 \mathrm{~m}^{2}\left(2029 \mathrm{ft}^{2}\right)$ & $296 \mathrm{~m}^{2}\left(1321 \mathrm{ft}^{2}\right)$ & House-B 1.5 times greater \\
\hline Room/Areas & Kitchen, Dining, 3 & Kitchen, Dinning, 3 \\
Bedrooms, 3 Washrooms & $\begin{array}{c}\text { House-B has additional } \\
\text { Washrooms, Family } \\
\text { family room and office } \\
\text { Room, Office }\end{array}$ & $\begin{array}{c}\text { area, but 1 less } \\
\text { washroom }\end{array}$ \\
\hline Garage Area & 2-car Garage & 3-car Garage & $\begin{array}{c}\text { House-B has 1 additional } \\
\text { car space }\end{array}$ \\
\hline
\end{tabular}

Note the higher GFA over building coverage of House-A due to it being smaller in layout with two-storey floor area. The other noteworthy difference is the additional family room $\left(33 \mathrm{~m}^{2}\right)$ and office space $\left(14 \mathrm{~m}^{2}\right)$ area for House-B. These two additional areas make up $47 \mathrm{~m}^{2}\left(514 \mathrm{ft}^{2}\right)$ in GFA, which is $6.3 \%$ of the total GFA of House-B. These two spaces contribute to approximately 20 metric tons out of the 329 total for House-B. 


\section{References}

Athena Institute (2004).Minnesota demolition survey: Phase two report. Retrieved from: http://www.athenasmi.org/resources/research-projects/

Athena Institute (2006). Service life considerations in relation to green building rating systems. Retrieved from: http://www.athenasmi.org/resources/publications/

Athena Institute (2006). LCI databases. Retrieved from:

http://www.athenasmi.org/our-software-data/lca-databases/

Bajpai, A., Ekane, N., Wang, X., Liu, X. A comparative life cycle assessment of a wooden house and a brick house. Royal Institute of Technology, Stockholm. Retrieved from: http://www.infra.kth.se/fms/utbildning/lca/project\%20reports/Group\%206\%20-\%20House.pdf

Begum, A. R. \& Siwar, C. \& Pereira, J. J. \& Jaafar, A. H. (2006). A benefit-cost analysis on the economic feasibility of construction waste minimisation: The case of Malaysia. Resources, Conservation and Recycling (48) 86-98.

Beng, R. J. G. (2004). Brick recycling and reuse. Engineering Sustainability, 157 (3), 155-161.

Boise Cascade (2011). Retrieved from: http://www.bc.com/wood/ewp/simpleFraming/allJoist.html

Bowyer, J., D. Briggs, L. Johnson, B. Kasal, B. Lippke, J. Meil, M. Milota, W. Trusty, C. West, J. Wilson, and P. Winistorfer. (2001). CORRIM: A report of progress and a glimpse of the future. Forest Products Journal. 51(10), 10-22.

Brick Salvage (2012). Reclaimed brick. Retrieved from: http://www.bricksalvage.com/catalog/ 
Bruce Lippke, Jim Wilson, John Perez-Garcia, Jim Bowyer, and Jamie Meil (2004). CORRIM: Life-cycle environmental performance of renewable building materials. Forest Products Journal. 54 (6), 819.

Building Science Corporation (2010). Advanced framing. Retrieved from: http://www.buildingscience.com/index_html

Canada Plan Service. Steel Beams for Large Door Headers. Retrieved from: http://www.cps.gov.on.ca/english/plans/E9000/9313/9313L.pdf

Canadian Construction Association (1992). A report on the waste management for the construction industry. Retrieved from the website: http://nrtee-trnee.ca/wp-content/uploads/2011/08/wastemanagement-construction.pdf

Carlos, T. F. and Soibelman, L. \& Cesare, C. \& Isatto, E. L. (2002). Material waste in building industry: Main causes and prevention. Journal of Construction Engineering \& Management, 316(4), 316-325.

CertainTeed (2013). Vinyl and polymer products: life cycle assessment report. Retrieved from: http://www.certainteed.com/resources/vs_lca_report_cts417.pdf

Cha, H. S. and Jeehye, K., and Ju-Yeoun, H. (2009). Identifying and Assessing Influence Factors on Improving Waste Management Performance for Building Construction Projects. Journal of Construction Engineering \& Management, 135(7), 647-656.

Chen, K. (1993). A comparative study of sate and traditional housing in china. Habitat Intl. 17 (3), 101 114.

CMHC (2000). Service life of multi-unit residential building elements and equipment. Retrieved from: 
http://publications.gc.ca/site/eng/93498/publication.html

CMHC (2001). Service life of multi-unit residential building elements and equipment. Retrieved from:

http://www.visoa.bc.ca/static/cmhcservicelife.pdf

CMHC (2003). The 2003 GTA residential land inventory survey. Toronto : Ontario Ministry of Municipal Affairs and Housing

CHMC (2004). Renovating for energy savings case studies. Retrieved from: http://www.cmhc-schl.gc.ca/en/co/renoho/reensa/upload/63720.pdf

CMHC (2012). Housing market outlook: Greater Toronto area. Retrieved from: http://www.cmhc-schl.gc.ca/odpub/esub/64319/64319_2012_B01.pdf

CSA (2006). Scope of the 'Guidelines for design disassembly and adaptability of buildings'. Retrieved from: http://www.csa.ca.ezproxy.lib.ryerson.ca

DESIGNING BUILDINGS ON THE FRONT END TO REDUCE WASTE. (2007). BioCycle, 48(10), 16. Retrieved from EBSCOhost.

Dixit, M. K., Fernández-Solís, J. L., Lavy, S., Culp, C. H. (2010). Identification of parameters for embodied energy measurement: A literature review. Energy and Buildings 42 (2010) 1238-1247.

Drywall Installation and Taping Service Toronto (2011). Retrieved from: http://drywalltaping.ca/author/master/

E-laws (2011). Regulation 307/102/103. Retrieved from the website: http://www laws.gov.on.ca/navigation?file=home\&lang=en 
Faniran, O. O., and Caban, G. (1998). Minimizing waste on construction project sites. Engineering, Construction, Architectural Management 5(2), 182-188.

Florida Building Code. Weights of building materials. Retrieved September 20, from: http://www2.iccsafe.org/states/Florida2001/FL_Building1/PDFs/Appendix\%20A_Weights\%20of\% 20Building\%20Material.pdf

Generic Vinyl Siding (2013). Product selection and description. Retrieved from: http://ws680.nist.gov/bees/ProductListFiles/Generic\%20Vinyl\%20Siding.pdf

Google Maps (2012). Retrieved from the website: http://maps.google.ca/maps?um=1\&hl=en\&qscrl=1\&rlz=1T4TSCA_enCA418CA424\&bav=on.2,or. r_gc.r_pw.r_qf.\&bpcl=38897761\&biw=1311\&bih=588\&wrapid=tlif135411898624811\&q=augusta \%20ave\%20and\%20denison\%20\&ie=UTF-8\&sa=N\&tab=il

GreenSpec (2012). Embodied energy. Retrieved from the website: http://www.greenspec.co.uk/embodied-energy.php

Gu, P. \& Hashemian, M. \& Sosale, S. \& Rivin, E. (1997). An integrated modular design methodology for life-cycle engineering. CIRP Annals - Manufacturing Technology, 46 (1), 71-74.

Gull, I (2011). Testing of strength of recycled waste concrete and its applicability. Journal of Construction Engineering \& Management; 137 (1), 1-5.

Guy, B. \& Gibeau E. M. (2003). Guide to deconstruction. Retrieved from: http://www.epa.gov/

Guy, B. (2011). Building Deconstruction: Reuse and recycling of building materials. Retrieved from: http://www.lifecyclebuilding.org/files/Six\%20House\%20Building\%20Deconstruction.pdf 
Hebron Brick Company (2012). Residential face brick. Retrieved from:

http://www.hebronbrick.com/Products/ResidentialBrick.aspx

Hoffmann, C., Schubert, S., Leemann, A., Motavalli, M. (2012). Recycled concrete and mixed rubble as aggregates: Influence of variations in composition on the concrete properties and their use as structural material. Construction and Building Materials, 35, 701-709.

Home Depot (2011). OSB. Retrieved from: http://www.homedepot.ca/product/5-8-4x8-oriented-strand board-tongue-and-groove-19-32/935757

Hopper, T (2012). The incredible shrinking home: Why Canada's houses are getting smaller. Retrieved from: http://www.nationalpost.com/index.html

Hutcheon, N. B. \& Handegord, G. O. P. (1996). Building science for a cold climate. Institute for Research in Construction: Ottawa.

InterNACHI (2011). InterNACHI's standard estimated life expectancy chart for homes. Retrieved from: http://www.nachi.org/life-expectancy.htm

Khasreen, M. M., Banfill, G. P. F., Menzies, G. F. (2009). Life-cycle assessment and the environmental impact of buildings: A review. Sustainability, 1, 674-701.

Lu, W. and Yuan, H. (2011) A framework for understanding waste management studies in construction. Waste Management, 31, 1252-1260.

Joseph Lstiburek (2010). Advanced framing. Retrieved from: http://www.buildingscience.com/documents/insights/bsi-030-advanced-framing 
McDonald, B., and Smithers, M. (1998). Implementing a waste management plan during the construction phase of a project. Journal of Construction Management Econ., 16 (1), 71-78.

Meredith, R. J., \& Mantel, J. S. (2006) Project management: A managerial approach. John Wiley \& Sons Inc.: New Jersey.

Ministry of Finance (2011). Ontario population projects update: 2010 to 2036 . Retrieved from: http://www.fin.gov.on.ca/en/economy/demographics/projections/projections2010-2036.pdf

Monahan, J., Powell, J.C. (2012). An embodied carbon and energy analysis of modern methods of construction in housing: A case study using a lifecycle assessment framework. Energy and Buildings 43 (2011) 179-188.

Morton Metals. Steel reference guide. Retrieved from: http://www.mortonmetals.ca/Morton_Metal_Product_CD.pdf

NABH (2007). Study of life expectancy of home components. Retrieved from: http://actionplus-hi.com/lifeexpectancy.pdf

National Design Specification for Wood (1986). Retrieved from: http://www.awc.org/pdf/WSDD/wsdd.pdf

Natural Resources Canada (2011). Construction and demolition recycling. Retrieved from the website: http://www.recycle.ab.ca/2008Proceedings/Michae/Clapham.pdf

Natural Resources Canada (2006). Construction and demolition recycling. Retrieved from the website: 
http://www.docstoc.com/docs/26449647/Michael-Clapham---Construction-and-DemolitionRecycling

Nitivattananon, V. \& Borongan, G. (2007) Construction and Demolition Waste Management: Current Practices in Asia. Proceedings of the International Conference on Sustainable Solid Waste Management, 97-104.

Norman, J., MacLean, H. L., \& Kennedy, C. A. (2006). Comparing high and low residential density: Life cycle analysis of energy use and greenhouse gas emissions." Journal of Urban Planning and Development.1 (10), 10-20.

O'Connor, J (2004). Survey of actual lives for North American buildings. Retrieved from: http://www.softwoodlumber.org/pdfs/SurveyonActualServiceLives.pdf

Poirazis, H. (2005). Single skin glazed office buildings. Retrieved from: http://www.ebd.Ith.se/fileadmin/energi_byggnadsdesign/images/Publikationer/Report_EBD_T_054_Harris.pdf

Poon, C. S. (1997). Management and recycling of demolition waste in Hong Kong. Waste Manage. Res., 15(6), 561-572.

Recycling Council of Ontario (2005). An examination of construction, demolition and renovation (CRD) waste diversion in Canada and associated greenhouse gas emission impacts. Retrieved from: https://www.rco.on.ca/uploads/File/projects/completed/Molehill/RC_Projects-Molehill-Rpt.pdf

Rogoff, M. J., and Williams, J. F. (1994). Approaches to implementing solid waste recycling facilities, Noyes, Park Ridge, N.J.

Sassi, Poala (2008). Defining closed-loop material cycle construction. Building Research and 
Information, 36 (5), 509-519.

Scott, D., Sridurangkatum, S., (1980). A comparative study of housing construction methods. Building and Environment, Vol. 17, 27-31.

Sentrigard (2012). Metal roofing system. Retrieved from: http://www.sentrigard.com/Sentriguide

Shen, L. Y. and Vivian W. Y. Tam \& C. M. Tam \& D. Drew (2004). Mapping approach for examining waste management on construction sites. Journal of Construction Engineering \& Management, 130 (4), 472-481.

Shen, L. Y. and Tam, W. Y. Vivian (2002). Implementation of environmental management in the Hong Kong construction industry. International Journal of Project Management 20(7), 535-543.

Statistics Canada (2011). Population by year, by province and territory. Retrieved from the website: http://www40.statcan.ca//01/cst01/demo02a-eng.htm

Tam, V. W. Y. and Tam, C. M. (2008). Re-use of construction and demolition waste in housing developments. New York: Nova Science Publishers.

TecCast Traditional Cills. Retrieved from: http://www.penninestone.co.uk/pdf\%5C02\%20Traditional\%20Cills\%20140mm.pdf

Toronto Green Standard (2012). Toronto green standard. Retrieved from: http://www.toronto.ca/planning/environment/index.htm

Toronto Green Standard (2010). New low-rise residential development. Retrieved from: http://www.toronto.ca/planning/environment/greendevelopment.htm 
United Nations (2004). World population to 2300. Retrieved from:

http://www.un.org/esa/population/publications/longrange2/WorldPop2300final.pdf

US Environmental Protection Agency (1998). Characterization of building-related construction and demolition debris in the United States. Retrieved from the website: http://www.epa.gov/osw/hazard/generation/sqg/c\%26d-rpt.pdf

Venta, G. J. (1997). Life cycle analysis of gypsum board and associated finishing products. Retrieved from: http://www.athenasmi.ca/tools/impactEstimator/companionReports/Gypsum_Wallboard.pdf

Winstone Gypsum (2012). Soil improvement. Retrieved from:

http://www.gypsum.co.nz/pages/product/soil.php

World Bank, World Development Indicator (2011). Retrieved from the website:

http://www.google.ca/publicdata/explore?ds=d5bncppjof8f9_\&met_y=sp_pop_totl\&idim=country: CAN\&dl=en\&hl=en\&q=canada+population

Yuan, H. and Shen, L. (2010). Trend of the research on construction and demolition waste management. Waste Management 31 (2011) 670-679

Zhang, J., Eastham, D. L., \& Bernold, L. E. (2005). Waste-Based Management in Residential Construction. Journal of Construction Engineering \& Management, 131(4), 423-430 